Review

\title{
Response of Mycorrhizal Diversity to Current Climatic Changes
}

\section{Stanley E. Bellgard ${ }^{1, *}$ and Stephen E. Williams ${ }^{2}$}

1 Landcare Research, Private Bag 92170, Auckland Mail Centre, Auckland 1142, New Zealand

2 Department of Renewable Resources, The University of Wyoming, Laramie, WY 82071, USA; E-Mail: sewms@uwyo.edu

* Author to whom correspondence should be addressed; E-Mail: bellgards@landcareresearch.co.nz; Tel.: +64-9-574-4165; Fax: +64-9-574-4101.

Received: 4 December 2010 / Accepted: 26 January 2011 / Published: 28 January 2011

Abstract: Form and function of mycorrhizas as well as tracing the presence of the mycorrhizal fungi through the geological time scale are herein first addressed. Then mycorrhizas and plant fitness, succession, mycorrhizas and ecosystem function, and mycorrhizal resiliency are introduced. From this, four hypotheses are drawn: (1) mycorrhizal diversity evolved in response to changes in Global Climate Change (GCC) environmental drivers, (2) mycorrhizal diversity will be modified by present changes in GCC environmental drivers, (3) mycorrhizal changes in response to ecological drivers of GCC will in turn modify plant, community, and ecosystem responses to the same, and (4) Mycorrhizas will continue to evolve in response to present and future changes in GCC factors. The drivers of climate change examined here are: $\mathrm{CO}_{2}$ enrichment, temperature rise, altered precipitation, increased $\mathrm{N}$-deposition, habitat fragmentation, and biotic invasion increase. These impact the soil-rhizosphere, plant and fungal physiology and/or ecosystem(s) directly and indirectly. Direct effects include changes in resource availability and change in distribution of mycorrhizas. Indirect effects include changes in below ground allocation of $\mathrm{C}$ to roots and changes in plant species distribution. GCC ecological drivers have been partitioned into four putative time frames: (1) Immediate (1-2 years) impacts, associated with ecosystem fragmentation and habitat loss realized through loss of plant-hosts and disturbance of the soil; (2) Short-term (3-10 year) impacts, resultant of biotic invasions of exotic mycorrhizal fungi, plants and pests, diseases and other abiotic perturbations; (3) Intermediate-term (11-20 year) impacts, of cumulative and additive effects of increased $\mathrm{N}$ (and $\mathrm{S}$ ) deposition, soil acidification and other pollutants; and (4) Long-term (21-50+ year) impacts, where increased temperatures and $\mathrm{CO}_{2}$ will 
destabilize global rainfall patterns, soil properties and plant ecosystem resilience. Due to dependence on their host for C-supply, orchid mycorrhizas and all heterotrophic mycorrhizal groups will be immediately impacted through loss of habitat and plant-hosts. Ectomycorrhizal (ECM) associations will be the principal group subject to short-term impacts, along with Ericoid mycorrhizas occurring in high altitude or high latitude ecosystems. This is due to susceptibility (low buffer capacity of soils) of many of the ECM systems and that GCC is accentuated at high latitudes and altitudes. Vulnerable mycorrhizal types subject to intermediate-term GCC changes include highly specialized ECM species associated with forest ecosystems and finally arbuscular mycorrhizas (AM) associated with grassland ecosystems. Although the soils of grasslands are generally well buffered, the soils of arid lands are highly buffered and will resist even fairly long term GCC impacts, and thus these arid, largely AM systems will be the least affect by GCC. Once there are major perturbations to the global hydrological cycle that change rainfall patterns and seasonal distributions, no aspect of the global mycorrhizal diversity will remain unaffected.

Keywords: Global Climate Change; ecological drivers; mycorrhizal diversity

\section{Introduction}

\subsection{Mycorrhiza Biology Basics}

The biology of mycorrhizas is a function partially of the wide diversity of fungi, partially of the wide diversity of plants involved, and partially the wide diversity of soils where plant and fungus interact, but also by the various morphologies these associations take. Simplistically, these associations between plant and fungus are symbiotic and almost entirely mutualistic in that both fungus and plant partners benefit [1]. The benefits seem predominately connected to improved nutrition of the host and the infecting agent, but extend to attenuation of hormonal balance, physical protection, chemical protection and modification of other rhizosphere organisms that impact competition for substrates (Table 1). The association, however, is tenuously balanced. It is easy to say that these mycorrhizal associations are mutualistic and not parasitic, but words do not capture easily the concept that there is a gradient from the mutualistic to the parasitic. Environmental conditions fluctuate enough that any given association moves back and forth along the mutualism-parasitism continuum. So it is likely that the benefits to the partners are not only quantitatively unequal but also qualitatively unbalanced: one partner gaining more than the other. In other words, one partner leans more towards parasitism than the other. One of the ironies of these associations is that it is not always clear, even in a general sense, which partner leans towards the parasitic and which partner is therefore forced towards being parasitized. Our human experience with pathogenic fungi would lead us to accept the notion that the fungi would tend towards the parasitic habit - the plant being parasitized. There is evidence, however, that one of the largest groups of fungi, those that form the arbuscular mycorrhizas, are heavily controlled by their plant partners. These plants lean towards parasitism of the fungi [2]. 
Table 1. Functions of mycorrhizal fungi in ecosystem processes (adapted from Miller [9]).

PHYSIOLOGICAL AND METABOLIC: PLANT-LEVEL

Decomposition of organic matter; volatilization of $\mathrm{C}, \mathrm{H}$, and $\mathrm{O}$

Elemental release and mineralization of $\mathrm{N}, \mathrm{P}, \mathrm{K}, \mathrm{S}$ and other ions

Elemental storage: immobilization of elements

Accumulation of toxic materials

Synthesis of humic materials

Instigation of mutualistic, commensalistic and exploitive symbioses

Increased survivability of seedlings

Protection from root pathogens

ECOLOGICAL: PLANT-COMMUNITY-LEVEL

Facilitation of energy exchange between above- and below-ground systems

Promotion and alteration of niche development

Regulation and successional trajectory and velocity

MEDIATIVE AND INTEGRATIVE: PLANT-ECOSYSTEM/BIOME-LEVEL

Facilitation and transport of essential elements and water from soil to plant roots

Facilitation of plant-to-plant movement of essentials elements and carbohydrates

Regulation of water and ion movement through plants

Regulation of photosynthetic rate of primary producers

Regulation of $\mathrm{C}$ allocation below ground

Modification of soil permeability and promotion of aggregation

Modification of soil ion exchange and water-holding capacity

Detoxification of soil (degradation, volatilization or sequestration)

Participation in saprotrophic food chains

Production of environmental biochemicals (antibiotics, enzymes and immunosuppressants)

\subsection{Natural History and Evolutionary Setting}

One of the most significant events in the successful colonization of land by plants was the evolution of biotrophic, root-inhabiting symbioses [3-5]. Mycorrhizas ("fungus-roots") are symbiotic associations between specialized soil fungi and plants, and represent one of the many specialized members of micro-organisms that inhabit the rhizosphere. These include $\mathrm{N}$-fixing symbioses including rhizobia and Actinomycetes and other specialized bacteria such as mycorrhiza helper bacteria [6-9]. Functionally, this group of fungi has evolved along with their plant-hosts (Table 2) and display a variety of ways in which they interact with both readily and poorly available nutrient resources. Such interaction often results in enhanced plant growth [1]. Mycorrhizal fungi have been shown to play a role in the dissolution of parent rock in more established soil, and the mycorrhizal association with plant roots provides a physical bridge-involved in the absorption and delivery of nutrients from the soil matrix - to the plant-host via the mycelial network [1]. This classical, symbiotic description of the mycorrhizal association is completed with the obligatory return of carbon from the plant-host to the fungus - in a completely balanced manner. However, each type of mycorrhiza is likely to have its own characteristic function, e.g., for achlorphyllous plant-hosts, this delivery mechanism can also involve the acquisition of carbon-resources via mycorrhizal-haustorial connections from adjacent autotrophic plants. 
Table 2. Mycorrhizal diversity in the context of past GCC.

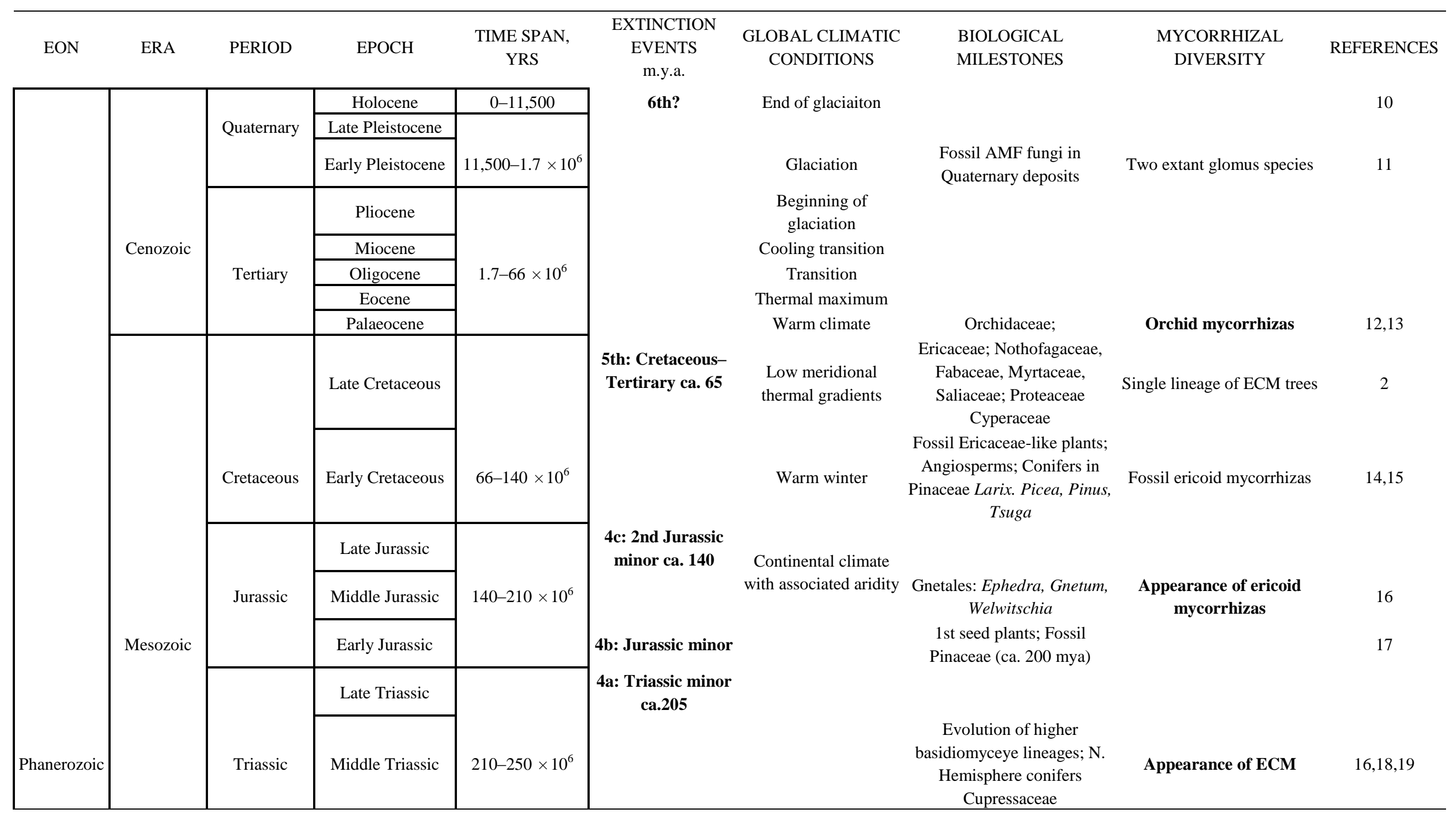


Table 2. Cont

\begin{tabular}{|c|c|c|c|c|c|c|c|c|c|}
\hline & & & Early Triassic & & & & $\begin{array}{c}\text { Cycad from Antarctica; S. } \\
\text { Hemisphere conifers } \\
\text { Araucariaecae, } \\
\text { Podocarpaceae }\end{array}$ & $\begin{array}{l}\text { Earliest fossil AMF; living } \\
\text { trees have AMF }\end{array}$ & 20 \\
\hline & & & Late Permian & & $\begin{array}{l}\text { 3rd: Permian } \\
\text { ca. } 250-251\end{array}$ & & & & \\
\hline & & Permian & Early Permian & $250-290 \times 10^{6}$ & & & $\begin{array}{c}\text { vascular plants; emergence of } \\
\text { Pinaceae; Ginkgoales e.g. } \\
\text { Ginkgo spp. }\end{array}$ & ECM in Gymnosperms & 13 \\
\hline & & & Late Carboniferous & & & & & & \\
\hline & & Carboniferous & $\begin{array}{c}\text { Early } \\
\text { Carboniferous }\end{array}$ & $290-360 \times 10^{6}$ & $\begin{array}{l}\text { 2nd: Late } \\
\text { Devonian } \\
\text { ca. 350-375 }\end{array}$ & $\begin{array}{l}\text { Global cooling-- } \\
\text { Gondwanan glaciation }\end{array}$ & Fossil Basidiomycetes & Most living ferns have AMF & 21,22 \\
\hline & & & Late Devonian & & & Maritime climate and & $\begin{array}{c}\text { Lycopods e.g. Lycopodium; } \\
\text { Sphenophytes e.g. } \\
\text { Equisetum; Pteridophytes; } \\
\text { Cycads }\end{array}$ & $\begin{array}{l}\text { AMF in sporophyte and } \\
\text { hyphae in gametophyte }\end{array}$ & 2 \\
\hline & & Devonian & Early Devonian & $360-410 \times 10^{6}$ & & & $\begin{array}{c}\text { Early land plants - unknown } \\
\text { affinities }\end{array}$ & $\begin{array}{l}\text { Fossils with AMF-like } \\
\text { hyphae and arbuscules; } \\
\text { fossil Scutellospora }\end{array}$ & $23-26$ \\
\hline & Palaeozoic & & Late Silurian & & & $\begin{array}{l}\text { Warming and return to } \\
\text { moderate }\end{array}$ & Fossil ascomycetes & & 27 \\
\hline & & Silurian & Early Silurian & $410-440 \times 10^{6}$ & 1st: Ordivician- & & Mosses & $\begin{array}{l}\text { No roots-some mosses } \\
\text { have fungal-endophytes }\end{array}$ & 2 \\
\hline & & & Later Ordovician & & Silurian ca.440-450 & $\begin{array}{l}\text { Global cooling- } \\
\text { glaciation }\end{array}$ & Liverworts and hornworts & $\begin{array}{l}\text { mycorrhizal fungi-like } \\
\text { structures }\end{array}$ & 28 \\
\hline & & Ordovician & Middle Ordovician & $440-500 \times 10^{6}$ & & & First land plants (ca.475 mya) & fossil Glomus-like fungi & $29-31$ \\
\hline & & & Early Ordovician & & & Ice-sheet expansion & Limited fossils without roots & mycorrhizas unknown & 2 \\
\hline & & & Late Cambrian & & $\begin{array}{l}\text { Cambian period is } \\
\text { marked by as many }\end{array}$ & & $\begin{array}{l}\text { Explosion of animal life } \\
\text { beneath the sea }\end{array}$ & $\begin{array}{c}\text { Pre-basidiomycete/ } \\
\text { ascomyctes diverged from } \\
\text { Glomaceae }\end{array}$ & 19 \\
\hline & & Cambrian & Middle Cambrian & $500-590 \times 10^{6}$ & $\begin{array}{l}\text { as four mass } \\
\text { extintions }\end{array}$ & & & & \\
\hline & & & Early Cambrian & & & & & & \\
\hline Proterozoic & & & & $590-2,500 \times 10^{6}$ & & Large-scale glaciation & $\begin{array}{l}\text { Suggested age of divergence } \\
\text { of fungi from other life }\end{array}$ & Major lineages of fungi? & 32,33 \\
\hline Archaic & Precambrian & & & $2.5-4.6 \times 10^{9}$ & & & & & \\
\hline
\end{tabular}




\subsection{Definitions}

For the purposes of this review: mycorrhizal fungi are dual soil-plant inhabitants; a mycorrhizal association is the relationship between the fungus and the plant-host; and mycorrhizal diversity encompasses the entire range of form and functions - ranging along the functional continuum from symbiotic, commensalistic, mutualistic all the way through to exploitive/parasitism [34]. Herein the discussion of parasitism will be limited to those circumstances where the normal mycorrhizal functionality has turned pathogenic. Propagules for this review refer to any material, sexual spores, asexual spores, hyphal fragments, infected root fragments, etc., that are capable of providing infection or colonization of an uninfected or uncolonized root resulting in a mycorrhizal association. Inoculum is nearly a synonym for propagules, but implies an anthropogenic overlay-propagules cultivated, enhanced or used by humans.

\subsection{Mycorrhiza Diversity-Definitions}

Currently, structural mycorrhizal diversity is categorized into seven types of equal taxonomic rank: arbuscular (AM), orchid mycorrhizas (OM), ericoid mycorrhizas (EM), ecto- (ECM), ectendo-(ECTENDO), arbutoid (ARBM), and monotropoid (MM) [13,35] (Table 3). Arbuscular mycorrhizas have turned out to be much more diverse in structural features than previously thought (e.g., [36-38]). There is much structural homology exhibited among ecto-, ectendo-, arbutoid and monotropoid mycorrhizas [2] and together they comprise a distinct ECM lineage. Imhof [38] proposes OM as a third, distinct lineage from AM and ECM. Smith and Read [35] provide an in-depth treatment of the mycorrhizal symbiosis.

In brief, Smith and Read [35] indicate that AM describe the association formed by members of the Glomeromycota. This is the most ancient of mycorrhizal types, with fossils from the Devonian containing both arbuscules and vesicles [23]. Fungi in this group have not been shown to be culturable on defined media and it is assumed that they are wholly dependent on the photosynthetic plant. In ECM, the fungus forms a structure called a mantle (or sheath) which encloses the rootlet. From it hyphae or rhizomorphs radiate out into the substrate. Hyphae also penetrate inwards of the root to form a complex intercellular system, which appears microscopically in cross section as a network of hyphae, termed the Hartig net [35]. The ECTENDO are similar in structural nature to ECM, except that the sheath may be reduced or absent, and hyphae penetrate into the cells of the plant. The distinction between these types is confounded in that the same species of fungus (fungi include members of all orders of Basidiomycetes and Ascomycetes) may form ECM on one species of plant and ECTENDO on others [35]. 
Table 3. Characteristics of mycorrhizal diversity and dark septate endophytes (adapted from Smith and Read [35] and Findlay [39]).

\begin{tabular}{|c|c|c|c|c|c|c|c|c|}
\hline $\begin{array}{l}\text { Mycorrhizal } \\
\text { association }\end{array}$ & $\begin{array}{l}\text { Arbuscular } \\
\text { mycorrhizas }\end{array}$ & Orchid & Ericoid & $\begin{array}{l}\text { Ecto- } \\
\text { mycorrhizas }\end{array}$ & $\begin{array}{l}\text { Ectendo- } \\
\text { mycorrhizas }\end{array}$ & Arbutoid & $\begin{array}{l}\text { Mono- } \\
\text { tropoid }\end{array}$ & $\begin{array}{l}\text { Dark septate } \\
\text { endophytes }\end{array}$ \\
\hline Abbreviation & $\mathbf{A M}$ & OM & EM & ECM & ECTENDO & ARBM & MM & DSE \\
\hline Fungi: septate & No & yes & yes & yes & yes & yes & yes & yes \\
\hline Fungi: aseptate & Yes & no & no & no & no & no & no & no \\
\hline $\begin{array}{l}\text { Intercellular } \\
\text { Colonization }\end{array}$ & Yes & yes & yes & no & yes & yes & yes & $\begin{array}{l}\text { yes } \\
\text { (microsclerotia) }\end{array}$ \\
\hline Fungal mantle & no & no & no & yes & yes and no & yes and no & yes & partial \\
\hline Hartig net & no & no & no & yes & yes & yes & yes & partial \\
\hline $\begin{array}{l}\text { Achlorophyllous } \\
\text { host }\end{array}$ & not usually & yes & no & no & no & no & yes & no \\
\hline \multirow{3}{*}{$\begin{array}{l}\text { Fungal taxa } \\
\text { Plant taxa }\end{array}$} & Glom & Basi & Asco & Basi/Asco/Glom & Basi / Asco & Basi & Basi & Asco \\
\hline & Bryophytes & & & Gymnosperms & Gymnosperms & $\begin{array}{l}\text { Ericales: } \\
\text { genera }\end{array}$ & & forest trees \\
\hline & $\begin{array}{l}\text { Pteridophytes } \\
\text { Gymnosperms } \\
\text { Angiosperms }\end{array}$ & Orchidaceae & Ericales & Angiosperms & Angiosperms & $\begin{array}{l}\text { Arbutus, } \\
\text { Arctostaphylos } \\
\text { \& Family } \\
\text { Pyrolaceae }\end{array}$ & $\begin{array}{l}\text { Monotro- } \\
\text { poideae }\end{array}$ & $\begin{array}{l}\text { shrubs } \\
\text { grasses } \\
\text { forbs/herbs? }\end{array}$ \\
\hline
\end{tabular}

Note. Ascomycetes (Asco), Basidiomycetes (Basi), and Glomeromycota (Glom). 
Heath plants (family: Ericaceae) are uniquely hosts to ericoid mycorrhizas [40]. In many autotrophic members of the Ericaceae and related families, the hair-like roots are enmeshed in an extensive weft of hyphae, which also penetrate the cells of the root-normally, no sheath is formed (cf. ECM) [35]. The fungi currently identified as forming EM are Ascomycetes [35] and Basidiomycetes [41]. Arbutoid mycorrhizas possess sheath, external hyphae and usually well-developed Hartig net. Arbutoid mycorrhizas are formed, in the main, by autotrophic trees and shrubs, although some of the plants, such as Pyrola, are herbs and are partially achlorophyllous [35]. The closely related Monotropoideae are all achlorophyllous (herbaceous sub-family of the Ericaceae). The first accurate descriptions of the fungal partners of monotropes were provided by Martin [42] again, septate-fungi belonging to orders of Basidiomycetes and Ascomycetes. Monotropoid mycorrhizas have a well-developed fungal sheath, and Hartig net. They also possess a highly specialized haustorium-like structure (the fungal peg) which penetrates the epidermal cells and goes through a developmental cycle of its own as the plant grows and achieves anthesis. Arbutoid and monotropoid mycorrhizas are variations of the ECM-type and the fungi associated can also form ECM on neighbouring, autotrophic plants, and hemi-parasitism of organic carbon is assumed [35].

Orchids can be either wholly or partially achlorophyllous for some part of their life cycle. They form mycorrhizas with Basidiomycetes of various affinities [35]. The division between orchids that are green for part of their lives and those that are wholly achlorophyllous is mirrored by the identities of their fungal associates - the fungal symbionts of green orchids are saprophytes (e.g., Rhizoctonia spp.) although known perfect stages are all Basidiomycetes [43]. The mycorrhizal fungi of achlorophyllous orchids are likely to form ECM on autotrophic hosts constituting a biological bridge between them and the carbon-seeking orchids. There is considerable detail known about the relationship of orchids to their fungal symbionts; however, relationships have not been wholly established such that general concepts can be articulated [35]. The impressive diversity of the single family Orchidaceae is matched only by the Asteraceae and the Poaceae [44]. Although largely tropical and subtropical in their habitat, of the estimated 700 genera and more than 25,000 species worldwide, there are members found in all terrestrial habitats except at the poles [45]. Most orchids are autotrophic, rarely saprotropic, but are not known to be parasitic on other plants. Almost half of all genera that contain achlorophyllous mycotrophic plants are in the Orchidaceae. Orchids are commonly terrestrial, lithophytic and epiphytic; they are rarely semi-aquatic or subterranean [43].

Continued consideration of $\mathrm{OM}$ and mycorrhizal associations will provide a useful construct for the interpretation of newly discovered mycorrhizal associations in both autotrophic plant-hosts (e.g., Monotropa) and achlorophyllous (e.g., Corallorhiza) plant-hosts-where the function of the association shifts from the mutualistic end of the symbiotic spectrum (via fungal nutrient acquisition for the host $-\mathrm{C}$ for the fungus), through to the exploitative/epiparasitic (via sequestration of $\mathrm{C}$ - from neighbouring, autotrophic plants). Although orchids represent a vibrant and diverse group of plants, there are species, especially at/near the limits of their range, which are subject to perturbations. In North America, the western prairie fringed orchid is a legally defined threatened and endangered species [46].

There are ongoing discussions around the definitions of mycorrhizas, mycorrhizal associations and hence, mycorrhizal diversity - especially with the emergence of the application of molecular-based techniques (see $[38,47,48]$ ). For the purposes of this review, we use mycorrhizal diversity in the 
broadest sense-encompassing the structural, form and functional diversity of plant-fungal root symbioses types or categories. Within each of the mycorrhizal types (taxonomic categories), there exists further levels of diversity. This takes into account multiple lineages of fungi that encompass diversity of nutrient uptake (e.g., phosphorus, zinc, sulphur, and nitrogen), other essentials (e.g., water), production of sequestering agents, production of antibiotics, enhancement of soil structure, etc.

\subsection{Mycorrhizas and Plant Fitness}

Population and community regulation can result from either promotion or reduction in the growth, fitness or reproductive potential of an organism. If the fitness of one organism in the community is altered to a greater or lesser extent than another, the result is a changed dominance of the favoured species in the community that occurs over successive generations [1]. Mycorrhiza influence the growth and fitness of the plant-host, through the extramatrical hyphal network providing access to a larger pool of nutrients - either mineral (e.g., phosphorus) or from organic sources (e.g., humus) or autotrophic plants. As such, the actual effect of the mycorrhizal association above the cost of the maintenance of the association is dependent on the rate of growth of the extraradical hyphae of the fungal species [49]. Mycorrhizas also improve plant-water relations [50,51], and reduce pathogenic infections. Mycorrhizas also contribute to plant C-allocation [52]. However, there is evidence that mycorrhizas mediate uptake of other non-nutrients and even toxic materials [53]. Alternatively there is evidence that AM fungi increase plant tolerance to heavy metals [54].

\subsection{Mycorrhizas and Plant Succession}

Because mycorrhizae influence plant fitness, the resulting enhanced plant nutrition may result in increased biomass production — which could be translated into improved reproductive success. Thus, the association can influence interspecific plant competition dynamics by preferentially improving recruitment. There is also evidence that the association may result in the uptake of metabolically active organics [55] or provide mechanical and chemical defenses against plant pathogens [56,57]. This in turn can influence plant demographic responses, community structure, and ultimately, the successional dynamics of some plant communities [58].

\subsection{Mycorrhizas and Ecosystem Function}

The major ecosystem function of mycorrhizas is to assist plant-hosts in the acquisition of resources (nutrients, water, C) from soil. Read [59,60] put forward a hypothesis that the dominant type of mycorrhiza in an ecosystem was related to the soil conditions and the nature of the major form of nutrient from which the plant community derived its nutrition. Read showed the geographical distribution of the main mycorrhizal types in the world as follows:

- AM habit was dominant in the temperate and tropical grasslands, tropical forests, and desert communities

- ECM were dominant in temperate and arctic forested ecosystems and

- EM were common in the boreal heathland ecosystems. 
In ecosystems dominated by graminoids, AM fungi are much more prevalent than other categories of mycorrhizal fungi. Physical disturbance of these grasslands has been shown to depress activity of these fungi [61]. Alpine and tundra grasslands also have a substantial community that is dominated by AM plants, although there are shrubs or stunted trees in the alpine grasslands that have ECM associations. And while the dark septate root endophytes (DSE, Table 3) in a range of plant taxa from Polar regions are not as yet considered to be true mycorrhizal symbionts [62], recent studies suggest some benefits to plant growth (under certain conditions).

The importance of mycorrhizal contribution in forested ecosystems was shown by Vogt et al. [63], who demonstrated that the percentage of net primary production represented by mycorrhizal fungi was $14-15 \%$ (with up to $45 \%$ in young forest stands and $75 \%$ in mature forest stands). ECM have been shown to produce $\mathrm{N}$-degrading protease enzymes and P-solubilizing acid phosphatase enzymesenabling them access to forest-floor nutrient pools [64] (see also [65]).

Weather conditions are major drivers of bacterial and fungal infectious diseases of emerging plants [66]. Environmental stresses such as drought or nutrient deficiency can predispose plants to diseases. The ecological impacts of non-indigenous invasive fungi as forest pathogens are increasing in global frequency [67]. Efficacious ECM associations are considered to convey some level of host resistance to tree hosts [56]. Therefore continuity in the ECM association will continue to provide ecosystem-resilience from pathogenic as well as other potentially invasive mycorrhizal fungi [68].

Numerous species of forest-dwelling small mammals rely on the fruiting bodies of ECM as a primary source of food [69]. Others too rely on hypogeous fungi, including Australian mammalsMarsupialia and Eutheria alike [70], while primates have also been shown to be mycophagous (e.g., [71]). Malajczuk et al. [72] considered that the morphology of some ECM increased their dependence on animal mycophagy for spore dispersal—as hypogenous fungi remain below ground and do not release spores into the air [73]. The lack of mammal-dispersed hypogenous ECM is considered to hinder Pinaceae invasions into previously unsuitable habitats [74]. Insects and other invertebrates are known to ingest spore materials of mycorrhizal fungi [75] and there is evidence these are important in the dispersal of mycorrhizal fungi [76,77].

The mycorrhizal fungi forming associations with ericaceous plant communities are capable of producing enzymes enabling the plant-host to access organic forms of nutrients. In addition to the direct nutritional benefits of EM colonization, the ability of the fungus to sequester, and in some cases metabolize, metal ions that are otherwise toxic appears to be of importance [35].

\subsection{Mycorrhizal Associations: Their Resiliency}

There are several scenarios that emerge when considering mycorrhizal association in the context of climate change. The central theme of this paper is to present those scenarios that are the most likely in the context of proposed climate change models. Central to examination of these possibilities is addressing the following fundamental questions: (1) What are the effects of environmental drivers on mycorrhizal plant-hosts? (2) What are the effects of environmental drivers on mycorrhizal fungi?

(3) How do these changes to mycorrhizal fungi affect mycorrhizal association with their plant-partner?

(4) What will happen to mycorrhizal diversity as a consequence of any de-coupling of mycorrhizal 
associations? (5) Will changes to mycorrhizal fungi in terrestrial soil-vegetation systems influence plant, community, ecosystem, and biospheric/global processes?

\subsection{Hypotheses: Proximal and Distal}

To address these questions, we pose four hypotheses. Addressing these is fundamental to addressing the resiliency questions in the last section.

1. Mycorrhizal diversity evolved in response to changes in GCC environmental drivers.

2. Mycorrhizal diversity will be modified by present changes in GCC environmental drivers.

3. Mycorrhizal changes in response to ecological drivers of GCC will in turn modify plant, community, and ecosystem responses to the same.

4. Mycorrhizas will continue to evolve in response to present and future changes in GCC-environmental factors.

\section{Evolution of Mycorrhizal Diversity and Associations with Plants}

The unraveling of DNA's structure, and interpretations since, have served to bring together the ideas of Darwin, the findings of Mendel as well as other arguments (see Quammen [78] for listings of many) into a dramatic thesis that fails to support the null hypothesis of evolution not being the basis of speciation. This central principle that there was sufficient time for evolution to take place mutation by mutation as well as the underlying principle of organized doubt [78] have directed this current investigation.

\subsection{Ecological Drivers of GCC}

The response of mycorrhizal associations to perturbations in their environment in the past is a predictor of how they will react to perturbations in the future. Global climate change (GCC) is driven by several fundamental ecologically important drivers [79]:

- Increasing atmospheric $\mathrm{CO}_{2}$ levels and associated climatic changes

- Global temperature rise

- Changes in global rainfall distribution

- Increased deposition of anthropogenically generated non-metals (e.g., N and S).

- Fragmentation and habitat loss, and

- Biotic invasions (and other threats to biodiversity).

\subsection{1. $\mathrm{CO}_{2}$ Enrichment}

Atmospheric $\mathrm{CO}_{2}$ concentration has fluctuated from 170 and 300 ppm over the past 160,000 years. However, since start of the Industrial Revolution (1750-1800), $\mathrm{CO}_{2}$ concentration has increased from 280 to approximately $365 \mathrm{ppm}$ at present. This rise is strongly correlated with the increase in consumption of fossil fuels, and there is apparently also significant contribution from the clearing of tropical rainforests [80]. A doubling of atmospheric $\mathrm{CO}_{2}$ concentration, expected by $2100 \mathrm{AD}$, and a rise in other so-called greenhouse gasses (e.g., methane, nitrous oxide) would potentially increase 
global temperature average of $4.5-6{ }^{\circ} \mathrm{C}$. In addition, related shifts in regional precipitation patterns may result in decreased soil water availability in many areas of the world [81]. Moreover, a $\mathrm{CO}_{2}$-enriched atmosphere and the corresponding change in climate may alter the density of vegetation cover, thus modifying the physical characteristics of the land surface [82].

\section{Global temperature increase}

The 10 warmest years since the beginning of meteorological measurements have all occurred since 1987 [83]. The global mean surface temperature has increased over the last century by approx. $0.6{ }^{\circ} \mathrm{C}$ [84] with the most pronounced and rapid changes at high latitudes and altitudes [85-87]. The general increase in global average temperatures includes spatial, temporal and directional (e.g., observed regional cooling as well as warming trends) heterogeneity [88]. The disappearance of glaciers is also an index of these changes [89]. Reconstructed air temperatures from the ice cores from a high elevation glacier in Wyoming indicate an increase in air temperature of $3.5{ }^{\circ} \mathrm{C}$ from the mid-1960s to the early 1990s, and between the end of the Little Ice Age (mid-1800s) and the early 1990s an air temperature increase of $5^{\circ} \mathrm{C}$ [90]. This is much larger than the global average for the last century of $0.7{ }^{\circ} \mathrm{C}$, but is consistent with other observationsat high elevations or high latitudes over similar time periods in Tibet [91], the Alps [89], Alaska [92] and the Western Arctic [93].

\section{Changes to global rainfall patterns}

GCC is certainly very likely to locally change the intensity, frequency, duration and amounts of precipitation [94]. Both drier and wetter conditions are predicted depending upon location, vegetation and circumstances [95].

\subsubsection{Increased N Deposition}

Wet and dry deposition of nitrogenous compounds (NOx and $\mathrm{NHx}$ ) emitted from agricultural operations and internal combustion engines have quickly become a dominant source of nitrate $(\mathrm{N})$ in many natural ecosystems [96]. Mycorrhizal colonization tends to decline with $\mathrm{N}$ deposition and fertilization for AM and ECM associations [97-100], Deposition of nitrogen compounds has been shown to significantly decrease activity of many microbial function groups (e.g., [101]). Eisenlord and Zak [102] show Basidiomycetes that convert lignins to $\mathrm{CO}_{2}$ are depressed by increased soil nitrogen input to the soil. But Actinobacteria that convert lignin to polyphenols are enhanced by nitrogen inputs..

\subsubsection{NOx, SOx and Related Issues}

Recent work at 4,000 m elevation in the Wind River Range [103] show a 10- to 100-fold increase in nitrate deposition rate since about 1960. Further, there are many reports that atmospheric deposition of nitrogen in general has increased during roughly the same time period (e.g., [104,105]). These changes are undoubtedly adversely impacting other critical micronutrients. There is evidence that selenium (Se) bioavailability is being attenuated by inputs from atmospheric deposition [106] in unmanaged, alpine soils. Further, inputs of such atmospheric ions as nitrate and sulphate (or more generally NOx and SOx) are acid formers. Many metals become increasingly mobile and therefore more biologically problematic as $\mathrm{pH}$ is lowered. 


\subsubsection{Mycorrhizal Diversity in the Context of Past GCC}

\section{Co-evolution of roots and mycorrhizas of land plants}

In Cairney's review [16], it is proposed that all extant land plants arose from an ancestral AM condition (see also [3,5]). Although fungi appear to be associated with the tissues of some of the very earliest structurally preserved land plants, extrapolation to functional significance is not possible [107]. Brundrett [2] methodically examined the mycorrhizal associations of living and extinct plants, with respect to the historical coevolution of roots:

- The first bryophyte-like land plants in the early Devonian (ca.400 m.y.a.) had endophytic associations resembling AM even before roots evolved

- Liverwort rhizoids are also colonized by the fungi of EM in some ecosystems

- Sphenophytes, lycopodophytes and pteridiophytes were the first plants with roots, and arose in the mid-Devonian:

- Equisetum (sphenophytes) sporophytic-phase possesses AM

○ in Lycopodium the gametophytic-phase possesses fungal structures akin to AM

○ ferns dominated the world from the Silurian to the Palaeozoic, and still possess AM

- In the gymnosperms, both living and Triassic fossil cycads had AM in roots. The gymnosperm trees dominated the Earth's forests in the Jurassic and Cretaceous:

- genera such as Agathis, Araucaria, Phyllocladus and Gingko have AM (the AM conifers have remained dominant in some forests of the Southern Hemisphere)

o members of the Pinaceae have ECM

- Angiosperms probably arose in the Early Cretaceous:

- monocots-AM/OM (plus exploitative)

○ eudicots - many ECM

- rosids-AM/ECM/ECTENDO

○ asterids - some AM, some ECM (especially in Australia [108])

Genera with dual EMC/AM associations include Acacia, Alnus, Casuarina and Salix (e.g., [37,108,109]), as well as Purshia and Cercocarpus (both in the Rosaceae [110]). This provides evidence of the continuing evolution of the mycorrhizal association, manifest as multiple, complementary synergisms on a single plant's root system. Kurtböke et al. [111] identified the coastal she-oak, Casuarina equsetifolium, with the bipartite associations of AM plus actinomycete N-fixing nodules. Previously, Bellgard [37] described Acacia longifolia (and other members of the Fabaceae) from the sandstone woodlands of the Hawksbury Sandstone as possessing the tripartite associations of AM, ECM and rhizobia N-fixing nodules. Williams [110] described Cercocarpus montanus and Purshia tridentata, both members of the Rosaceae, as tripartite with AM, ECM and actinomycete N-fixing nodules. Herrmann [112] describes numerous species in the Fabaceae in NE China as having tripartite associations. The occurrence of two or three types of multi-species root symbioses in/on the same root systems raises important questions about the cost-benefit ratio of maintaining all of the associations and competition between symbiotic species for the available root-space (see [113]). 
Influence of past global perturbations (Table 2).

Survival through and adaptation to mass extinctions are crucial for species survival. Further, the current rate of climate change is commensurate with rates posited for previous mass extinctions.

There have been, arguably, five major extinctions in the four-billion-year history of life [10]):

- The first (Ordivician-Silurian), 450 m.y.a., occurred shortly after the evolution of the first land-based plants and 100 m.y.a. after the Cambian Explosion of animal life beneath the seas.

- The second came 350 m.y.a., near the end of the Devonian, causing the formation of the coal forests.

- The Permian is marked geologically by the final assembly of Pangaea, glaciations in the southern extreme of Gondwana, and the greatest mass extinction in Earth's history, which occurred at the close of the period.

- Triassic-Jurassic extinctions: At the end of the Triassic a mass extinction occurred and the Jurassic saw two mass extinctions. The first occurred about one-third of the way through the period, during the early Jurassic. At the close of the Jurassic, about 140 m.y.a., a second minor mass extinction happened.

- The fifth mass extinction, probably caused by a giant meteor impact, at the end of the Cretaceous period, ended the reptilian dominance of the Earth-ushering in the current mammalian domination.

Global cooling tied to Gondwana glaciation has been proposed as the cause of the 1st and 2nd extinction events (see [114,115]). Conversely, the Permian mass extinction was associated with an extremely warm climatic phase [116]. Mayhew et al. [117] exhort that the fossil record and ecological models endorse the view that global warming will adversely affect biodiversity. Much of the fossil evidence would suggest that desiccation was one of the primary selective pressures responsible for certain types of structures (e.g., resistant spores) [107]. The sequential development of plant communities following major environmental perturbations such as glaciations and volcanic activity are well documented [35]. It is acknowledged that scarcity of nutrients in the poorly weathered materials exposed by such events may signify the early stages of the primary succession [118].

\section{The first appearanceof mycorrhizas?}

It has been proposed that the apparent lack of, or at least poor development of, roots in the earliest plants, in tandem with a scarcity of essential plant nutrients in the rudimentary soils, necessitated the evolution of symbioses to assist the successful colonization of land by plants [4,5,119]. Arbuscular mycorrhizas coincidentally appeared with the first colonization of land plants some 450-500 m,y.a. [23]. As such, they have persisted through the major global climatic changes (i.e., glaciations and inter-glaciations) that have occurred since early Devonian times. Similarly, ECM in gymnosperms were also established by the Permian and so have also persisted through the global perturbations since the Permian [13].

Cairney [16] asserts that "on-going parallel evolution of the partners in response to environmental change on both widespread and more local scales may most readily explain extant patterns of mycorrhizal diversity and specificity". Extinction is another outcome of environmental change [120]. 
We postulate that past global environmental changes acted on the evolutionary, physiological, etiological and ecological trajectories of the early fungal partners. The development of the different mycorrhizal functional groups was therefore in response to a complex set of environmental drivers including (but not limited to) drastic changes in ambient temperature (leading to desiccation), global cooling (a consequence of glaciations), and the nutritionally-depauperate nature of the rudimentary soils. In the present biogeographical context, climate exerts the dominant control over the natural distribution of species. Evidence from the fossil record and from recent observations confirms that changing climate has a profound influence on the expansion and contraction of species' ranges. It is therefore predicted that the environmental consequences of GCC will have a significant impact on the distribution of species. This is particularly relevant to obligate biotrophs such as mycorrhizal fungi, as changes in the abundance and/or distribution of their host-plant partners will impact their viability, productivity, longevity and efficacy as a symbiotic partner.

\subsubsection{Functional Diversity}

Mycorrhizas may be balanced mutualistic associations in which the fungus and plant exchange commodities required for their mutual survival and growth. However, mycorrhizal fungi also function as endophytes, necrotrophs and antagonists of hosts or non-hosts plants, with roles that vary during the lifespan of their associations [121] (Table 4). Mycorrhizas also encompass mycoheterotrophic plants, which have exploitative mycorrhizas where transfer processes apparently benefit only plants [121]. Brundrett [2] actually proposed a sequence of stages in mycorrhizal evolution: (1) endophytic associations that are either commensalistic and/or amensalistic, (2) mutualistic associations that provide benefits to both partners and (3) exploitative associations, which are mycoheterotrophic and assist only the plant-host.

- Primordial endophytic associations: where the fungal endophytes benefit from occupying plant roots by gaining greater access to exudates, first to access organic substances after the death of the host and to avoid competition. The first hypothesized stage in the evolution from endophytic to mycorrhizal, fungi would have putatively become more efficient at absorption of food within plants, ultimately resulting in complete dependence on the plant as a source of energy. Concomitantly, absorptive hyphae within plants increase surface area and permeability [2].

- Towards balanced mutualistic associations: According to a number of sources, fungi occupied Precambrian soils long before plants (e.g., [32]), and could be considered to have evolved efficient ways of acquiring essential mineral nutrients for their sustenance [2]. Precambrian climatic and edaphic conditions were challenging - with surface temperatures of around $65{ }^{\circ} \mathrm{C}$ [122] and the rudimentary soils being largely newly formed Entisols with little or no structure or anisotropic properties [123]. The potential existence of fungi with the capacity to exploit nutrients from the rudimentary soils may have provided the appropriate spatial alignment for the first cellular, fungal-plant exchanges to have occurred. It is considered that an increased permeability of fungal cells resulted in the leakage of their contents becoming available to the plant [2]. Continuing selection of fungal-plant 
combinations would see the emergence of specialized interface organelles paired with fungi with superior "mechanisms that improved uptake of limiting resources" [2].

- Arrival of exploitative mycorrhizas: The third proposed stage in mycorrhizal evolution involved the plant gaining control over the mycorrhizal fungi [5]. This subjugation involves the plant relying on the fungus to supply both mineral nutrients and energy-without the fungi benefiting from these associations [52]. This evolutionary trend results in mycoheterotrophic plants without chlorophyll that are fully dependent on their fungi.

\subsubsection{Ecosystem Fragmentation and Habitat Loss}

Fragmentation of natural ecosystems is a consequence of colonization by humans and their associated domesticated animals. Habitat loss from the conversion of wildland and forest ecosystems to agricultural lands not only contributes to $\mathrm{CO}_{2}$ enrichment, but also threatens biodiversity. This is of particular significance to orchids and other achlorphyllous plants that are reliant upon intact plant-hosts to acquire carbon [124].

Sporocarp consumption of AM fungi by small mammals has been demonstrated in a Panamanian cloud forest [125]. Tripartite interrelationships between animals, mycorrhizal fungi and plant-hosts for successful dispersal of inoculum is one that will continue to be impacted by a range of GCC-induced habitat changes. This is because many various levels of the soil food web are involved in these relationships, and so small-scale perturbations can have large-scale ramifications from primary invertebrate consumers (such as mites, millipedes, beetles [126]) through to higher-order mammalian herbivores. Further to this, unique, intrinsic ecosystem processes such as wildfire will also be relevant-because some species of plants and ECM only fruit in response to fire $([127,128]$ respectively).

\subsubsection{Natural Biological Invasions}

In North America, the invasive annual Bromus tectorum (cheat grass) has become exceptionally problematic. This plant is a winter annual. It germinates in autumn and grows slowly in winter and in spring puts on abundant growth out-competing most other plants. The plant is reported to be facultatively mycorrhizal, but apparently remains non-mycorrhizal during most of its growth period, only hosting mycorrhizal fungi late in its growth period when other plants are becoming active [129-131]. The genome of this plant seems highly plastic, but change to warmer climatic conditions likely favours the capacity of cheatgrass to invade [132].

Invasive agents can also include herbivores such as pine bark beetles and fungi [68]. Pine bark beetles (Dendroctonus) in especially western North America are secondary causative agents of epidemic-scale die-offs of many species of pines (Pinus) as well as fir (Abies) and spruce (Picea). Principal causes of die-offs are attributed to drought and depressed colonization by mycorrhizal fungi [133]. 
Table 4. Functional diversity of mycorrhizas and DSE (adapted from [2]).

\begin{tabular}{llllllll}
\hline & AM & ECM & EM & ARBM & MM & OM & DSE \\
\hline ASSOCIATION: & & & & & & & \\
Plant provides a key habitat for fungus & yes & partial & unknown & unknown & unknown & unknown & yes \\
Fungus efficient at mineral uptake from soil & yes & yes & yes & unknown & possibly? & yes & unknown \\
Interface hyphae highly specialized & yes & yes & no & yes & yes & no & no \\
Plant-fungus coevolution & yes & yes & unknown & yes & no & unknown & no \\
Estimated age of association (m.y.a.) & $>400$ & $>100$ & $<100$ & recent & recent & $<80$ & $>400$ \\
Host-fungus speciality & low & medium & medium & High & high & high & high? \\
FUNGUS: & & & & & & & \\
Multiple lineages of fungi & no & yes & yes & yes & yes & yes & yes \\
Recruitment of new fungal lineages continues & no & yes & yes & yes & yes & yes & yes \\
Obligate (host required for growth) & yes & yes & unknown & unknown & yes & yes & partial \\
Capable of independent growth & no & partial & yes & unknown & partial & yes & yes \\
ROLE: & & & & & & & \\
Mineral nutrient transfer to plant & yes & yes & yes & unknown & yes & yes & unknown \\
Energy transfer of fungus & yes & yes & partial & unknown & no & unknown & partial \\
Energy transfer of plant & partially & partial & no & unknown & yes & partial & no \\
PLANT: & & & & & & & yes \\
Switched to new fungus lineage & no & yes & yes & yes & yes & n.a. \\
Recruitment of new plant lineages continues & unknown & yes & no & $?$ & yes & no & yes \\
Obligate requirement for association & partial & yes & partial & $?$ & yes & yes & no \\
\hline
\end{tabular}




\subsubsection{Human-Mediated Biological Invasions}

The introduction and spread of exotic and invasive species is one of the most important problems in conservation biology [134] and an increasing risk to national border biosecurity. GCC will alter climatic, atmospheric and edaphic conditions, which will provide opportunities for competitive/invasive exotic plant species to extend their present distributions [135] — diluting and reducing biodiversity values. The invasive agents can also include herbivores such as pine bark beetles [136,137] and fungi [68]. In turn, plant defoliation has been shown to influence mycorrhizal community structure [138].

Other than weeds, plant diseases can also be moved via the pan-continental movement of bulk transport. Emerging infectious diseases have also shown to be caused by new pathogens arising from hybridization favoured by novel co-occurrence of allopatric fungal species of related species [68]. The opportunities for these to arise have in some cases been created through the accidental movement of pathogenic agents, being associated with the global horticulture and forestry trade.

2.1.9. Extrapolated Impact of Previous Climate Change on Mycorrhizal Associations: Why Mycorrhizal Diversity?

Assuming that mycorrhizas functioned in the past much as they do now, as such, mycorrhizas have been benefiting plants since the end of the glaciation associated with the end of the Palaeozoic era [139]. During that time, the classical "Big Five" mass extinctions [140] of geological proportions (see Table 2: Major Epochs, Climatic Conditions, Biological Milestones, Mycorrhizal Diversity) occurred. According to Leakey and Lewin [10], we are currently going through the initial phase of the "Sixth Extinction" (Table 2).

Mycorrhiza likely radiated with land plants as they explored and colonized new niches and, despite radical changes in atmospheric and edaphic conditions, continued to maintain their affiliation with plants. Climatic, atmospheric and edaphic changes associated with GCC will see opportunities emerge for plant species to invade habitats that have been, under past environmental regimes, unsuitable for them to colonize. As in the past, mycorrhizal fungi will continue to play a relevant part in the successional positioning of the new plant species distributions as they adjust to GCC. Mycorrhizal diversity contributes to ecosystem productivity and resilience to perturbations. Thus maintenance of mycorrhizal diversity will be consequential in the maintenance of productivity and resilience of global ecosystems especially in high altitude and high latitude grasslands, heaths and forests, and equatorial and tropical regions where habitat fragmentation and ecosystem conversions to monoculture threaten rare and geographically-restricted plant taxa.

2.1.10. Implications for Evolution of Plant Communities and Ecosystems: Mycorrhizal Diversity Further Expanded

The various meanings of diversity generally reflect the variation in species assemblages within a given community [9]. Mycorrhizal diversity is the structural and functional diversity that exists within these 
fungi. Reviews by Brundrett [121], Leake and Read [52] andSmith and Read [35] comprehensively cover classification, terrestrial habitats and all aspects of mycorrhizal diversity, form and function. Herein we summarize these works into a framework that allow interpretation of the various responses of mycorrhizal fungi and associations (and hence mycorrhizal diversity) to the key environmental drivers of GCC.

\section{Structural diversity}

Brundrett [121] recommended that diverse interactions between mycorrhizal fungi and plants be defined and classified primarily by anatomical criteria regulated by the plant-host. The characteristics of mycorrhizal types recognized by Smith and Read [35] can be split based on their fungal associates into (1) aseptate endophytes (in the Glomeromycota) and (2) septate fungi in the Basiodiomycetes and Ascomycetes (Table 3).Imhof [38] has a three-level hierarchy based on the three mycorrhizal types recognized by Smith and Read [35]:

- AM group

- ECM group (comprising Cortical ECM [141]; Epidermal ECM [142]; ECTENDO [35]; EM [15]; ARBM [143]; MM [144]

- OM group

This approach resonates with the phylogenic and ecological basis Trappe [145] used to articulate his synthesis of the evolution of mycotrophy and angiosperms.

\section{Functional diversity}

A. Taxonomic diversity: affinities and origins of the fungal partners.

The major taxonomic revision of the fungi constructed by Hibbett et al. [146] resulted in significant revision of the traditional phylum Zygomycota. The sub-phylum "Zygomycotina" and class "Zygomycetes" have been discontinued and the phylum Glomeromycota (first proposed by [147]) now encompasses the AM fungi. This revision is one of the most significant findings in mycorrhizal research in the last ten years $[35,47]$. The AM fungi are considered primitive because of their simple spores and lack of sexual reproduction, and because there are relatively few species of these fungi and they associate with a wide diversity of plants [148].

ECM fungi include at least 6,000 species, primarily of Basidiomycetes with some Ascomycetes [2] as well as hypogeous fungi forming ECM relationships (listed in [35]). It is likely that a rapid diversification of the Basidiomycetes occurred in the Cretaceous, as plants with ECM became increasingly important [2]. The large Basidiomycete ECM families Amanitaceae, Boletaceae and Russulaceae probably arose at this time and are still major ECM-players.

Ectendomycorrhizas in the extant flora are restricted to a taxonomically narrow group of plant-hosts in the Ericales_-Ericaceae (found predominantly in the Northern Hemisphere) and the Epacridaceae (found predominately in Australia) [149]. Cullings [15] suggested that because the host-plants had a monophyletic origin, their mycorrhizal fungi may be also closely related. Nixon and Crepet [14] discovered fossil evidence of the Ericales-like taxa existing from the Early Cretaceous (contemporaneous 
with the ECM expansion described above). Molecular comparisons of EM from extant Ericales in the Northern and Southern hemispheres indicate that they are taxonomically closely related [150].

While there is only limited fossil evidence of Paleozoic fungi [151], recent advances in the development of molecular tools now pinpoint that both AM and ECM fungi diverged from deep in the Proterozoic $[13,31,152]$. Thus it is probable that the first terrestrial fungi pioneered land colonization before plants permanently established themselves in a terrestrial niche.

Orchids have mycorrhizal associations with soil fungi essential for seed germination and assist the growth of adult plants [2]. The level of specialization in terrestrial orchids has been reviewed by Swarts and Dixon [124]. Ramirez et al. [153] indicate that the world's most diverse floral family (Orchidaceae) probably started with a single common ancestor that existed about 80 m.y.a. The diversity and functionality of fungi that associate with the orchids is equally impressive. Perfect stages of Orchid Rhizoctonias [154] are relegated to at least three families within the Basidiomycetes: Tulasnellaceae, Ceratobasidiaceae, and Termellaceae (see compilations in $[44,155]$ ). The diversity of fungi interaction with a diversity of orchids results in a predictable diversity of physiological responses. Carbon can move from the orchid to fungus and back, $\mathrm{P}$ only from fungus to plant, $\mathrm{N}$ substances (ammonium) move bothways and amino acids, urea and vitamins move both ways [156,157]. Many of the Orchid Rhizoctonias enhance seed germination and may be required for germination of orchid seeds. Some of the germination-stimulating fungi may become mycorrhizal symbionts, whereas others do not become mycorrhizal symbionts. There is considerable specificity between germination-enhancing fungi and orchid species [158].

The degree of dependence in mature orchids on mycorrhizas shifts as the plants mature and depends also on the autotrophic or heterotrophic lifestyle of the orchid [159]. The order Orchidales contains the many mycoheterotrophic species [35]. Some remain non-photosynthetic throughout their lives engageing in complex tripartite associations.

\section{B. Biogeographic diversity: global distribution of mycorrhizal types.}

Dighton [1] articulates the Read-Hypothesis to explain the variation in geographical distribution of mycorrhizal types. It provides a convenient framework to discuss mycorrhizal biogeographic diversity .

The Read-Hypothesis ascribes the dominant type of mycorrhiza in an ecosystem as a response to the the major forms of the nutrients used by the plant community:

- Extreme north and south latitudes or high altitudes (where development of soil is constrained by climate and litter is slow to decompose): (1) organic matter accumulates faster than it can be decomposed resulting in the accumulation of undecomposed humic materials, (2) ericoid mycorrhiza (i.e., EM and ECTENDO) dominate within a plant community of ericaceous species (see also [160]), (3) production of a range of enzymes enables EM-forming plants to access $\mathrm{N}$ tied up in undecomposed organic matter, and (4) also provide buffering from generally harsh, acidic edaphic conditions of the heathlands [15] 
- Mid-latitudes and mid-range of altitude

- Here a mixed range of organic plant litter resources provides a mixture of easily decomposed and recalcitrant edphic resources

- Nutrients in both an inorganic and organic form

- Coniferous and deciduous forest ecosystems dominate with their predominantly ECM

- Grasslands - organic matter is decomposed and recycled so quickly it winds up as organic $\mathrm{C}$ in the soil rather than litter on the surface. Graminoids predominately AM-associated

- Broad mycorrhizal host-range with specificity at the level of host genus [161]

- The ECM have a range of physiological functions from efficient inorganic nutrient uptake to a high degree of enzyme activity for acquisition of nutrients that are poorly plant available

- Low equatorial latitudes and low altitudes (and in certain ecosystems at mid-latitudes, e.g., some grasslands)

- Soils with a generally acidic reaction and variably weathered

- Plant litter material is usually readily decomposed and soils contain a higher proportion of nutrients in an inorganic form

- AM dominate, encompassing all plant growth forms

○ Low host specificity [16]

- AM more adapted for efficiency of inorganic nutrient uptake and have lower abilities to access organic forms of nutrients

Our reinterpretation of concepts of hierarchy and scales within ecosystem processes first proposed by Friese et al. [162] pictorially represents the scales of mycorrhizal diversity that have resulted from the coevolution of plants under the various regimes of GCC over the past 400 million years (Figure 1). One must acknowledge the hierarchy of scale of interactions that exists from the level of a fungal hypha, through to its plant-host(s), and up through plant-communities and ecosystems, to global biomes and ultimately, the biogeochemical cycles that govern the balance of atmospheric constitution (see Figure 1). We acknowledge that the complexity of mycorrhizal diversity and that the processes existent (in Figure 1) are over-generalizations. However, it is important to capture the direction of selection as a consequence of GCC and how the trophic interactions that they disrupt influence mycorrhizas and, and in turn, their plant-hosts (see [163]). 
Figure 1. Concepts of hierarchy and scale in ecosystems. The relationship between scales (double-headed arrows $\leftrightarrow$ ) is crucial for evaluating the impact of function of a lower scale on processes at higher scales. Processes may overlap from one scale to another and scales are also only approximate (Adapted from Friese et al. [162]).

SCALE

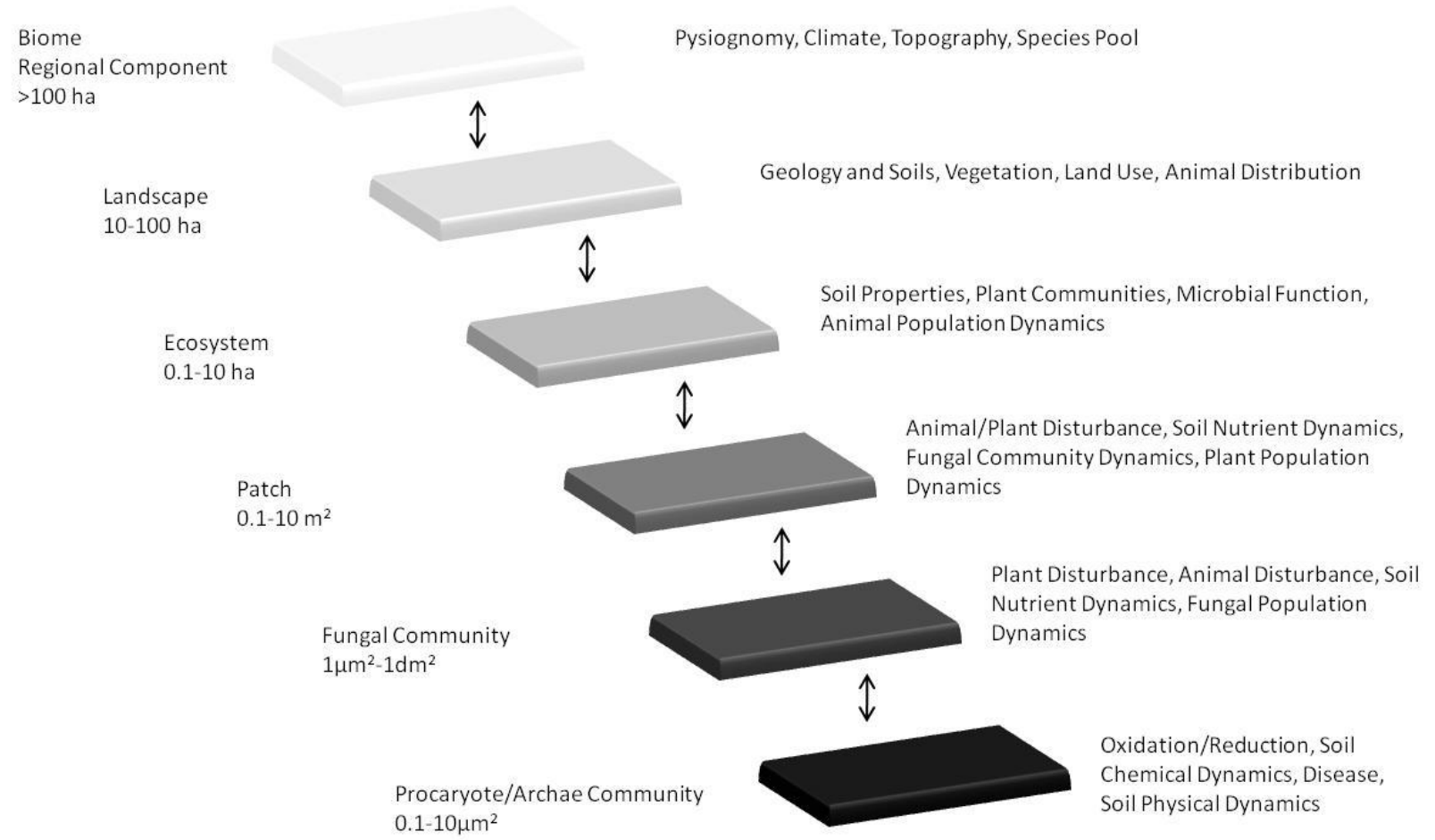

\section{Impact of Current GCC on Mycorrhizal Diversity}

\subsection{What Are the Direct and Indirect Effects of GCC-mediated Environmental Changes to Mycorrhizas?}

It is a central premise of biogeography that the broad-scale distribution of terrestrial ecosystem complexes is determined largely by climate and, as such, can be altered by climatic changes due to natural and human-mediated activities [164]. Climate is also a major determinant for the phenology, physiology, distribution and interactions of plants (determined largely by temperature range, quality and quantity of light, seasonal water availability, humidity, barometric pressure and the generation of wind, and extent and intensity of erosion of parent material). The strong interrelationship between climate, soils and plants is a basis for anticipating substantial changes in natural terrestrial biomes in response to GCC (Figure 2). 
Figure 2. Direct and indirect impacts of an environmental factor, here envisioned as a global climate change (GCC) factor, on a simplified mycorrhizal fungal community. An environmental factor (GCC factor) can have direct affects on both plants and associated mycorrhizal fungi (solid arrow $\rightarrow$ ). The factor can also affect mycorrhizal fungi indirectly via impacts on the plant-host (dashed arrows …….... ) . Interspecific interactions (dot-dashed double arrows $(-\rightarrow>$ ) at levels of plants and mycorrhizal fungi attenuated by climate, topography, other organisms, geological substrates, and maturity of the system will determine plant and mycorrhizal community structure (curved solid arrow $\rightarrow$ ). Finally, the plant and mycorrhizal fungal communities both influence one another (double two-way arrows $\longleftrightarrow$ ). This model has been used by others $[165,166]$. We extend the model to include a soil layer through which most GCC factors must pass and may be attenuated.

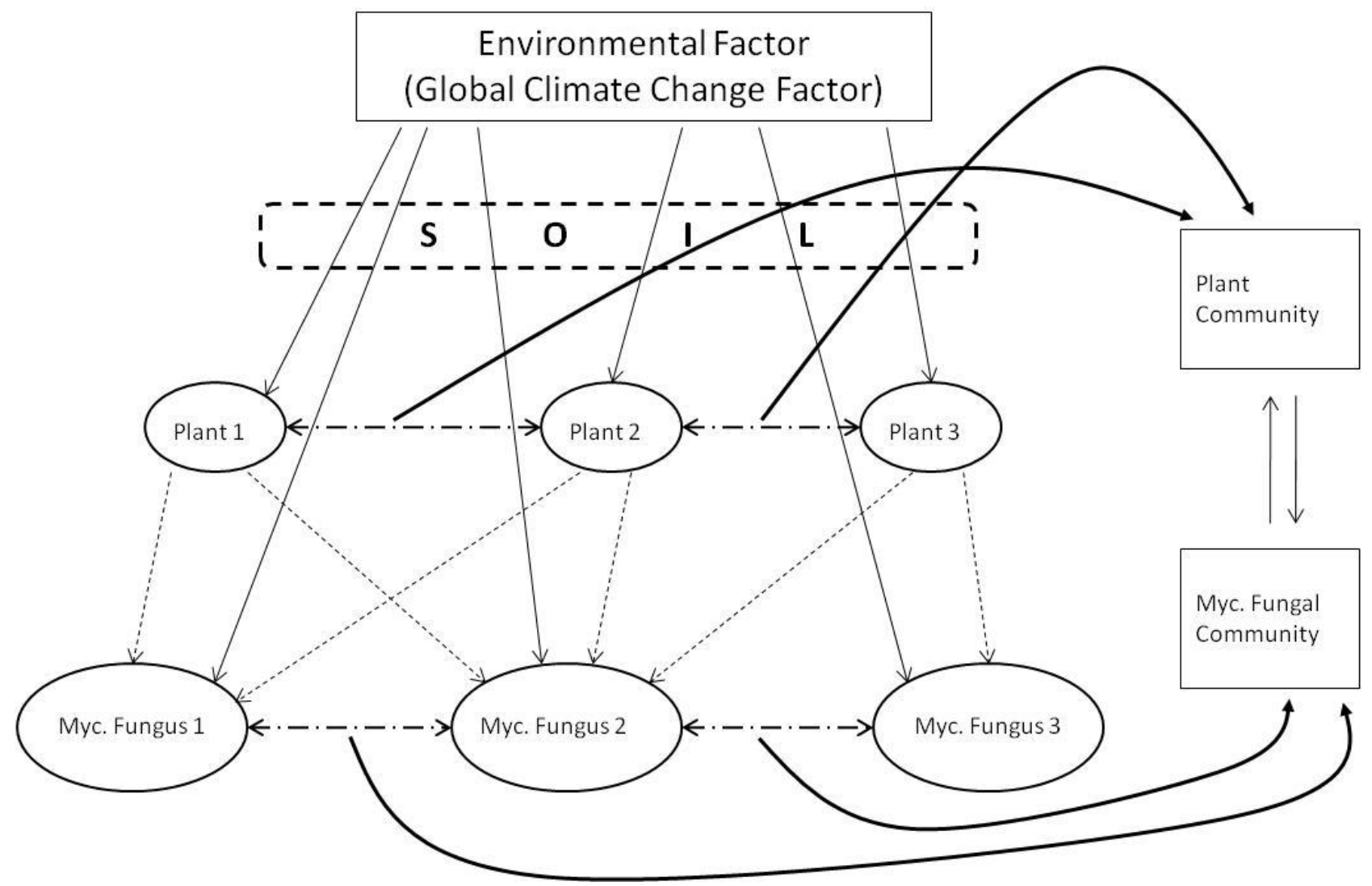

\subsubsection{GCC-Mediated Changes to Plant and Fungal Performance}

The GCC-mediated changes to plants and plant ecosystem complexes are well documented in literature, and are broadly classified into either direct or indirect effects (Figure 3 and Table 5). Here (Figure 3) four themes are allocated to either direct effects or indirect effects. These are followed (in Table 5) by conjectured summarial impacts on mycorrhizas from putative impacts on mycorrhizal function. 
Figure 3. Environmental drivers conceptually impart changes to plants which ultimately influence mycorrhizal associations and mycorrhizal fungi. The drivers are well documented as well as the changes to plants (see Table 5). The impacts on mycorrhiza are putative, and impacts on mycorrhizal fungi somewhat speculative. Putative impacts are conjectured in Table 5 , but they do have a basis in the literature (see text).

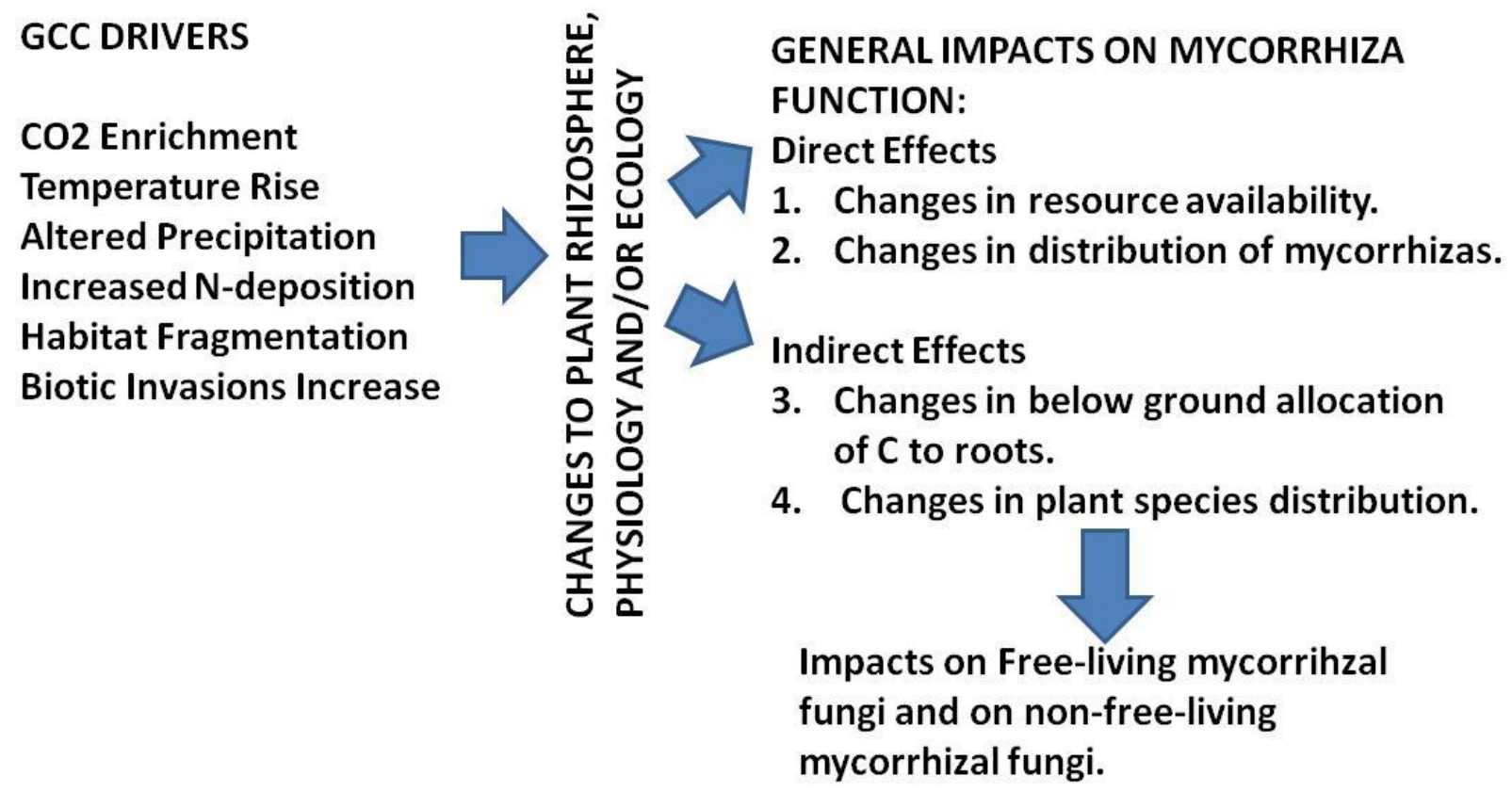

We have then interpolated the putative mechanism(s) where these direct or indirect effects can/will impact mycorrhizal function (Table 5). On further review of these impacts, there emerge recurring themes amongst the impacts that link to mycorrhizal function (see Summarial Impact column in Table 5). The mechanisms that can alter mycorrhizal function can be viewed as either:

1. Direct effects changing:

- the amount of resources available to mycorrhizas (e.g., $\mathrm{CO}_{2}$ and nutrient enrichment; temperature increase; water availability and gas exchange in the rhizosphere), or

- the distribution of mycorrhizas and mycorrhizal propagules.

2. Indirect affects changing:

- the below-ground allocation of $\mathrm{C}$ to roots and mycorrhizas, or

- the host-plant species distribution.

Despite the absence of observation to support the specific putative impacts on mycorrhizal associations, there is support more generally for these direct and indirect impacts (see Figure 3 and Table 5). 
Table 5. GCC-drivers mediating changes to plants and ecosystems relevant to mycorrhizal function. See Figure 3 for conceptual relationships intrinsic to this table. PHS = Photosynthesis; NPP = Net Primary Productivity.

\begin{tabular}{|c|c|c|c|c|c|}
\hline GCC-driver & $\begin{array}{l}\text { Change to plant physiology/ } \\
\text { ecology/rhizosphere conditions }\end{array}$ & Authorities & $\begin{array}{c}\text { Direct/indirect effect on } \\
\text { mycorrhizas }\end{array}$ & $\begin{array}{l}\text { Putative impact upon mycorrhizal } \\
\text { function }\end{array}$ & $\begin{array}{c}\text { Summarial impacts; Thematic } \\
\text { Area } 1,2,3 \text {, or } 4 \\
\end{array}$ \\
\hline \multirow[t]{6}{*}{$\mathrm{CO}_{2}$ enrichment } & Increased PHS and NPP & {$[167-172]$} & Indirect & $\begin{array}{l}\text { via changes in C-economy of plant and } \\
\text { mycorrhizas }\end{array}$ & $\begin{array}{l}\text { 3. Change in below-ground } \\
\text { allocation of } \mathrm{C} \text { to roots }\end{array}$ \\
\hline & $\begin{array}{l}\text { Increased growth and } \\
\text { below-ground } \mathrm{C} \text { allocation }\end{array}$ & {$[169,172-176]$} & Indirect & $\begin{array}{l}\text { via change in below-ground allocation of } \\
\mathrm{C} \text { to roots and mycorrhizas }\end{array}$ & $\begin{array}{l}\text { 3. Change in below-ground } \\
\text { allocation of } \mathrm{C} \text { to roots }\end{array}$ \\
\hline & Decreased stomatal conductance & {$[168,177-180]$} & Direct & via change in plant water use efficiency & $\begin{array}{l}\text { 1. Change in resource } \\
\text { availability }\end{array}$ \\
\hline & $\begin{array}{l}\text { Changes in plant species density } \\
\text { and diversity (incl. flowering } \\
\text { phenology) }\end{array}$ & {$[169,176,181]$} & Indirect & $\begin{array}{l}\text { via changes in spatial distribution of } \\
\text { plant-hosts }\end{array}$ & $\begin{array}{l}\text { 4. Change in plant species } \\
\text { distribution }\end{array}$ \\
\hline & $\begin{array}{l}\text { Increase rate of release of soil- } \\
\text { and rhizosphere-stored C }\end{array}$ & {$[171,182,183]$} & Direct & via $\mathrm{CO}_{2}$ enrichment of rhizosphere & $\begin{array}{l}\text { 1. Change in resource } \\
\text { availability }\end{array}$ \\
\hline & Increased fine root growth & {$[183-187]$} & Direct & $\begin{array}{l}\text { via increase in availability of roots for } \\
\text { mycorrhizas to colonize }\end{array}$ & $\begin{array}{l}\text { 1. Change in resource } \\
\text { availability }\end{array}$ \\
\hline \multirow[t]{5}{*}{ Temperature rise } & $\begin{array}{l}\text { Accentuated changes at high } \\
\text { altitudes and latitudes }\end{array}$ & $\begin{array}{c}{[62,85,164,} \\
188-190]\end{array}$ & Direct/Indirect & $\begin{array}{l}\text { via changes in spatial and temporal } \\
\text { distribution of plant-hosts and alteration } \\
\text { to mycorrhizal phenology }\end{array}$ & $\begin{array}{l}\text { 2. Change in the distribution of } \\
\text { mycorrhizas; and } 4 \text {. Change in } \\
\text { plant species distribution }\end{array}$ \\
\hline & Increased rate of PHS & [191-194] & Indirect & $\begin{array}{l}\text { via change in C-economy of plant and } \\
\text { mycorrhizas }\end{array}$ & $\begin{array}{l}\text { 3. Change in below-ground } \\
\text { allocation of } \mathrm{C} \text { to roots }\end{array}$ \\
\hline & $\begin{array}{l}\text { Warmer winters in Northern } \\
\text { Hemisphere }\end{array}$ & [195] & Direct/Indirect & $\begin{array}{l}\text { via extended growing periods altering } \\
\text { spatial distribution of plant-hosts and } \\
\text { mycorrhizal pheonolgy }\end{array}$ & $\begin{array}{l}\text { 2. Change in the distribution of } \\
\text { mycorrhizas; and } 4 \text {. Change in } \\
\text { plant species distribution }\end{array}$ \\
\hline & $\begin{array}{l}\text { Increased tree growth in high } \\
\text { altitudes and latitudes }\end{array}$ & {$[196,197]$} & Indirect & $\begin{array}{l}\text { via change in below allocation of } \mathrm{C} \text { to } \\
\text { roots and mycorrhizas }\end{array}$ & $\begin{array}{l}\text { 3. Change in below-ground } \\
\text { allocation of } \mathrm{C} \text { to roots }\end{array}$ \\
\hline & $\begin{array}{l}\text { Alteration to plant flowering and } \\
\text { fruiting phenology }\end{array}$ & {$[88,198-201]$} & Indirect & $\begin{array}{l}\text { via changes in spatial distribution of } \\
\text { plant-hosts }\end{array}$ & $\begin{array}{l}\text { 4. Change in plant species } \\
\text { distribution }\end{array}$ \\
\hline
\end{tabular}


Table 5. Cont.

Advance plant development ontogeny

Longer growing seasons

Alteration to plant species

composition

Alteration to plant species ranges

/migrations

$88,202,203]$

Direct/Indirect

$[120,195$

$205,206]$

$[195,204$,

207-213]

Changed fire frequency in

selected plant communities

[214-218]

Increased opportunity for plan

invasions

Increased soil bioactivity leading

to release of $\mathrm{C}$ and nutrients

Increased fine root growth and

turn-over

$[183,185$,

$219,220]$

Direct

Increased soil OM

decomposition rates

[221-225]

Direct

respiration via changes in spatial distribution of plant-hosts and mycorrhizas

via change in below-ground allocation of

$\mathrm{C}$ to roots and mycorrhizas

via changes in spatial distribution of plant-hosts

via changes in spatial distribution of plant-hosts

via changes in spatial distribution of plant-hosts and mycorrhizas

via changes in spatial distribution of plant-hosts through novel introductions via $\mathrm{CO}_{2}$ enrichment of rhizosphere and increased nutrients effecting plant-host and mycorrhizas

via increased amount of roots for

mycorrhizas to colonize

via $\mathrm{CO}_{2}$ enrichment of rhizosphere and increased nutrient affecting plant-host and mycorrhizas

via $\mathrm{CO}_{2}$ enrichment of rhizosphere

via increased nutrients affecting planthosts and mycorrhizas
2. Change in the distribution of mycorrhizas; and 4. Change in plant species distribution

3. Change in below-ground allocation of $\mathrm{C}$ to roots

4. Change in plant species distribution

4. Change in plant species distribution

2. Change in the distribution of mycorrhizas; and 4. Change in plant species distribution

4. Change in plant species distribution

1. Change in resource availability

1. Change in resource availability

1. Change in resource availability

1. Change in resource availability

Change in resource availability 
Table 5. Cont.

\section{Altered}

\section{precipitation}

patterns

\begin{tabular}{l} 
N-deposition \\
\hline Increased \\
\hline Fragmentation of \\
habitats
\end{tabular}

Increased frequency of drought

leading to plant stress

Increased frequency of

water-logging leading to

plant stress

Increased infiltration and

solubilization of mineral

nutrients

Increased susceptibility to insect

pests and plant pathogens

Drought leading to decreased

OM decomposition and reduced

fire return intervals

Increased short-term

above-ground plant growth rates

Alteration to plant chemistry

(e.g., C:N ratio)

Increased severity and frequency

of plant pathogen infections

Soil disturbance and disruption

of extramatrical mycelial

networks
$[94,215$,

227-232]

Direct/Indirect

via changes in root growth and belowground allocations, plant species and mycorrhizal distributions

via changes in rhizosphere gas exchange leading to change in root and mycorrhizal respiration

via nutrient enrichment of rhizosphere increasing root growth and changing mycorrhizal colonization.

via changes in spatial distribution of plant-hosts and mycorrhizas

via changes in spatial distribution of plant-hosts and mycorrhizas

via increased change in below-ground allocation of $\mathrm{C}$ to roots and mycorrhizas via changes in $\mathrm{C} / \mathrm{N}$-economy of plant and mycorrhizas

via changes in spatial distribution of plant-hosts

via dislocation of plant from mycorrhiza and disruption of infective potential
1. Change in resource availability; 2. Change in the distribution of mycorrhizas; and 4. Change in plant species distribution

1. Change in resource availability

1. Change in resource availability

2. Change in the distribution of mycorrhizas; and 4. Change in plant species distribution

2. Change in the distribution of mycorrhizas; and 4. Change in plant species distribution

3. Change in below-ground allocation of $\mathrm{C}$ to roots

1. Change in resource availability

4. Change in plant species distribution

\section{Change in mycorrhizal} distribution 
Table 5. Cont.

Removal of plant-hosts from mycorrhizas

[61,250-252] Direct/Indirect

Loss of geographically-restricted

plant taxa

$[124,253,254]$

Direct/Indirect

Loss of habitat for micro-, meso-

and macro-fauna that disperse

mycorrhizas

Lack of native animals to

disperse mycorrhizas
[74]

Direct via changes in spatial distribution of plant-hosts and mycorrhizas

via changes in spatial distribution of plant-hosts and mycorrhizas

via a loss of dispersal mechanism,

changes in spatial distribution of mycorrhizas

via a loss of dispersal mechanism,

changes in spatial distribution of mycorrhizas
2. Change in the distribution of mycorrhizas; and 4. Change in plant species distribution

2. Change in the distribution of mycorrhizas; and 4. Change in plant species distribution

2. Change in mycorrhizal distribution

2. Change in mycorrhizal distribution

Increase in biotic

invasions

Natural

Extension of plant range

distributions

Changes in patterns of

herbivores and pathogens

Human-mediated species

Introduction of exotic pathogens

Increased spread and

introduction of exotic insect

pests and pathogen-vectors (e.g.,

viruses and mycoplasmas).
Indirect

Indirect

Indirect

$[212,215,256]$ via changes in spatial distribution of plant-hosts

via changes in spatial distribution of plant-hosts

via changes in spatial distribution of native plant-hosts

via selected mortality of key-stone species leading to changes in spatial distribution of plant-hosts

via changes in spatial distribution of plant-hosts
4. Change in plant species distribution

4. Change in plant species distribution

4. Change in plant species distribution

4. Change in plant species distribution

4. Change in plant species distribution 


\section{Direct effects of GCC-mediated changes to mycorrhizal function}

\section{Changes to resource availability}

Mycorrhizal fungi exist in an environment rich in $\mathrm{CO}_{2}$, both inside the root and in the soil [95]. Little information is available on the direct impact of $\mathrm{CO}_{2}$ enrichment on the physiology of the extramatrical hyphae of mycorrhizas. Elevated above-ground $\mathrm{CO}_{2}$ often increases internal root colonization, but this is a result of an increase in plant growth, rather than a direct stimulation of mycorrhizal physiology (see indirect impacts below).

High N decreases root length colonized by AM fungi [257]. The colonization of particularly native plants by ECM tends to decline with $\mathrm{N}$ deposition [258,259], although this effect is highly dependent on levels of $\mathrm{P}$ and plant growth form [97]. The growth of the extramatrical mycelium in ECM has also been shown to be reduced with nitrogen amendments [260]. Additionally, several studies have shown that sporophore yield and biomass in ECM decrease with increased $\mathrm{N}$ deposition (e.g., [258,259]). Increased soil temperature has also been sometimes positively correlated with increased root colonization (e.g., [257,261,262]); however, drought negatively affects AM fungal colonization [263].

Reduced soil $\mathrm{pH}$ resulting from $\mathrm{SO}_{2}$ dissolution apparently caused a decrease in the colonization of Pinus banksiana roots by Laccaria laccata in a sandy soil [264].

\section{Changes to distribution of mycorrhizas and mycorrhizal propagules}

Patterns of mycorrhizal fungal spore dispersal affect gene flow, population structure and fungal community structure [126]. Sporulation and reproduction of mycorrhizal fungi, like colonization of the root system, are directly affected by seasonal dynamics that govern their growth and reproductive physiology. Large seasonal fluctuations in number of spores of AM fungi have been observed (e.g., [265-267]). The external mycelium is important in the production of spores in AM fungi and translocates relatively large amounts of carbohydrate to the biomass of the fungus outside the root [35]. Increased biomass in the extramatrical network has been associated with an increase in spore production in AM fungi [268,269]. Temporal changes to seasonal boundaries can also impact the phenology of fungal growth and sporocarp production as various abiotic and biotic factors influence the fruiting of ECM [270]. For example some fungi might become active at times of the year when they are currently dormant [95]. Or changes resulting from warmer winters or longer growing seasons could see areas invaded by exotic fungi that find the new set of environmental conditions conducive to their survival (e.g., [271]).

Natural ecosystems are subject to a continuum of disturbance ranging from partial degradation to complete destruction caused by conversion to a new land use (e.g., agriculture or mining). The disturbance of topsoil associated with habitat fragmentation is known to decrease the infective capacity of the extramatrical hyphal network of AM fungi (e.g., [250]). The coenocytic hyphae of these fungi are particularly sensitive to soil disruption [252]. In particular, the extrinsic rarity of orchids is considered to be a reflection of anthropogenically threatening processes directly disturbing, limiting or reducing the distribution and abundance of orchid species and populations of their mycorrhizal partners $[124,254]$. 
Topsoil that is stripped prior to the extraction of minerals from underlying strata is reapplied post-disturbance as a source of plant propagules (e.g., [272]). The AM propagule viability within these stockpiles is known to decrease with time (e.g., [273,274]) and at different water potentials [275].

Ecosystem fragmentation directly impacts dispersal and the dispersal agents of mycorrhizal fungi. ECM fungi can profoundly affect conifer establishment, thereby limiting ability of conifer species to colonize new regions [276]. Malajczuk et al. [72] considered the tripartite association amongst vertebrate animals, vascular plants and ECM fungi important in the distribution of native tree species in Eucalyptus forests after chronic disturbance. Constraints to sporocarp dispersal resulting in lack of suitable mycorrhizal partners (due to the degree of host specificity) can limit plants from colonizing certain areas, thus reducing their competitive ability [74]. Fire frequency can also directly trigger "blooms" in sporocarps of selected ECM families (e.g., Mesophelliaceae). This has been shown to coincide with increased mycophagy by mammals - the attraction of the post-fire food source, encouraged bettongs (Bettongia gaimardi) to move considerable distances to enter burnt areas [128]. The return of resident animals to unburnt areas meant dispersal of the fire-adapted ECM species into the unburnt areas.

\section{Indirect effects of GCC-mediated changes}

3. Change in $\mathrm{C}$-allocation to roots and mycorrhizas.

Because mycorrhizal fungi acquire most of or all their $\mathrm{C}$ directly from living plants, the increase in below-ground allocation of $\mathrm{C}$ to roots may mean a concomitant increase in C-supply for all types of mycorrhizas (e.g., [184,277]. An increase in C supply to the roots will enhance energy-dependent processes in all mycorrhizal types, notably their development and physiological and biochemical activities [165], as $\mathrm{C}$ is limiting for the production of fungal biomass. Increased $\mathrm{CO}_{2}$ concentration has been reported to increase both percentage root colonization and growth of the external mycelial network in AM fungi (e.g., [95,257,278-280]) and ECM fungi [281]. In a similar way, Olsrud et al. [282] demonstrated a similar positive response in EM colonization and functioning in response to increased $\mathrm{CO}_{2}$ concentration.

Monotropoids and achlorophyllous orchids, which derive their $\mathrm{C}$ from their plant-hosts, may also be advantaged through an increase below-ground $\mathrm{C}$-allocation to roots, as this may mean increased C-supply scavenged via their haustorial mycorrhiza from their plant-host.

4. Change in host-plant species distribution.

GCC-mediated shifts in plant species (e.g., advancement of treelines) (e.g., [213]), will mean a concomitant shift in distribution and abundance of mycorrhizal fungi associated with the invading plant species into previously marginal habitats. This is considered to be particularly critical in high latitudes and altitudes where shifts in climatic envelopes are considered to threaten $32 \%$ of Europe's higher plants by 2050 [283]. Other factors influencing plant species distributions affected by GCC-mediated changes include alteration of natural patterns of disturbance cycles/regimes, e.g., natural wildfire regimes [284] and frequency of droughts and pathogen impacts [68]. Human-mediation can accelerate/facilitate a number of shifts in spatial distribution of plant species through trans-continental transport; these exotic plants effectively expanding their native range through 
accidental or deliberate introduction (e.g., [135]). Humans can also facilitate the introduction of exotic plant pests that impact upon plant fitness of native plants, and also of exotic plant diseases into native forests and wildland ecosystems. One of the most well-known are the globally distributed diebacks mediated by Phytophthora species [e.g., 236,285]. These epiphytotics effectively remove keystone plant species, negatively impacting upon their mycorrhizas.

It seems clear there will be impacts on the efficacy/efficiency of the mycorrhizal associations as mediated by the changes articulated (and sometimes speculated) above. Figure 2 aims to highlight the dynamism of the interspecies relationships that could hypothetically be occurring both contemporaneously, and over time - with the realization that the complexity of interactions exist at a range of scales, viz. between mycorrhizal species of the same classification (AM), between mycorrhizas occupying or sharing the same host rhizosphere, and between the various broad mycorrhizal classifications/groups within a given habitat. Moreover, because of their influence on plant-host physiology, there will be a range of flow-on effects that will impact on host performance and viability. These changes in turn will be significant, even if they are only transient, as competition for space and resources will also be driving selection of the plant species composition in a patch. So, which of the mycorrhizal types are the most vulnerable and why? What are the consequences for individual host fitness as a response to changes in the efficacy of their mycorrhizal partners? And, do subsequent shifts in plant community dynamics represent a response to changes in mycorrhizal diversity as mediated by GCC?

\section{Mycorrhizal benefit with altered resource availability}

Respiration of the external mycelium of AM fungi was not impacted by increased $\mathrm{CO}_{2}$ concentration [286]. Increased $\mathrm{N}$-deposition has been shown to impact negatively on mycorrhizal colonization of roots and the growth of the extramatrical mycelium in AM and ECM fungi. However, any such growth depression of the plant could be partially offset by the growth enhancement provided through the direct fertilization effect of increased $\mathrm{N}$ on the plant roots. (The literature is filled with references showing positive plant response to additions of nitrogen fertilizers. See Troeh and Thompson [287], chapter 10). This enhancement, however, is attenuated in somewhat unpredictable manners due to the negative feedback of excess nitrogen in the soil on the nitrogen-fixing process in symbiotic- as well as asymbiotic-driven systems [288]. Similarly, exposure to $\mathrm{SO}_{2}$ reduced respiration of Thelephora terrestris and Pisolithus tinctorius infected roots in pure culture [289]. However, addition of sulphur may also offset sulphur deficiencies, although this will seldom equal the offset produced by nitrogen [287]. Soils high in sulphur tend towards having depressed $\mathrm{pH}$. In extreme situations such as exists in thermal basins, sulphur and its associated acids may accumulate such that pHs are extremely low (below 3) and sulphur can be significant (above 1\% in soils). In such cases most mycorrhizal fungi are eliminated, although Pisolithus tinctorius seems well adapted to such environments and apparently thriving [290].

Impacts of temperature on mycorrhizal associations will clearly be attenuated as boundaries between ecotones change as temperatures change. Mycorrhizal benefit has been shown to be enhanced with increasing temperature in arctic herbs [291]. Drought frequency and AM fungi in desert vascular plants have an impact on water relationships [263]; AM fungal associations have been shown to be 
very important in scavenging water by some plants [51]. Under warmer temperatures and drier moisture regimes, these associations may be evolutionarily selected.

\section{Mycorrhizal benefits with altered distributions in mycorrhizas and mycorrhizal propagules}

Changes in the abundance, distribution and viability of mycorrhizal inoculums will have significant impact upon the mycorrhizal benefits provided by the symbioses-especially those obligate associations within the following mycorrhizal categories: AM, ECM, MM and OM. Decreases in mycorrhizal propagules do not mean there will be a decrease in mycorrhizal infection of root systems or in functionality. However, generally when mycorrhizal propagules have very low soil densities, mycorrhizal colonization will be very low too. Of course, when mycorrhizal fungi are missing altogether, mycorrhizal infection will be nil. Loree and Williams [292] and especially White et al. [293] showed degraded soils having low propagule numbers had low infection rates and did not host well plants that were obligate mycotrophs.

Altered fire history/frequency may also contribute to a redistribution and potential loss of infectivity of mycorrhizal propagules. Miller et al. [294] showed there were considerable changes in ectomycorrhizal fungal diversity following fire and that after severe fires the category of mycorrhizal fungi could be changed (e.g., from ECM in conifers to AM of grasslands). While, conversely, Bellgard et al. [295] demonstrated that there was little to no change in AM infectivity-a response intimately linked to capacity of the flora being studied to resprout from below-ground rootstock that were not killed by the fire. Bowman and Fensham [296] have clearly demonstrated the role of fire-protection in the regulation of the monsoon forest-savanna boundaries - with reference to the role played by nutrient enrichment by the evergreen shrubs. The influence of the underlying edaphic factor will of course be influenced by the presence or absence of the necessary mycorrhizas that will be moving along with the ecotonal boundary that is controlled at the landscape-level by fire (or in this case the absence of fire) that creates opportunities for invasive plant taxa to take advantage of the fire-mediated ecosystem disturbance.

\section{Mycorrhizal benefits associated with increased below-ground allocation of $C$}

Dighton [1] proposed that enhancement of photosynthetic activity with increased $\mathrm{CO}_{2}$ would provide a larger pool of carbohydrates to support mycorrhizal development, fruiting, community diversity and investment in extraradical hyphal exploitation of soil. As a consequence, services provided by the fungus might be enhanced, the best characterized of which is phosphate uptake, although resistance to drought and pathogens and increased uptake of other mineral nutrients are also known to occur [297]. Several studies support the hypothesis that atmospheric $\mathrm{CO}_{2}$ enrichment will influence the balance between mycorrhizal costs and benefits [298]. Wolf et al. [299] shows that increased $\mathrm{CO}_{2}$ (at 1.52 times the ambient) did increase spore production by one of $11 \mathrm{AM}$ fungi studied and decrease spore production by another.

\section{Mycorrhizal benefits associated with changes in plant-host distributions}

Changes in the abundance and distribution of suitable plant-hosts will have significant impacts on the mycorrhizal benefits provided by the symbioses - especially those obligate mycorrhizal categories 
such as AM, ECM, ARBM, MM and OM where either the plant or the fungus displays an obligatory dependency.

Synthesis-environmental driver's attenuation of the efficiency/efficacy of mycorrhizal associations and resultant changes to mycorrhizal diversity

Our postulated, summarial GCC-mediated impacts to plants and mycorrhizas (see Table 5) are:

- changing the amount of resources available to mycorrhizas (e.g., $\mathrm{CO}_{2}$ and nutrient enrichment; water availability and gas exchange in the rhizosphere; temperature increasedirect effects)

- changing the distribution of mycorrhizas and mycorrhizal propagules (direct effects)

- changing the below-ground allocation of $\mathrm{C}$ to roots and mycorrhizas (indirect effects), and/or

- changing the host-plant species distribution (indirect effects).

It is a central theme of this work that these impacts are great enough to change the cost:benefit ratio of hosting the mycorrhizal association. For example, N-deposition reduces mycorrhizal colonization (e.g., [136]). Is it possible for the mycorrhizal nutrient acquisition function to become superfluous through increased external/exogenous sources from the atmosphere of plant-mineral nutrients? Fertilization treatments have been shown to reduce the efficacy of the mycorrhizal function. Other changes in the chemistry of soil can also change mycorrhizas. Addition of an alkaline retort process water to plots of native, high desert plants resulted in marked changes to the mycorrhizal fungal populations in the treated soils even 4 years after application [300].

Spatial separation physically de-couples the plant from its fungal partner. However, a number of authors have demonstrated the resiliency of low-specificity AM fungi to soil disturbance (e.g., [301]). However, for more highly specialized associations (e.g., ARBM, MM and OM), lack of specific propagules can impact upon fitness and reproductive success of these geographically restricted plant taxa. Changing the plant and mycorrhizal propagule distribution has been shown to have some detrimental effects on mycorrhizas, e.g, according to Swarts and Dixon [124], some orchids have little capacity to continue growth without their symbiotic partner.

Increased below-ground $\mathrm{C}$ seems to be advantageous to mycorrhizal fungi and seems to enhance the function of the mycorrhiza. So, here, GCC-mediated impacts can be seen as a benefit to mycorrhizas. But, is it possible that changes in the C-economy of the host-plant make hosting/housing the mycorrhizal fungi no longer energetically-efficient for the plant to maintain? The manifestation of such a de-coupling would be progressive and cumulative - and highly variable from season to season and year to year, dependent upon the variability and magnitude of increased C-inputs. As such the continuum of change in host-plant mycorrhizal dependency is considered to be a mechanism that possesses a longer, slower trajectory than the impacts associated with catastrophic soil disturbance (further developed in Section 5).

Changes in plant species distribution effectively contributes to the separation of the plant from the fungus through changes in host-plant species ranges. The invasions of patches by non-mycorrhizal species could impose another form of separation (via competitive exclusion) that could be detrimental to the fungus. Changes in plant phenology could impose a temporal barrier (e.g., changes in plant 
phenology, diversity or distribution). In North America, the exotic invader Bromus tectorum (cheat grass) has moved into many native plant communities, especially desert grasslands and shrublands where it has proven to be highly competitive and even destructive of native vegetation in part due its capacity to alter fungal symbiotic composition and effectiveness [302-305]. It is considered that such impacts would not occur immediately, and thus are considered intermediate-term impacts. These different temporal scenarios of GCC-mediated environmental change will be further elucidated in Section 5.

Any impacts to mycorrhizal associations (be they direct, indirect; immediate, intermediate-term or long-term) will be attenuated by soil characteristics. To predict or hypothesize how GCC will impact mycorrhizas will be a function, in part, of how the chemical and physical manifestations of GCC interact with and are neutralized or enhanced by soil properties. The next section introduces soils at a very broad scale and attempts to classify how various groups of soils will react with products of GCC and consequently how these will impact mycorrhizas.

\section{Edaphic Factor Linking and Mediating Mycorrhizal Diversity to GCC-Mediated Changes}

Arguably the most unexplored part of the mycorrhizal habitat is the soil component. There are good reasons for this. Soil is massive, anisotropic and awkward to sample (e.g., compared to either above- or below-ground plant material). Classification of soils even broadly is not well understood or codified. Much of the reason for the complexity of soils lies in the variability of the soil-forming (or state) factors: climate, topography, organisms, and parent materials (or geological substrates) all integrated across time [306]. That there are so many taxonomies of soils being used today around the world is evidence that soil science (or at least soil taxonomy) has yet to uncover unifying principles of organization. But the reality is that to understand soil science needs at the very minimum a comprehension of physical, chemical and biological characteristic of soils. Understanding of soil biology spans all known organismic groups as well as their biochemical transformations.

The chemical, physical and biological information that pertains to soils and could be related to mycorrhizal associations is voluminous. Herein we rely on soil taxonomy as a way to summarize these properties into a matrix to insert mycorrhizal diversity and to draw general conclusions.

\subsection{Fundamentals of Soil Taxonomy}

Most soil taxonomies rely on measurement of abiotic properties for categorization. In Jenny's [306] state factors, the organismic factor is generally ignored or minimized perhaps because it is hard to measure and not well understood. Soils represent a continuous tension between abiotic factors (e.g., topography, geology and some of climate) and biotic factors (organisms, biochemicals and the rest of climate). This tension is integrated across time such that at any instant soils are manifest with characteristics which in themselves are complex. A conceptual simplification (and probably over-simplification) is to place soil in a spectrum that ranges from the completely abiotic at one end to the completely biotic at the other. The completely abiotic end could be little more than physically weathered rock (e.g., by freezing and thawing, wetting drying, etc.) but with no significant biological components. The completely biotic end for all practical purposes does not exist, but imagine a site with a diversity of plants, plant roots, arthropods, fungi, etc., and with deep, rapidly decomposing litter and 
high levels of organic carbon in the upper soil horizons (rich, black, earthy). With characteristics of abiotic and biotic parameters, any given soil can be placed appropriately along this continuum: some where abiotic parameters dominate; others where biotic factors dominate.

The focus here is to place soils into a GCC context as ameliorators of GCC and as habitat for mycorrhizal associations. A soil taxonomy has been chosen to explain how mycorrhizal forms and functions are attenuated by overarching soil characteristics and how these soil characteristics stratify mycorrhizal forms and function in a maxtrix of GCC.

The taxonomy chosen for this is the US Taxonomy. The US Soil Taxonomy [307] is translatable into some other taxonomies (e.g., the New Zealand Taxonomy [308]; The FAO system [309], the World Reference Base of Soil Resources for soil correlation [310], the French Taxonomy [311] andThe Russian Taxonomy [312]). Fundamental soil taxa of the US Soil Taxonomy [307] (especially at the Order level) have characteristics that suggest that they fit naturally and easily in nature. However, the separation between one order and another is often artificial. For example, the US Soil Taxonomy separates grassland soils (Mollisols) from all other soils by the amount of organic matter in the surface soil and that these soils are fertile. That this is defined precisely as "a soil having at least $1 \%$ soil organic matter (or $0.58 \%$ organic carbon) in the surface soil when mixed to $18 \mathrm{~cm}$, and having a base saturated of at least 50\%" illustrates the artificial demarcation.

\subsubsection{Categories of Soil Taxonomy: Soil Orders}

The US Soil Taxonomy [307] is divided into 12 orders at its coarsest level of organization. Most of these orders can be placed into an approximate developmental sequence (Figure 4) and it is here that their relationship to mycorrhizal form and function becomes more apparent. The following provides fundamental characteristic(s) for each soil order and includes notions about $\mathrm{pH}$ of the typical (typic or central tendency of the order) as well as the central tendency of the buffering capacity of each. Buffering capacity can be conceptualized as the tendency of a material to resist change, especially change in $\mathrm{pH}$. This concept is expanded in the following discussion.

$\underline{\text { Entisols }}$ are embryonic soils without pedogenic horizons. These tend to occur on very resistant parent materials and/or in locations where new parent materials are being regularly deposited (sand dunes or along flood plains). Soil $\mathrm{pH}$ can vary widely depending on the parent material, but $\mathrm{pH}$ from 6 to 8 is common [313]. The mycorrhizal types found in these soils are potentially diverse but mostly limited to ECM and AM associations. These soils tend to be poorly weathered, with very little clay and/or colloidal-sized particles, usually few salts and thus low buffering capacity.

$\underline{\text { Aridisols }}$ are developed soils in arid environments. These may evolve slowly from Entisols over long periods of time. Many have clay accumulation in subsurface horizons and/or sodium, calcium or other basic salts in surface and subsurface horizons. Soil $\mathrm{pH}$ of 7-8 is common. Often there are very hard layers of calcium carbonate within $1 \mathrm{~m}$ of the surface [313]. They are occupied almost entirely by AM associations. High clay and salt result in high buffering capacity. 
Figure 4. Soil world taxonomic orders (according to the US Taxonomy [307]) and principal mycorrhizal associations that inhabit those orders. Also shown is the $\mathrm{pH}$ range of a typic soil of each order and the buffering capacity (BC) of each. Some mycorrhizal associations are shown but prefixed by $\sim$, meaning these are present but at low levels or restricted. The arrows in this figure show general soil evolution.. This evolutionary sequence is imperfect in that often soils reach an endpoint in development that only will be passed if there is a massive change in, for example, climate. In other cases, a particular soil will only develop if there is a particular geological substrate present.

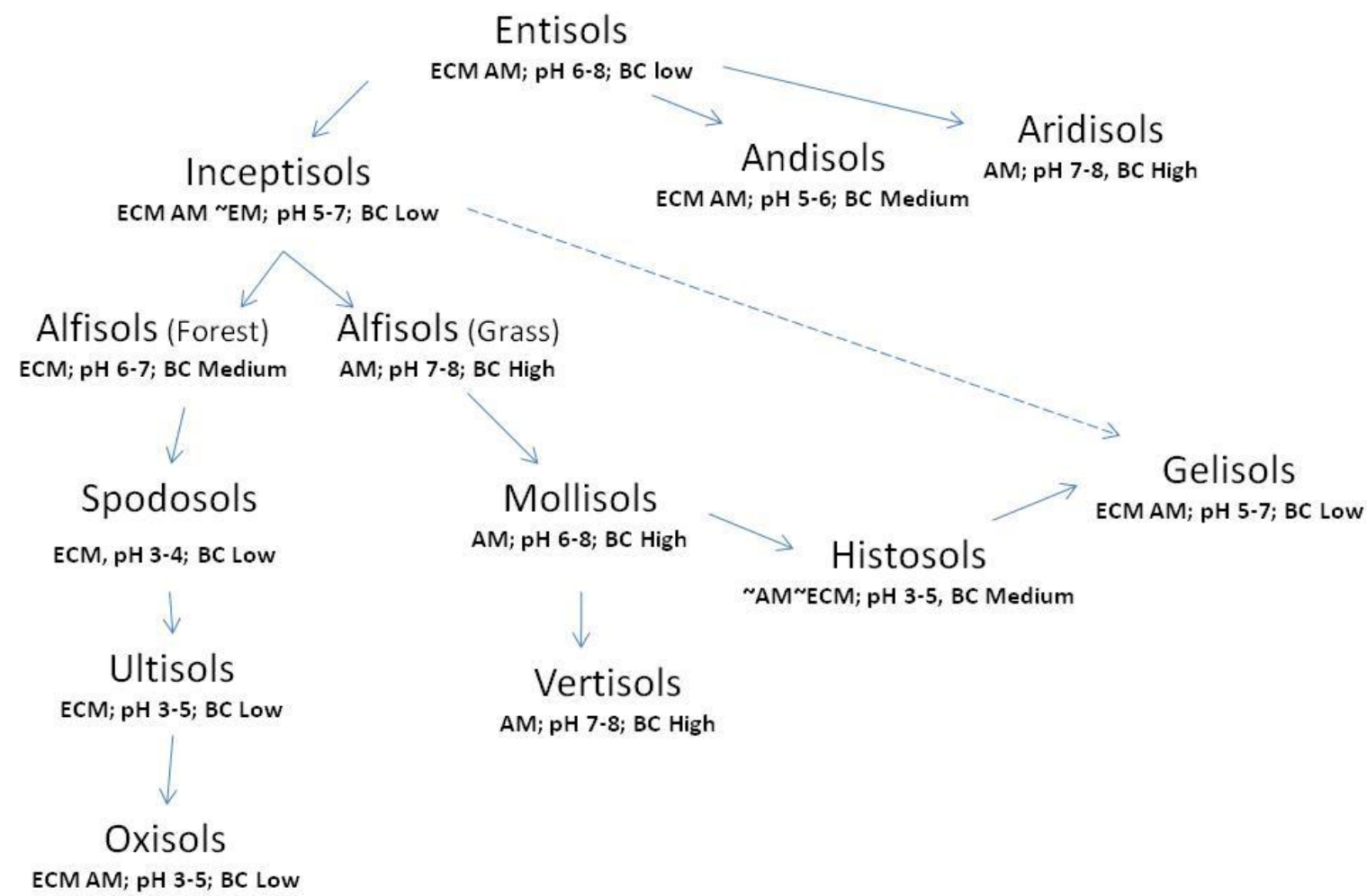

$\underline{\text { Inceptisols }}$ are soils with muted subsurface horizons often in areas where erosion removes weathered materials. They are highly diverse, but these soils develop, conceptually, from Entisols. They may have high or low surface organic matter content, and may exist from tropical to cold climates. They may have horizons of altered parent material, but no horizons of accumulation. Arid Inceptisols may evolve into Aridisols, but the wetter Inceptisols weather into Alfisols. Soil pH varies from 5 to 7 [313]. Mycorrhizal associations include ECM and AM, some EM, and more rarely ARBM, $\mathrm{OM}$, and MM. Low concentrations of basic salts and few clays result in low buffering capacity.

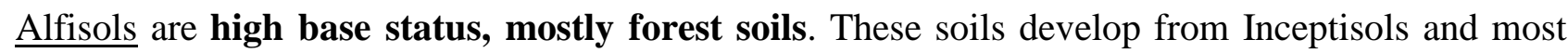
are or were forest soils, frequently with organic accumulations at the surface, subsurface accumulation of clay and are relatively fertile. Soil pH is commonly 6-8 [313]. Where forested, they are occupied by ECM mostly with some OM, MM and EM associations. Where these soils are in dry or Mediterranean climates, AM fungi dominate (labeled as "grass" in Figure 4). Moderate to high base saturation and moderate clay content, result in moderate buffering capacity.

$\underline{\text { Spodosols }}$ are soils with substantial subsurface accumulation of iron/aluminum oxides and humus. These are very acid (pH of 3 or 4 ), low nutrients, and low clay content but considerable quartz 
sand. They develop from Alfisols and are or were forest soils in cool to seasonally cold environments [313]. They are occupied by ECM mostly, with a few OM, MM and EM associations. Low base saturation and clay result in and low buffering capacity.

$\underline{\text { Ultisols }}$ are low base status, mostly forest soils and have subsurface accumulation of highly weathered clays. They form in warm, humid environments,conceptually are a more weathered continuum from the Spodosols but many did not weather from Spodsols but rather from Inceptisols. They are very acid, usually with $\mathrm{pH}$ of 3-4-5 [313]. Typically occupied by ECM associations but also by AM associations after disturbance and a few OM and EM.. Base status of these soils is very low and clays, although often a fairly high content, are low activity clays. The buffering capacity of these soils is thus low.

$\underline{\text { Oxisols }}$ are highly weathered soils of warm climates under moisture regimes from very wet to dry. They are old soils and all were likely formed under moist conditions. They have few horizons but considerable clay content. These clays are highly weathered and resistant to further weathering. Very low fertility, especially phosphorus, characteristic. These soils may have weathered from Ultisols, but many are on very old surfaces. They are very acid with $\mathrm{pH}$ ranging from 3 to 5 [313] and occupied mostly by AM and ECM associations. They have very low base content and saturation as well as very low activity clays and thus of very low buffering capacity.

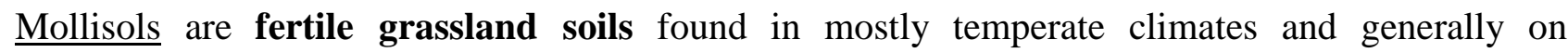
sedimentary parent materials on flat to rolling surfaces; dark coloured, especially near the surface, due to high organic matter content. They have a subsurface accumulation of clay and may form directly from Entisols, Inceptisols or even from Alfisols. They are slightly acid to alkaline ( $\mathrm{pH}$ of 6.5 to 8.5) [313] and are occupied almost exclusively by AM fungi. These soils have high base status, often high $\mathrm{pH}$ and active clay, and thus buffering capacity is high to very high.

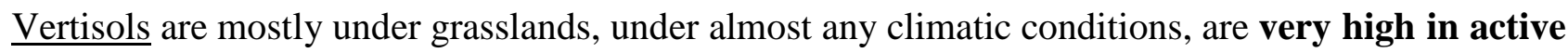
or swelling clays. They exist on relatively flat surfaces, but shrink and swell such that pedoturbation obviates development of plants with woody roots. Theys may develop first as Mollisols, but due to the high clay content readily transform. The $\mathrm{pH}$ of these soils is neutral to slightly alkaline ( $\mathrm{pH}$ from 7 to 8 [313]) and are occupied almost exclusively by AM associations. They high base status, high content of active clays and thus have very high buffering capacity [313].

$\underline{\text { Histosols }}$ are very high organic matter soils. Conceptually they can be visualized as being derived from Mollisols, but form where organic carbon generation exceeds decomposition. This most often happens in water-saturated environments that have a cold climate. Soil $\mathrm{pH}$ can be 3 or lower and up to 5 or a little higher [313]. These soils are wet, often having very low oxygen content. Mycorrhizal associations do not develop except in the top-most layer. In some situations EM may be present. In others there may be some ECM and some AM associations. These soils can have considerable exchange capacity and some bases, but nitrogen is low. Buffering capacity of these soils is moderate.

Gelisols are soils that have been modified by frost mixing (cryoturbation) have a subsurface layer of permafrost. They can have high organic matter at the surface, but most have properties similar to the Inceptisols except that they have permafrost. Soil $\mathrm{pH}$ can vary widely but is mostly 4-7 [313]. These soils are occupied by ECM, AM, and EM when they are essentially Inceptisols with a subsurface layer of ice or permafrost. When they have histic materials at the surface, they lack mycorrhizal associations as do the Histosols. Buffering capacity of these soils is low. 
$\underline{\text { Andisols }}$ are soils derived from volcanic ejecta (ash, cinders, pumice, and lava). They have clay materials often described as amorphous that tend to accumulate acid-forming ions as much as base formers. They have a reputation for high natural fertility, although $\mathrm{pH}$ is often acid (from 5 to 6 or 6.5) and can exist under any climate and have a diversity of vegetation types [313]. They are inhabited by ECM, AM, EM, OM, and probably MM and ARBM associations, variably depending on climate and presence of appropriate hosts. Low $\mathrm{pH}$ and modest levels of amorphous clays tend to result in these soils having low to moderate buffering capacity.

\subsection{Soil Taxonomy and Mycorrhizal Associations}

In the weathering of soils are several trends among mycorrhizal associations. First is that slightly weathered or embryonic soils (Entisols and Inceptisols) can be generally occupied by a full spectrum of mycorrhizal associations. Where Entisols and Inceptisols occur in deserts - a common occurrencethese systems are dominated by AM associations to the probably complete exclusion of ECM associations. Staffeldt and Vogt [314] found desert plants in New Mexico (USA) to be infected with AM fungi. These included grasses, shrubs, forbs, cacti and yuccas. In Entisols from central Wyoming (USA) Singleton and Williams ([315] - Torriorthents) found exclusively AM associations on clayey and sandy substrates. Others have also observed AM associations in desert environments on a diversity of plants growing in Entisols and have not observed ECM mycorrhizas ([300,316]Torrifluvents); ([53]—Torriorthents, Ustifluvents and Torrifluvents). Klopatek et al. [317] showed that AM fungi dominated in an Inceptisol under Pinus edulis and Juniperus osteosperma woodland although they recognized these systems had ECM components too (on Pinus).

On soils in alpine environments and derived from crystalline and calcareous parent materials (probably Entisols and Inceptisols, respectively) Lesica and Antibus [318] found plant species (grasses, forbs and shrubs) to be associated with AM fungi, but they found ECM fungal associates as well (e.g., with Dryas and Polygonium spp.). Haselwandter [319] confirms this mixture of AM and ECM plants in alpine areas of Europe and points out that alpine areas may also have abundant members of the Ericaceae and thus ericoid mycorrhizas (EM). Williams et al. [320] confirm mixtures of AM and ECM plants in alpine environments on alpine turf soils (Inceptisols-[Cryumbrepts]).

A highly studied soil type is that derived from dune sand. Often these have little or no horizon development but still classify as sandy Entisols [Psamments]. Active dunes appear to be colonized, sometimes heavily, by AM fungi only [111,266,321-324]. Jehne and Thompson [325] made the same observation but noted the presence of ECM associations in stabilized dune sites. Kurtböke et al. [111] described that hind-dune vegetation was characterized and dominated by the presence of a Casuarina species with the bipartite symbiotic complex comprised of AM and actinomycte-facilitated N-fixation [326].

In the Alfisols (Figure 4) the order divides into those soils dominated by grasses thus principally occupied by AM associations and those dominated by forest trees thus principally occupied by ECM associations. The AM occupy soils that on further development become Mollisols and Vertisols (both having near-neutral to alkaline $\mathrm{pH}$ ) where these fungal associations generally dominate. The vegetation on these soil-types is mostly grass and forbs. Alfisols that have been grasslands and then converted to 
intensive agriculture continue to be occupied by AM associations [327]. Forested Alfisols, however, have mostly occupancy by ECM [328-332].

In undisturbed grasslands (Mollisols), AM mycorrhizal associations dominate to the near exclusion of other mycorrhizal associations (e.g., [333-336]). In farmed Mollisols, soils remain dominated by AM associations even on non-native plants [337]. Plants normally associated with ECM fungi do so only when appropriately inoculated [338].

Presumably Vertisols would be occupied by AM mycorrhizas. Because of the shrinking and swelling driven pedoturbation, woody plants would not survive on these soils, but only herbaceous and graminoids. Dry Vertisols that do not shrink and swell regularly would be too dry and likely too alkaline to support plants occupied by ECM fungi.

The ECM fungal associations develop and become dominant in those soils that are more leached and become more acid: Ultisols, Spodosols. The vegetation on these soils is dominated by conifers and deciduous forests, at least historically. Ultisols are characteristically dominated by ECM associations on conifers and other hosts (e.g., Quercus spp.) under undisturbed conditions [339]. Ultisols are often farmed, however, and undergo transformation to systems where AM fungi are present [340,341].

Spodosols are noted by several authors as hosting primarily ectomycorrhizal systems ([98]—Abies balsamea, [342]-Pinus radiata and Pinus elliottii, [343]). Hayman and Mosse [344] show that Spodosols in the field could support AM associations when original vegetation was removed, replaced with Trifolium repens, fertilized and inoculated with an AM fungus. Haselwandter [345] has shown that ericaceous plants growing on subalpine and alpine Spodosols are EM.

Aridisols generally evolve from Entisols but have characteristics of other soil orders too, but with the caveat that they are dry. Almost universally they have high accumulation of salts and considerable levels of high-exchange-capacity clays. Plants in this soil order have almost all AM associations (e.g., [315,292]—Haplargids, [316]—Haplargids, Calciorthids \& Comborthids]).

Oxisols are highly weathered soils not known outside of the tropics or subtropics. They may evolve from the Mollisol-Vertisolic soil branch (Figure 4), but are more likely to evolve from the Ultisol-Spodosolic branch. These soils may be occupied by a diversity of mycorrhizal associations including AM, ECM and others. When forested, these soils are occupied by associations that are AM, ECM, ECTENDO and presumably OM [346]. Thomazina [346] looked at plants from more than 23 families including the Orchidaceae. When disturbed and planted to crops, these soils eventually become inhabited mostly by AM fungi in part because these soils are characteristically phosphorus deficient and crop plants do not survive well without AM associations [347-349].

Andisols, as noted, develop in a diversity of climates and can have a full component of mycorrhizal associations. Waters et al. [350] report ECM associations on mature Abies stands in Northern California. James et al. [351] report similar from Andisols in Scotland.

Histisols as noted are mostly too wet for abundant occupancy by any mycorrhizal associations although there are exceptions. Indeed, all of the other orders (except Aridisols) have wet or aquic phases (designated at the suborder or great group levels) where mycorrhizal associations are depauperate because of excessive wetness. Even the Gelisols that have histic properties are also characterized by a general lack of mycorrhizal fungi. Theorodou [352] showed five ectomycorrhizal fungi and their host, Pinus radiata, were intolerant of high water contents. In his 1974 review, Slankis [99] reported that excessive water prevented formation of ECM on hosts. The Gelisols that 
have inceptic properties are likely much more diverse in their mycorrhizal associations. Linkins and Antibus [353] report ECM associations of Salix rotundifolia on Gelisols (polygonal soils with $2 \mathrm{~cm}$ of surface organic matter) in the Alaskan tundra. Christie and Nicolson [354] report AM fungi on two angiosperms (one a grass) were infected with AM fungi on Gelisols on the Faulkland Islands $\left(51^{\circ} \mathrm{S}\right)$ and the South Georgia Islands $\left(54^{\circ} \mathrm{S}\right)$ but were uninfected on similar soils on the South Orkney Islands $\left(60^{\circ} \mathrm{S}\right)$, the South Shetland Islands $\left(64^{\circ} \mathrm{S}\right)$ and the Antarctic Peninsula $\left(64-68^{\circ} \mathrm{S}\right)$.

For AM fungi, in their review, Sylvia and Williams [355] indicated these fungi were intolerant of high soil-water contents where oxygen was restricted and $\mathrm{CO}_{2}$ elevated (i.e., anaerobic conditions). AM fungi, however, have been reported on aquatic plants/vegetation complexes where aqueous conditions were aerobic (review by Sylvia and Williams [355]). At the dry end of the spectrum, numerous studies show AM fungi infect plants at very low water potentials and may substantially aid plants in uptake of water under drought conditions (reviewed [355]).

Lodge [356] showed that Salix and Populus species, genera that can be both ECM and AM infected, were both dominated by AM infection under dry soils. For Populus plants, they were equally infected by AM and ECM under very wet conditions. For Salix, however, in very wet soils plants were dominated by AM associations and in moist soils dominated by ECM associations. Haselwandter [319] points out that plants in alpine environments in nivation hollows are not mycorrhizal presumably due to the excessively wet conditions due to high snow accumulation and persistent snow melt wetness. In summary, wetness and acidity controls the type of mycorrhizal association that will develop on a given soil. Where soil orders are not distinctly acid or wetness is variable or dry, these drive the type of mycorrhizal association that can colonize and result in occupancy of wider mycorrhiza diversity.

A soil feature that also determines mycorrhizal development is buffering capacity. In this review, buffering capacity is the capacity to resist changes in $\mathrm{pH}$ and for this definition captures important characteristics of climate change. Atmospheric pollutants are often manifest as deposition of NOx and $\mathrm{SOx}$, both of which in the presence of water in soils will result in a tendency towards lowering $\mathrm{pH}$. Increased partial pressure of $\mathrm{CO}_{2}$ in the atmosphere results in generation of carbonates as carbonic acid. Increased average temperatures will increase decomposition, which in turn releases more $\mathrm{CO}_{2}$, but also generates more organic acids in soils. Buffering capacity is germane to issues of GCC since so many processes in GCC result in generation of acids. The summarial result is that many GCC processes contribute to the decrease of soil $\mathrm{pH}$ - and in turn, low $\mathrm{pH}$ may be attenuated by buffering capacity. In systems where buffering capacity is high (Aridisols, Mollisols, Vertisols) the input of atmospheric acids will be neutralized for often a very long time. Soils with low buffering capacity (Entisols, Inceptisols, Ultisols, Spodosols, Oxisols) will be much more impacted by acid inputs. Acid inputs will accentuate the depression $\mathrm{pH}$ in these soils and thus depress biological activity. It follows that those soil taxa characterized typically with moderate buffering capacity (Alfisols, Histisols, and some Andisols) will be moderately impacted by atmospheric inputs of acid formers.

Several authors indicate that ECM associations are particularly sensitive to inputs of nitrogen (e.g., $[165,259,357])$. When then $\mathrm{N}$ comes from the atmosphere, it is mostly as the $\mathrm{NO}_{3}$ anion. When it is as ammonium $\left(\mathrm{NH}_{4}{ }^{+}\right.$cation) then this is often converted by prokaryotes to $\mathrm{NO}_{3}{ }^{-}$with additional release of acidic protons $\left(\mathrm{H}^{+}\right)$. Whether the overall negative impact of increased $\mathrm{N}$ inputs on the ECM system is due to imbalance of nutrients (ECM fungi dislike high available $\mathrm{N}$ ) or to increased acidity is not well worked out, but it is clear this is detrimental to ECM associations. Some ECM 
associations are highly tolerant of or even thrive in very low $\mathrm{pH}$ systems. The ECM fungus Pisolithus tinctorius is among those fungi most tolerant of acidity, with three New Zealand species only co-occurring in geothermal areas [358]. However, this species appears to be tolerant mostly of acidity derived from sulphur (e.g., sulfate) and not from nitrogen (nitrate).

\subsection{Soil and Mycorrhizal Associations Susceptible to GCC}

A fundamental observation is that ectomycorrhizas generally occupy soils of fairly low $\mathrm{pH}$ and high accumulations of organic surface litter. Some of these fungi are adapted even to very low pH (e.g., $P$. tinctorius), but many are intolerant of further decreases in $\mathrm{pH}$ and almost universally they are intolerant of high pH and high salts. In a 1974 review, Slankis [99] showed that most ECM species in pure culture had maximum growth between $\mathrm{pH}$ of $4-6$, some were capable of growth at $\mathrm{pH}$ as low as 2.7, but none grew at $\mathrm{pH}$ above 7 .

Arbuscular mycorrhiza fungi were shown to exist in soils at a wide range of $\mathrm{pH}$ [359] from 4.5 up to 8.5, but there was considerable species-specificity for particular $\mathrm{pH}$ optima. Green and Graham [360] showed very similar results in their 1976 report on the germination of AM spores. Sylvia and Williams [355] in their review cite numerous reports that support the contention that "AM fungi do not readily adapt to soils with a $\mathrm{pH}$ different from their soil of origin...However, there are AM fungi that are adapted to a wide range of soil $\mathrm{pHs".}$

The typic soil taxa at the order level of the US Soil Taxonomy [307] can be grouped according to their buffering capacity. Those with low buffering capacity are the Entisols, Inceptisols, Spodosols, Ultisols, Oxisols and Gelisols. Those with intermediate buffering capacity are the forested Alfisols, Andisols and Histosols. Those with high buffering capacity are the Aridisols, grassy Alfisols, Mollisols, and Vertisols. Further, those taxa with low buffering capacity tend to have low pHs especially those that are more weathered. Those taxa with high buffering capacity tend towards higher pHs. Those with intermediate buffering capacity have near neutral or variable $\mathrm{pH}$.

As each of the various soil orders of the US Soil Taxonomy are examined in detail, there are many examples that violate the above principles of buffering capacity and $\mathrm{pH}$. For that matter, there are many that violate the principles articulated in the last section regarding mycorrhizal occupancy. These chemical principles as well as the mycorrhizal principles reported herein are those that are most likely, according to sweeps made of the literature that correlated with the central tendencies of the 12 order-level taxa of US Soil Taxonomy. Clearly these principles must be viewed as hypotheses but the literature we have examined fails to support the contrary view (i.e., the null hypothesis).

Several other principles can be drawn from the above. In the forested and related soil-taxa, or those that are unweathered or only slightly weathered, ECM associations are common if not dominant. These are all of the taxa with low $\mathrm{pH}$ and low buffering capacity. Certainly other associations can be found too. $\mathrm{OM}$ are sometimes common, MM can be present, in the understorey of many forests EM can be found and of course the elusive ECTENDO may be present. However, ECM dominate and are associated with the dominant and deeper rooted species. When these soils are disturbed-e.g., forest removed and soils ploughed or forests removed via fire that deeply heats the soil-often AM associations will become established on such sites. Where such soils are converted to intensive crop agriculture, often these systems are dominated by AM associations to the exclusion of ECM and other 
mycorrhizas. Those soils of low buffering capacity and moderate to low $\mathrm{pH}$ are also susceptible to changes in $\mathrm{pH}$. Clearly in such situations where soil $\mathrm{pH}$ drops, those ECM that are tolerant or adapted to a low $\mathrm{pH}$ environment will survive and perhaps proliferate. Those that are not so adapted or tolerant will be selected against. Hosts of fungal associations may also have intolerance or tolerance to depressed $\mathrm{pH}$ and may or may not provide an appropriate host for ECM fungi. Further, increases in average temperature may enhance decomposition of soil organics. This increased decomposition can be further enhanced by the input of inorganic nitrogen. Often nitrogen is limiting to decomposition in high organic carbon systems. Input of nitrate, even though an acid former, will accelerate organic matter decomposition which, among other things, produces organic acids that have the potential to further exacerbate decomposition. Recent work by Eisenlord and Zak [102] present an argument that in part supports this view, but they also make the point that increased soil organic matter accumulation could result.

In those soil taxa that have high buffering capacity and which are often neutral to relatively high $\mathrm{pH}$, AM associations dominate. There are situations where other mycorrhizas can exist and even persist in these soils. OM may exist as well as EM and perhaps a few MM. However, ECM and ECTENDO are for all intents absent. Certainly plants can be inoculated and introduced into such systems [338], but this is rare and artificial. Further, when these high buffering capacity, high pH systems are disturbed, ECM do not invade these soils [316]. They remain as AM-dominated systems. Also, these systems are fairly immune to changes in $\mathrm{pH}$. To summarize then, ECM occupy soils that are susceptible to increasingly lowering of $\mathrm{pH}$. Further, these mycorrhizas do not invade soils of high $\mathrm{pH}$ and high buffering capacity. Conversely, AM fungi dominate in systems having much higher $\mathrm{pH}$ and buffering capacity. These systems are often immune or nearly so from changes in $\mathrm{pH}$ derived from atmospheric deposition. Further, as low-buffering-capacity soils are disturbed, perhaps even disturbed by radical changes in soil $\mathrm{pH}$, the $\mathrm{AM}$ associations have the capacity to move into these systems and form associations with the exotic/invasive opportunistic plant-hosts that are either resistant to the change, or have the capacity to quickly invade available niches. Many invasive species seem, however, to be non-mycorrhizal or facultatively mycorrhizal — but, there is emerging evidence to suggest that the situation is both species and context dependent. Sanon et al. [361], in their study of the invasive, non-mycorrhizal tree Gmelina arborea, observed that AM colonization was significantly and positively correlated with plant diversity (i.e., in the absence of the invasive tree, diversity was higher). While, the work of Greipsson and Di Tommaso [362] demonstrated that exotic weeds had the ability to form mycorrhizal associations with the native suite of AM fungi-their results suggest that invasion into new areas by non-native plant species may alter the occurrence of AM fungi in the resident soil. Furthermore, the exotic plants were shown to be able to selectively recruit a particular AM fungal partner from the native AM fungal suite, causing a shift in mycorrhizal diversity by preferentially allowing the chosen AM fungal partner to rapidly proliferate. The outcome of this selective inoculum's amplification resulted in improved performance of the weed-species compared to the non-mycorrhizal counterpart - so the weed actually gained a benefit from the association with the indigenous AM fungi. Pringle et al. [363] summarize the suite of interactions succinctly: several criteria can determine the potential for mycorrhizal symbioses to constrain or facilitate the invasion process, particularly whether an introduced plant requires the mycorrhizal association, the invasive plant's degree of flexibility in associating with a range of the indigenous species, and whether or not suitable mycorrhizas "co-invade" 
with the invasive plant (or arrive independently). Following their successful establishment, invasive plants are influenced by (and can influence) their own (and neighbouring) mycorrhizal symbioses, and these can further influence the trajectory of the invasion, with flow-on effects which can impact community integrity and resilience to future incursions.

\section{Postulated Temporal Scale of GCC and Impacts on Mycorrhizal Diversity}

\subsection{Time Frames of GCC-mediated Changes}

One of the consistently challenging conundrums that have emerged through this review process is that mycorrhizal diversity ranges across many spatial scales - and within the rhizosphere of a given plant-host there exist opportunities for further levels of diversity (e.g., [364]). This variation in scales works its way up from the microscopic-level through to influencing biospheric process-and furthermore, there is the real potential for reverse feed-back loops, from the level of biosphere back down, to influence the physiology of the individual mycorrhizal hypha (see Figures $1 \& 2$ ). A further layer of complexity is delivered when we consider these changes across a temporal scale - in keeping with the seasonal rhythms that influence plant and fungal phenology (especially leaf and root flush of plants and the hyphal extension and sporulation of fungi). Swarts and Dixon [124], in their paper on integrated approaches to orchid conservation, provide a temporal continuum from immediate impacts (1-2 years) to long-term impacts (20-50 years) in relation to the sequence of abiotic and biotic factors that have an impact upon terrestrial orchid populations. Figure 5a reproduces their derived timescale, and while this eloquently articulates the impacts on orchids and orchid mycorrhizas, we consider that a putative timescale for GCC impacts could be generated from this basis - to incorporate all mycorrhizal types, and hence, mycorrhizal diversity.

We also consider there to be a compelling nexus between the timescale articulated by Swarts and Dixon [124] regarding orchid conservation and the identified ecological drivers that are associated with GCC (as per [79]) listed below:

- Increasing atmospheric levels and associated climatic changes

- Global temperature rise

- Changes in global rainfall distribution

- Increased deposition of anthropogenically fixed nitrogen $(\mathrm{N})$

$\circ$ Ecosystem fragmentation and habitat loss, and

- Biotic invasions (and other threats to biodiversity).

We have pictorially amalgamated the timescale of Swarts and Dixon [124] with the ecological drivers of Tylianakis et al. [79]. In Figure 5b we have retained the immediate and long-term time references, but have also added, short-term (3-10 years) and intermediate-term (11-20 years) time references, based on our interpolation of the time frames for the ecological drivers of GCC on mycorrhizal diversity (Figure 5b). The individual ecological drivers have been partitioned into four putative timescales as follows: 
- Immediate (1-2 years) impacts associated with ecosystem fragmentation and habitat loss will be immediately realized through the removal of plant-hosts and significant disturbance of the soil/rhizosphere habitat of mycorrhizas (Figure 5c)

- Short-term (3-10 year) impacts: where biotic invasions from exotic mycorrhizal fungi, plant and pests, diseases and other abiotic perturbations (such as the impacts of natural volcanism) will be realized (Figure 5c)

- Intermediate-term (11-20 year) impacts: where the cumulative and additive effects of increased $\mathrm{N}$ deposition, soil acidification and pollutants will be realized (Figure 5c)

- Long-term (21-50+ year) impacts: where increased temperatures associated with $\mathrm{CO}_{2}$ increase will result in the destabilization of global rainfall patterns, combining to have significant impacts on plant ecosystem resilience (Figure 5c).

Figure 5. Impacts of different GCC temporal scenarios on mycorrhizal diversity (Swarts \& Dixon [124]; Tylianakis et al. [79]).

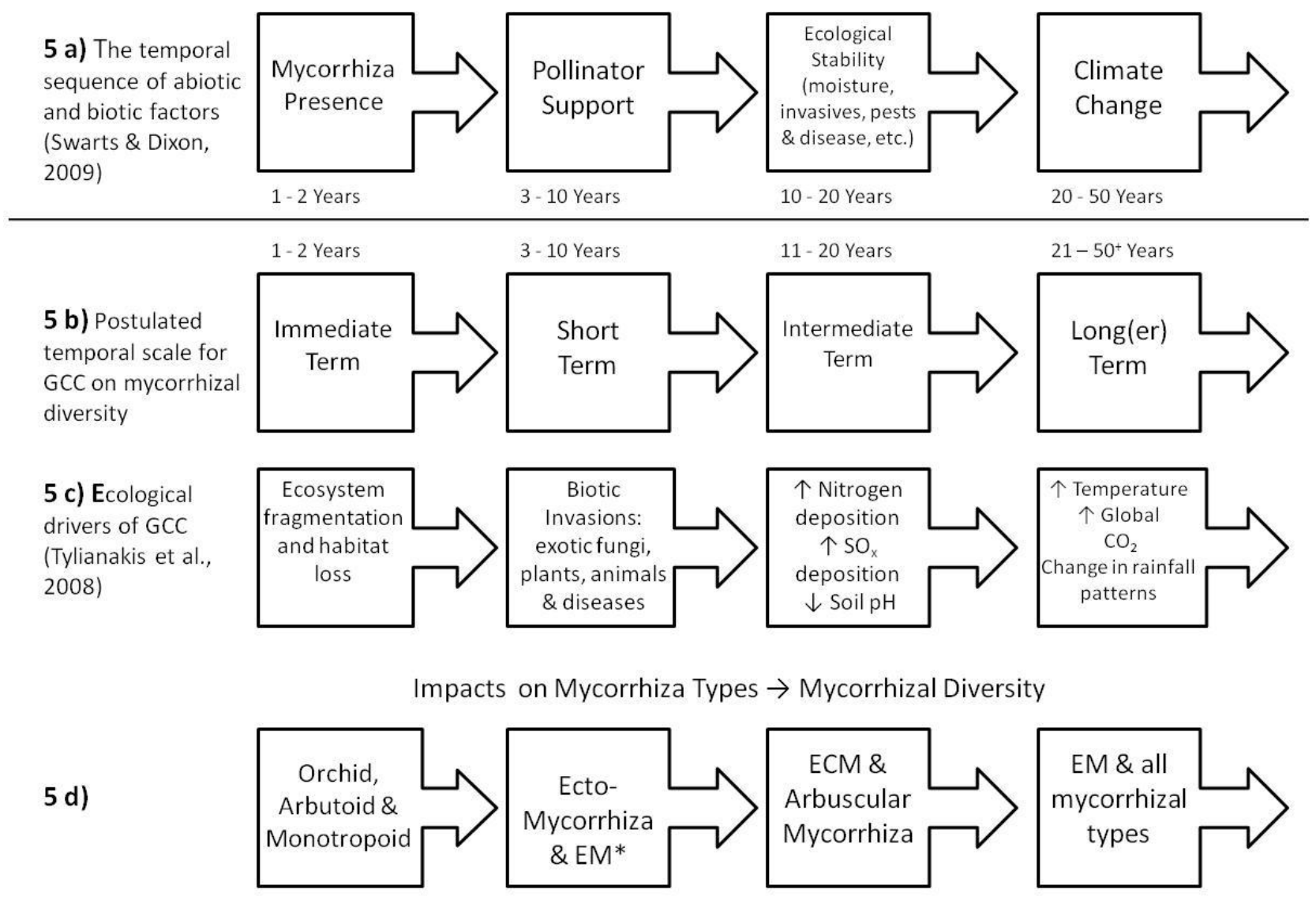

* EM at high elevations and high latitudes

The above- and below-ground impacts of chronic/catastrophic ecosystem modification that results in permanent land-use change will potentially result in:

- The loss of geographically restricted plant taxa

- The loss or displacement of mycorrhizal propagules

- The loss of macro-faunal vectors that assist in the dispersal of mycorrhizal propagules, e.g., mycophagous mammals and ectomycorrhizas. 
5.2. Responses of Mycorrhizal Diversity to Ecosystem Fragmentation and Habitat Loss (Immediate Impacts Occurring in 1-2 Years)

Because of their dependence upon their host for C-supply, orchid mycorrhizas and all heterotrophic mycorrhizal groups will be immediately impacted through ecosystem fragmentation leading to loss of habitat and, more importantly, their plant-hosts (Figure 5d). Orchid mycorrhizas are described as "delicately balanced mutual antagonisms" [43,44]. Further, plant propagules (spore-like seeds) are often difficult to germinate and undergo a saprotropic phase prior to development of mycorrhizal forms. Although orchids and their mycorrhizal symbionts have evolved to occupy a remarkably diverse set of habitats $[43,44]$, most of these habitats are of low to moderate $\mathrm{pH}$ and low buffering capacity and as a consequence are susceptible to further acidification.

Transient changes in the availability of some classes of mycorrhizal inoculum have not been seen to permanently alter the infective ability of AM mycorrhizas (e.g., [301]). This is because some of the propagules (such as infected root pieces) are quite robust and can remain for some time as a viable source of inoculum. Reinvasions by soil mesofauna also provide a mechanism for AM inoculum to be returned to a site. Klironomos and Moutouglis [365] demonstrated that soil arthropods such as collembola can act as effective dispersal agents. More recently, Perez-Morena and Read [366] have demonstrated a pathway for the transfer of nutrients from dead nematodes to mycorrhizal plants - thus demonstrating the capacity for mycorrhizal fungi to recycle nutrients, even more effectively than from saprotrophic fungi alone.

However, habitat modification leading to the displacement of larger, mycophagous mammals has been implicated in the loss in the dispersal pathway for ECM fungi [72]. Indeed, Pyare and Longland [367] concluded that the integrity of entire small-mammal communities may be important to the maintenance of ECM diversity in coniferous forests. However, like AM fungi described above, the loss of infective propagules may only be transient. In his study on the effects of fire on Tasmanian bettongs (Bettongia gaimardi), Johnson [128] demonstrated that all measured variables returned to control values about four months after fire. This follows the findings of Bellgard et al. [295], whereby the ability of the flora to resprout from underground organs provides for a stable habitat and carbohydrate supply for the mycorrhizal partners to survive the effects of wildfire, and continue their below-ground functions.

5.3. Response of Mycorrhizal Diversity to Biotic Invasions and Competitive Exclusion (Short-Term Impacts Occurring in 3-10 Years)

The invasion of native ecosystems by adventive incursions of weeds, pests and plant diseases will potentially result in:

- Invasive mycorrhizal fungi displacing native symbionts to the detriment of native/indigenous plant-hosts (e.g., [368])

- Invasive exotic plants such as ruderal weeds altering natural plant species distributions to the exclusion of native plant-hosts (see [369])

- Introduction of exotic plant diseases such as Phytophthora species into native forests that kill plant species including some keystone species (e.g., [67]). 
We consider that ECM fungi will be the principal group of mycorrhizas that will be subject to short-term impacts (Figure 5d). Dickie et al. [370] consider that the process is facilitated by coinvasion of plants and their mycorrhizal counterparts. Their example of Pinus contorta invading endemic communities of Nothofagus solandri var. cliffortioides also demonstrates the potential for exotic mycorrhizal fungi to displace native fungal species and drive the mycorrhizal community to a more simplified version of the native complement. The preceding example of course raises the role of human-mediated introductions that result from the global trade in horticultural and agricultural plant species. These effectively remove plants from their native context and place them into non-indigenous regions. The new arrivals are placed into situations where their usual associates are not present - this release from the usual suite of herbivores and pathogens may explain their success in the introduced range.

Hansen [285] considers that many Phytophthora species are benign in their native, coevolved plant communities, but given the opportunity of introduction to new hosts in new environments, new opportunities for dispersal, or unexpected sexual recombination, can result in dramatic epidemics in forests around the world. Phytophthora ramorum (cause of sudden oak death in western North America and also damaging in Europe) provides a current example, dramatically illustrating the potential of these pathogens for rapid ecological damage. The consequence of removal of native mycorrhizal plant-hosts will be a concomitant decrease in their abundance. While it is unlikely that these invasive plant pathogens will push any of their major susceptible hosts to final range-wide extinctions, death of the tree hosts creates opportunities for invasions by exotic plants and/or exotic mycorrhizal fungi. The additive effects of disease and biotic invasions may be enough to realize local endemic plant extinctions, and the concomitant loss of their ecosystem services, including hosts of ECM fungi.

\subsection{Response of Mycorrhizal Diversity to Increased N Deposition, Soil Acidification and Aerial} Pollutants (Intermediate-term Impacts Occurring in 11-20 Years)

Alteration to the nutritional balance of soils through the enrichment of $\mathrm{N}$, decrease in soil $\mathrm{pH}$ (e.g., through enrichment with $\mathrm{NOx}$ and $\mathrm{SOx}$ ) and addition of environmental pollutants will potentially result in:

- Changes in insect herbivory patterns

- Change in below-ground allocations to mycorrhizas [136]

- Reduced growth of extramatrical ectomycorrhizal mycelium (e.g., [260])

- Acid-induced increase in the availability of toxic metal ions in soil (e.g., [165])

- Pollutant-induced reduction in photosynthetic capacity of trees (e.g., [259]).

Empirical evidence suggests that there are several mechanisms by which $\mathrm{N}$ deposition may affect interactions between plants and insect herbivores. The most likely mechanisms are deposition-induced shifts in the quality and availability of plant-host tissues [371]. In New Mexico and Arizona, there have been massive die-offs of the Piñon pine (Pinus edulis) due proximally to bark beetles (Coleoptera: Curculionidae, Scolytinae). The empirical study of Jones et al. [372] demonstrated that tree mortality increased $8 \%$ and beetle activity increased $20 \%$ under the highest rates of nitrogen. The other factors 
involved in this complex problem such as ozone (as an atmospheric pollutant) and drought will be discussed in the following sections, but for our current purposes, the summarial removal of keystone plant species from forest ecosystems will have a concomitant impact upon the distribution and diversity of ECM fungi.

Associated with increases in grassland $\mathrm{N}$-economies was a reduction in the below-ground allocation of $\mathrm{C}$ to arbuscules, coils and extraradical hyphae [136]. Concomitant impacts to the species composition of the AM fungal community was also observed - probably associated with the allocation plasticity within individual fungal taxa [136]. From her earlier study, Johnson [373] had indicated that 8 years of fertilization altered the species composition of AM fungal communities - there was an observed reduction in species diversity and a disproportionate increase of a single Glomus species. From her controlled greenhouse study, she demonstrated that fertilization of nutrient-depauperate soils favours the proliferation of inferior AM fungal mutualists. Additionally, the community-level shifts in AM species abundance may be an indirect response to increasing fungal competition for a more limited supply of host photosynthate.

Conversely, however, in a long-time, conventionally tilled agricultural soil in Czechia, a synergistic effect of organic and mineral fertilization on the development of AM was demonstrated by Gryndler et al. [374]. The length of AM mycelium and sporulation both increased in proportion with increasing mineral fertilization. However, correlation analysis showed the dependence of length of AM hyphae and sporulation on soil available P. The observed differences could therefore be related to the original fertility status of the experimental field-soil studied in Czechia. If, as suggested by Johnson [373], the suite of AM fungi had already been altered through the long fertilization history, selection of inferior mutualists may have already occurred. Thus, the observed extraradical stimulation may not have had any biological significance with respect to plant performance.

Arnebrant [260] demonstrated that all five of the different ECM fungal isolates she examined were negatively affected by nitrogen amendments, although sensitivity to amendments varied between the isolates. The extramatrical mycelial growth was inhibited in all species examined-although the percentage inhibition varied between 3 and $80 \%$. This suggests that some ECM species may be more tolerant to $\mathrm{N}$ amendments and thus could have some selective advantage in an $\mathrm{N}$-enriched soil environment. This selection could in turn shift the ECM community composition, if the N-sensitive species were not able to produce a competitive quantity of extramatrical hyphal growth to compete with the more N-resistant strains.

Roth and Fahey [375] demonstrated a shift in the composition of the ECM community that occurred in response to acid precipitation treatments. Among the seven ECM types studied, the percentage composition of one morphotype increased and another decreased in response to higher rain acidity. Nitrogen and S depositions are usually connected with each other in the field, and it is often impossible to distinguish their effects. Large concentrations of ammonium in rainwater [376] or gaseous ammonia [377] have been found to cause a decline in the amount of mycorrhiza in coniferous seedlings. Markkola et al. [258] demonstrated a reduction in sporophore production of ECM fungi at high N sites. As stated by Sårstad and Jenssen [378] the high niche differentiation and high species diversity of fungi in forest ecosystems means that marginal differences in environmental factors can result in substantial shifts in species composition within an area. However, it has been observed that "generalist" ECM species that form a symbiosis with a wide range of species seem to less affected by 
increased $\mathrm{N}$ availability than "specialist" ECM species, especially those living in symbioses with conifers [379]. Frey et al. [380] identified that the active fungal biomass was 27-61\% and 42-69\% lower in the $\mathrm{N}$-fertilized compared with control plots in hardwood and pine stands, respectively. In the pine stand, ECM fungal community diversity was lower in the N-treated plot than in the control plot. Finally, differences were also observed in ECM community structure between control and N-fertilized plots - with a reduction in those species with the highest relative frequencies in the control community.

Edaphic inputs of SOx that effectively reduce soil $\mathrm{pH}$ can liberate toxic metals such as aluminium, manganese and magnesium [165], and hence make them more plant available. This increased toxicity leads to reduced root growth, root dieback and reduced mycorrhizal fungal growth and colonization. Dighton and Skeffington [357] found that simulated acid rain caused a change in the ECM community structure by reducing the occurrence of mycorrhizal morphotypes that were multibranched and that were associated with large amounts of extraradical hyphae. In Finland, Markkola and Ohtonen [381] demonstrated that Piloderma, Dermocybe and Hebeloma were significantly reduced in the presence of acidifying pollutants, whereas Cenococcum was seen to increase in frequency. Once again, there was the identification of differential susceptibility to soil acidification-akin to the differences in responses to amendments of $\mathrm{N}$. This demonstrates the potential for soil acidification to select ECM that are more tolerant to decreases in soil $\mathrm{pH}$. If this change in frequency is great enough to affect the individual's reproductive fitness, then we will see a permanent shift in the community diversity of ECM.

Pollutant-induced reductions in the photosynthetic capacity of tree canopies potentially reduces the allocation of $\mathrm{C}$ to roots and their mycorrhizas [1]. Reduced energy supply both reduces the overall mycorrhizal colonization of roots and favours those fungal species that can survive on low carbohydrate supplies [165]. Stankevičienè and Pečiulytė [259] demonstrated that the lowest diversity of ECM morphotypes was associated with forests characterized by the highest concentrations of heavy metals and mineral nutrients ( $\mathrm{N}$ and $\mathrm{P}$ ). Interestingly, microfungal abundance was negatively correlated with the distance from the pollution source; meanwhile the number of genera (i.e., diversity) increased with distance from the pollution source. The favoured microfungi included the phytopathogenic species of the genera Cladosporium spp. and the entomopathogenic fungus Paecilomyces farinosus. Other pollution-resistant microfungal taxa included Mucor hiemalis and Trichoderma viridies - both fungi known to improve the mobility of heavy metals in polluted soil [382]. This indicates that the shift in microfungal diversity favours the proliferation of pollution-resistant species, some which can further exacerbate the toxic nature of the soil-potentially excluding the return of metal-sensitive species (including ECM fungi).

Thus, vulnerable mycorrhizal types subject to intermediate-term GCC changes include "specialist" ECM species associated with forest ecosystems and AM associated with grassland ecosystems (Figure 5d). AM have repeatedly been demonstrated to alleviate heavy metal stress of plants. Associated with plants under heavy stress of either $\mathrm{Cd}, \mathrm{Cu}, \mathrm{Zn}$ was the response of specific AM fungal genes in the intra- and extra-radical mycelium [383]. This "level" of responsiveness was interesting, as "heavy metal-derived oxidative stress may be the primary concern of the fungal partner in the symbiosis". The level of pre-adaptation to tolerance to heavy metal stress would vary-thus presenting a selective pressure on the AM fungal community. 
5.5. Responses of Mycorrhizal Diversity to Change in Rainfall Distribution, $\mathrm{CO}_{2}$ Increase and Global Temperature Rise (Longer-Term Impacts Occurring in 21-50+ Years)

Alteration of rainfall distributions will increase the frequency of droughts, which will cause plant stress. Coupled with this will be temperature increase in response to increased $\mathrm{CO}_{2}$ concentration. The combined influence of these factors will result in:

- Increased frequency of drought facilitating pathogen invasions in forests (e.g., [68])

- Increased insect-caused tree mortality (e.g., [384,385])

- Changes in plant species diversity (e.g., [299,386])

- Accentuated changes to plant communities at high altitudes and high latitudes

- Changes in soil carbon storage and C/N-cycle feedbacks (e.g., [247,387])

- Changes in stomatal conductance with consequences for soil moisture [137].

Drought-induced predisposition, rendering plants and trees susceptible to pathogenic infection, has long been recognized (e.g., [228]). However, drought-induced tree mortality is difficult to predict, because it is a non-linear, threshold process [388]. The severe drought and heat wave experienced in Europe during the summer of 2003 raised concern, especially if warmer temperatures raised the effects of drought on tree mortality-both for background rates of mortality and for regional die-off events [68]. Considerable circumstantial evidence is available linking drought and disease in forest ecosystems in Europe, North America and Australia-with the principal agents of disease being canker/dieback pathogens (e.g., Botryosphaeria) and root disease (e.g., Phytophthora). The relationship between the severity of the environmental stress, prevalence of the pathogen, and the severity of disease is articulated via the "disease triangle" - with the well-being/susceptibility of the host being a critical factor in understanding the extent of damage to the host by the disease [389].

Direct drought effects on pathogens are generally negative, and potentially also affect mycorrhizal efficacy. The results of Valdés et al. [390] demonstrated that both total fine-root biomass and ECM-root biomass are strongly affected by severe drought in high elevation, tropical plantation forests. The comprehensive review of water relations, drought and AM symbiosis of Augé [180] highlights the following facts on the influence of AM fungi and drought physiology:

1. AM effects on plant water relations are not as dramatic and consistent as those on $P$ acquisition and host growth

2. AM influences on tissue hydration and foliar gas exchange are often subtle, transient and probably circumstance and symbiont specific, and

3. AM influence on host water relations and drought physiology can be substantive - but only occasional.

Seasonal and drought-related declines in the extraradical hyphae of AM fungi and percent root colonized have been observed in many, but not all studies [263]. Commonly, the decline in exploitation of soil has been associated with a decline in soil water content. Increased frequency and duration of drought episodes will impact negatively on AM plants through the concomitant reduction in access to essential plant nutrients (in the water phase). However, compensatory effects associated with increased $\mathrm{CO}_{2}$ enrichment may offset any short-term losses; however, sustained invasion 
pressures from non-mycorrhizal, exotic plants may be at some advantage if the efficacy of AM association is reduced through reduced soil exploitation.

Interactions between Phytophthora infections, flooding and droughts are well known and generally accepted as triggers of epidemics (e.g., [391]). However, conjecture remains on the interaction between water availability and disease expression. This is especially relevant for oomycete root-rot pathogens (such as Phytophthora), whereby sufficient soil water is essential to facilitate the germination and sporulation of dormant propagules (e.g., oospores). Permanent changes to rainfall distributions could potentially increase the frequency of episodic rainfall events leading to local waterlogging. For example, Phytophthora-mediated oak decline in Central Europe and parts of Western and Northern Europe has been attributed to long-term changes in climatic conditions in the second half of the 20th century (i.e., a continuous increase in mean winter temperatures, a seasonal shift of precipitation from summer into winter-time, and a tendency towards episodic, heavy rainfall events) [392]. Indeed, waterlogging or impeded drainage has been shown to be sufficient to kill trees in the absence of root pathogens. Davison [393] investigated the interaction between waterlogging alone and in combination with infection by $P$. cinnamomi. She articulated that there were indeed a complex of disorders: deaths of mid- and understorey species caused by P. cinnamomi, deaths of groups of Eucalyptus marginata (jarrah) caused by waterlogging, a background mortality of isolated jarrah deaths, and a crown decline of jarrah — on some sites all problems occurred simultaneously (see also [394]). Thus through either a predisposition and/or a multiple stress hypothesis, decline of keystone species in forest ecosystems will impact on the viability and ultimately the diversity of mycorrhizas.

In our previous discussion, bark beetle impacts on forest health were linked to $\mathrm{N}$-amendments. Another particular concern is the potential for warmer temperatures to compound the effects of increasingly severe droughts by triggering widespread vegetation shifts via woody plant mortality [385]. Adams et al. [385] provide compelling evidence that warmer temperatures shorten the time to drought-induced mortality in Piñon pine trees by nearly a third, with temperature-dependent differences in cumulative respiration costs implicating carbon starvation (whereby trees keep stomata closed to maintain safe levels of xylem pressure-but stopping most photosynthesis), as the primary mechanisms for mortality. Furthermore, projected increase in drought frequency due to changes in precipitation and increase in stress from biotic agents (e.g., bark beetles) would further exacerbate tree mortality. The death of tree hosts would impact upon the fitness of the associated ECM-with broad-scale removal of a keystone species, effectively disrupting the host-mycorrhiza relationship: thereby reducing mycorrhizal diversity.

Cullings et al. [138] showed that by experimentally defoliating Pinus contorta (lodgepole pine) while maintaining the canopy of Engelemann spruce (Picea engelmannii) the ectomycorrhizal species composition responded accordingly. The premature defoliation of Pinus contorta changed the relative abundance of ECM of the two tree species from a ratio of approximately 6:1 without treatment to a near 1:1 ratio post-treatment. In addition, ECM species composition changed significantly post-defoliation; the system dominant, an Inocybe species, was rare in defoliation plots, while Agaricoid and Suilloid species that were rare in controls were dominant in treatments. Furthermore, species of ECM fungi associating with both lodgepole pine and Engelmann spruce were affected, 
which indicates that changing the photosynthetic capacity of one species can affect mycorrhizal associations of neighbouring non-defoliated trees.

Indeed, vegetation shifts have profound ecological impacts as they provide important climate-ecosystem feedback through their alteration of carbon, water and energy exchanges of the land surface [385]. Mycorrhizal diversity will respond to temperature changes. Invasion by warm-season plant-hosts will change mycorrhizal functioning. This will likely be accompanied by invasions of warm-season-adapted ECM fungi [395]. Wolf et al. [299] showed that $\mathrm{CO}_{2}$ enrichment and plant species richness impact AM fungal spore communities. Under plant monocultures, only Glomus clarum responded significantly to $\mathrm{CO}_{2}$ elevation out of 11 species present. In contrast, under polyculture, this response was not detectable. In a similar way, Chung et al. [386] showed that higher plant species richness fostered greater microbial biomass as well as the abundance of saprophytic and AM fungi. Moreover, the effect of plant species richness on microbial communities was significantly modified by elevated $\mathrm{CO}_{2}$ and $\mathrm{N}$ deposition. For instance, microbial biomass and fungal diversity increased with greater species richness, but only under combinations of elevated $\mathrm{CO}_{2}$ and ambient $\mathrm{N}$, or ambient $\mathrm{CO}_{2}$ and $\mathrm{N}$ deposition.

Further to this, Johnson [137] found that plant species responded individualistically to the presence of AM fungi and the availability of $\mathrm{CO}_{2}$. Starting with mesocosms of 14 plant species, ambient or elevated $\mathrm{CO}_{2}$ and low or enriched $\mathrm{N}$ factorial treatments were investigated. After 1 year, significantly, different plant communities arose under different treatment conditions. Plant species richness was lowest at plus $\mathrm{N}$ mesocosms, and highest in plus $\mathrm{AM}$ and plus $\mathrm{CO}_{2}$ treatments. At ambient $\mathrm{CO}_{2}, \mathrm{AM}$ fungi reduced plant richness but at elevated $\mathrm{CO}_{2}$ they increased it. This was caused by preferential mortality of several $\mathrm{C} 3$ forbs and may suggest that $\mathrm{CO}_{2}$ enrichment ameliorates the carbon cost of some AM symbioses.

Many studies have demonstrated plant responses to warming temperatures, but as advancement in the timing of phenological events and in range shifts. Mountain gradients have provided a very powerful opportunity for studying species range changes (e.g., [396]) —and furthermore, these particular contextual settings are appropriate, as GCC-induced changes to vegetation are expected to be accentuated at high latitudes and altitudes (e.g., [87]). Dullinger et al. [397] considers that invasion of abandoned subalpine pastures and tundra grasslands will be facilitated by invasive, aggressive conifers (in this case, Pinus mugo Turra). It is well accepted that the degree of resistance to invasion of grasslands by tree and shrub species is strongly affected by competition with vigorous grass and herb species (e.g., [398]). However, the concomitant supply of propagules (i.e., seed from P. mugo) and the depressed resistance to invasibility (due to invasion pressure from a highly competitive Carex sp.) of the "host communities" will see shifts into these grassland communities by trees.

A curious, complex interaction is emerging in another high altitude/latitudinal complex associated with the forest-steppe ecotone of Mongolia. In this contextual setting, drought and high temperatures at the soil-air interface are crucial for inhibiting tree encroachment. For example, the southern distribution of taiga forest dominated by the keystone species Larix sibirica, although modified by human activities (e.g., logging, livestock breeding and wildfire), is still largely determined by seasonal drought (e.g., [399]). Treelines towards the steppe are generally not static-but underlie spatial variation with temporarily varying influences of climate, fire activity, herbivore densities, and human utilization [400]. However, interannual variation in insect herbivore pressure is actuating another layer 
of selective pressure to restrict tree establishment. The sowing and planting experiments of Dulamsuren et al. [399] demonstrated that drought exerts a strong "post-zygotic" pressure on seedling mortality. However, 2-year-old seedlings of L. sibirica suffered from drought as well as from feeding pressure by Gypsy moth larvae (Lymantria dispar), early in the growing season. Follow-up herbivory pressure from grasshoppers and rodents persisted throughout the growing season, resulting in two-thirds of seedlings dying due to insect and small mammal herbivory and one-third due to drought-related damage. Hauck et al. [400] identified that herbivory pressure was greatly exaggerated at the forest edge, and that while defoliation of trees growing at the forest edge was severe in the first year of their study, the gypsy moth invasion responsible for this defoliation did not cause lethal damage in the trees. However, sub-lethal damage in seedlings can be exacerbated through the added impact of waves of herbivory pressure that can cause a spatial shift in the treeline- - with a concomitant impact upon the mycorrhizal complement.

Olsrud et al. [401] examined the how EM, fine edophytes and DSE in roots responded to elevated atmospheric $\mathrm{CO}_{2}$ concentrations and warming in the dwarf understorey of a birch forest in the subarctic region of northern Sweden. The EM colonization in ericaceous dwarf shrubs increased under elevated $\mathrm{CO}_{2}$ concentrations, but did not respond to warming following 6 years of treatment. It was suggested that the higher EM colonization under elevated $\mathrm{CO}_{2}$ might be due to increased transport of carbon below-ground to acquire limiting resources such as $\mathrm{N}$, which was found to be diluted in leaves of ericaceous plants under enhanced $\mathrm{CO}_{2}$. Conversely, the elevated $\mathrm{CO}_{2}$ did not affect total plant cover but the plant cover was increased under warming, which may reflect increased $\mathrm{N}$ availability in the soil. Fine endophyte colonization decreased in grass roots under enhanced $\mathrm{CO}_{2}$ and under warmingpossibly due to an increase in root growth. DSE hyphal colonization in grass roots significantly increased under warmer conditions, but did not respond to elevated $\mathrm{CO}_{2}$. For this reason we have placed $\mathrm{EM}^{*}$ in the 3-10 year, short-term temporal scenario depicted in Figure $5 \mathrm{~d}$. This may only be relevant at high latitudes and altitudes, but it seems that the three-way interaction identified by Olsrud et al. [401] could be a powerful predictor of the possible outcomes of competitive interactions between mycorrhizal fungi and other root endophytes.

Conjecture remains as to the plausible function of DSE - clearly DSE form symbiotic associations with roots of their plant-host; the fungal symbionts inhabit the absorbing organs of the host forming the dual organ as described by Trappe [402]. Questions remain as to the function of this dual organ; whether it is an organ of absorption and whether DSE associations can be considered facultatively mutualistic, with occasional instances or parasitism [403-405]. Regardless of function, it is obvious, because of their location in the grass-root rhizosphere and their ability to respond to GCC drivers, that they may be capable of competitive exclusion - to the detriment of symbiotic fungi (e.g., AM). The picture of total "environmental DNA" generated by Vandenkoornhuyse et al. [406] demonstrated that the roots of the grass Arrhenatherum elatius contained 49 different sequences (so called "phylotypes"). Of the 40 different phylotypes, all were found to be fungal! From this analysis, it was clear that among the phylotypes were relatives of mutualistic AM fungi. However, the authors could only speculate on the possible roles of the other $94 \%$ of the root fungal diversity that they documented. Is it possible one or more of these phylotypes could usurp the root-space to the competitive exclusion of mutualistc partners? 
This type of analysis sheds light on the unknown spectrum of micro-fungal diversity of fungi that are potentially in competition with mycorrhizal endophytes for host-root tissue. The GCC-driven changes affecting soil microhabitats could be seen to favour certain non-mycorrhizal components of the soil microflora. As described in our above example, Olsrud et al. [401] found that soil warming favoured DSE but did not enhance EM colonization. What are the consequences of the competitive exclusion of EM fungi in this circumstance? A reduction in the efficacy of the EM association could in turn alter the plant community structure (potentially from shrubs to grasses). The fertilization effect of enhanced N (thought to be a consequence of GCC along with soil warming) may change the level of host dependence upon mycorrhizal endophytes. This in turn may continue to favour rapidly colonizing, aggressive AM-dominated monocots. With the concomitant shift in mycorrhizal diversity from EM-dominated ericaceous shrubs to AM-dominated grasslands will be changes to soil biology, which in turn will potentially alter the biological component involved in the adhesion of soil particles to form peds (i.e., structure) and, ultimately, influence the biogeochemistry of subarctic soil ecosystems [401].

The increase in $\mathrm{CO}_{2}$ has been associated with an increase in root biomass and an increase in the $\mathrm{C}: \mathrm{N}$ ratio, possibly due to a change in the balance between allocation of $\mathrm{C}$ to root growth and carbon storage [1]. Mycorrhizal tissue has been estimated to comprise a significant fraction of soil organic matter and below-ground biomass in a range of systems. The current literature suggests that in an enriched $\mathrm{CO}_{2}$ environment, mycorrhizal fungi might sequester increased amounts of $\mathrm{C}$ in living, dead and residual biomass in the soil $[247,407]$. The concomitant stressors being applied from increased $\mathrm{N}$ additions, drought frequency and biotic invasions of non-mycorrhizal plants could see dis-function and a "resource-based" dislocation of the C-fixing machinery delivered through mycorrhizal diversity. Important to recognize is that below ground, mycorrhizal plants shifted allocation of carbon to pools that are rapidly turned over, primarily to fine roots and fungal hyphae [407], and host root and fungal respiration. Mycorrhizae alter the size of below-ground carbon pools, the quality and, therefore, the retention time of carbon below ground. The data of Nottingham et al. [387] indicate that if elevated atmospheric $\mathrm{CO}_{2}$ and altered climate stressors alter mycorrhizal colonization in forests, the role of forests in sequestering carbon could be altered. Further to this, changes in ECM assemblages have been shown to occur in response to increased $\mathrm{CO}_{2}$ (e.g., [408,409]). Arguments of Eisenlord and Zak [102] suggest that increase in exogenous $\mathrm{N}$ will shut off the certain carbon degradations of Basidiomycetes. This function is taken over by other lignin-degrading organisms that do not degrade lignin to $\mathrm{CO}_{2}$, but rather to polyphenols.

Both $\mathrm{CO}_{2}$ enrichment and mycorrhizae can indirectly influence soil moisture via effects on stomatal conductance (e.g., [410]). Soil moisture can increase under elevated atmospheric $\mathrm{CO}_{2}$ because of the commonly observed reduction in stomatal conductance, particularly in C3 plant species [411]. The increased soil moisture generated by elevated $\mathrm{CO}_{2}$ has been shown to increase rates of microbial metabolism and nutrient cycling. Stomatal conductance and transpiration rates are generally higher in AM compared with non-AM plants in both mesic and drought conditions [180]. Increased $\mathrm{N}$ availability typically stimulates above-ground plant productivity, stomatal conductance and whole-plant water use. Because elevated $\mathrm{CO}_{2}$, AM fungi and $\mathrm{N}$ availability have contrasting effects on plant growth, water use, and soil moisture, the interactive effects may have unexpected effects on plant community structure [137] (see also [412]). Superimposed upon this are the potentiality of biotic incursions, and other stressors threatening biodiversity (including abiotic factors). 
Once there are major perturbations to the global hydrological cycle that permanently change rainfall patterns and distributions, no aspect of the global mycorrhizal diversity will remain unaffected (Figure 5d). Why do we consider that these modified interactions affecting mycorrhizal diversity are so important for plant performance?

- Because presence and/or absence of mycorrhizal symbionts can affect distribution and abundance of plant species, which in turn influences evolution of the host and plant community response.

- The relationship between mycorrhizal diversity and the success of plant invasions/migrations is regulated by the level of dependency on highly evolved partnerships and will govern the direction of the shift in response to opportunities or constraints delivered through GCC.

- The consequences of potential changes to species assemblages of mycorrhizal fungi in terrestrial soil-vegetation systems will have implications on a global scale, as mycorrhizas contribute to the amelioration of challenging edaphic substrates, and by influencing the rate of restoration of disturbed/cleared ecosystems.

\section{Concluding Discussion}

\subsection{Concluding Synthesis}

GCC is not a recent phenomenon, but has played a principal role in historical evolution of the diversity of life on planet Earth at least over the last 500 m.y. The episodic punctuation of the continuity of life on Earth has, in the main, been associated with significant GCC events (e.g., expansions of ice-sheets). Fungi emerged in the Proterozoic and so have witnessed the suite of six major extinction events and other GCC drivers. Historically, fungi (including ancestral mycorrihzal fungi) were mining nutrients from primitive, undeveloped soils. All primitive plants that successfully colonized land required some form of fungal partnership, because their roots were not capable of accessing the necessary essential plant nutrients and water. This continued until such time as some root systems became sophisticated enough (and/or soils became sufficiently developed) for plants to "go it alone" without a fungal partner.

The source and extent of mycorrhizal diversity was due, in part, to GCC. There have been five episodes when two-thirds cumulative of all living species were removed from the planet. And while this represented the end for some, these events represented opportunities for mycorrhizal fungi to diversify their host range-repeatedly. Thus mycorrhizal diversity is the result of an accumulation of [plant-host] "associative-memory", reinforced by "new encounters" with plant species that relied upon a successful mycorrhizal association in order to become established in the post-apocalyptic edaphic substrates.

Pankhow et al. [413] suggested that the main role of the mycorrhizal symbiosis is not during the early productive stages of plant succession in ecosystems, but rather in the protective stages during which most resources are entrained in plant biomass. As such, perturbations to this association that influence the efficacy/benefits to plants will affect plant health. Poor plant health can predispose them to diseases as mycorrhizae play an important role in protecting plant-hosts against pathogens $[35,414]$. 
Thus mycorrhizas are essential components contributing to plant health and, hence, contribute to the resilience of ecosystems to perturbations such as climate change, invasive species incursions and pollution. But is this significant in relation to the trajectory of plant communities through the influence of autecological patterns?

Kohut [415] propounds that genetic selection occurs when an entity (in this case mycorrhizal fungi) is subject to an agent of selection (in this case GCC) and three conditions for a property (in this mycorrhizal diversity) responsive to the agent are satisfied at the population level. Firstly, there must be variation in the population. Secondly, part of the variation is genetically controlled, and finally, variation in the property must affect reproductive fitness. If these conditions are satisfied, the frequency distribution of the property, and gene frequency associated with it, will change over time in response to selection.

It is obvious that variation exists at a range of scales within mycorrhizal fungi within populationsacross all types or categories of mycorrhizas. This variation is governed by a complex array of genetic-based processes - and even though the balance of the genetic systems varies across the mycorrhizal types (i.e., they do not all follow the classical, panmictic, Mendelian-based construct), they are all genetically-based. And, it is obvious that there are direct physiological influences of GCC, and indirect influences of GCC-mediated changes to plant-hosts that affect the reproductive fitness of mycorrhizal fungi-their physiology, biology and ecology. These factors dictate that there will be changes in relative gene frequencies that will be realized as changes in the species composition at the community-level.

And because of the above, the GCC-induced changes which influence mycorrhizal fungal fitness will principally influence mycorrhizal diversity through:

1. Ecosystem fragmentation/habitat loss, which can spatially de-couple the mycorrhizal fungi from their plant-host. Habitat fragmentation will lead to loss of rare taxa; this will influence mycorrhizal diversity by selection against highly-specialized, co-evolved "clades" of fungi which form intimately-linked, mutually-dependent partnerships.

2. Biotic invasions of exotic mycorrhizas and non-mycorrhizal plants, which will contribute to the selective pressure on indigenous mycosymbionts and lead to local shifts that may drive out mycorrhizal-dependent hosts.

3. N-fertilization amendments, which may serve to de-couple the association by making plants less reliant on mycorrhizas, or selecting for suites of mycorrhizal fungi that do not have the same symbiotic efficacy as the native complement.

4. Acidification of soils releasing toxic metals, thus selecting for resistant mycorrhizal types or those with the phenotypic plasticity to tolerate changes in soil chemistry.

The schema extracted from Staddon et al. [166] (Figure 2) usefully articulates the two-way arrows introduced in Figure 1 between the various hierarchical levels that exist in complex ecosystems. This schema articulates some of the levels of interactions and demonstrates the various feedback mechanisms at a simple scale of a three-species system. We have demonstrated that changes in mycorrhizal diversity will occur at the level of: 
- $\quad$ species

- populations

- communities

- ecosystems

- biomes and

- the biosphere

The relationship between mycorrhizas and plant productivity will continue to influence the Earth's atmospheric composition through the following escalation of scales commencing from the individual fungal hypha upwards to the global biomic-level via the following set of interrelationships:

1. Mycorrhizal fungi form absorptive accessories to roots, linking them to the individual fitness of their plant-host.

2. This in turn confers success/failure of plant-hosts in the competitive contexts of their 'patch' through nutrient and water acquisition.

3. This in turn underpins primary production in forests and grasslands ecosystems, through the provision of a range of ecosystem-services.

4. These dominant ecosystems contribute to landscape-level biogeochemical cycling influencing atmospheric edaphic conditions, and

5. Ultimately, continuing to influence global climate through $\mathrm{C}$-source/storage, partitioning of energy at the vegetation-atmosphere interface, mobilization and fixation of $\mathrm{N}$, and influencing plant water use efficiency and return of water to the atmosphere.

Thus changes in mycorrhizal diversity will have consequence at the biospheric-level and thus can either contribute to ameliorating the long-term effects of GCC (e.g., through C-storage, or facilitating the revegetation and hence restoration of ecosystem processes) or facilitate the GCC drivers (e.g., through release of C). GCC was also instrumental in achieving a habitable planet, 100 billion years ago. Fungi (including the ancestral mycorrhizas) contributed to making the planet habitable for terrestrial plants, which, in turn, facilitated the change in oxygen concentration necessary to allow more sophisticated levels of macro-evolution [33]. This ultimately led to the evolution of humans. The irony is that there is little support of the null hypothesis that humans over the last 10,000 years have NOT facilitated the commencement of the sixth major extinction and further, there is little support of the null that through their contributions to GCC now do not threaten the diversity of mycorrhizas.

Changes in geographical distribution of plant species along with their associated mycorrhizal fungi has been a long-term and slow change as plants have colonized new areas since the early Devonian. Plants species have continued to change in distribution as suitable climatic and edaphic conditions that allow them to successfully compete with established plant species become available. Climatic, atmospheric and edaphic changes associated with the environmental consequences of GCC will allow plants to invade marginal habitats as conditions become suitable). The newly established plants will facilitate the establishment of their associated mycorrhizal partners to access key plant nutrients. As a consequence, the plants and their associates that are eased out of formerly optimal habitats (either through GCC, habitat fragmentation or human-mediated biotic invasions) will be those that are dependent on highly evolved associations with mycorrhizal fungi (e.g., Orchidaceae and other achlorphyllous plants). This includes low-buffering-capacity ecosystems on highly weathered or 
recalcitrant substrates (e.g., alpine ecosystems on crystalline substrates) most highly leached forested systems, many highly weather systems in the humid tropics and others (see section 4). Additionally, biodiversity hotspots, which once covered $12 \%$ of the land surface but today are restricted to $1.4 \%$, seem especially conducive to local or even general botanic extirpation because the majority of this loss is recent, and many of the species in these areas are already geographically restricted and threatened with extinction (see [416]).

\subsection{Hypotheses Revisited}

It is a legitimate criticism that the hypotheses that initiate this review are simplistic and indeed they are. However, we have used them in part to ground this review to the point that we can make some general projections. This is fraught with problems. The laboratory in which this review attends is the entire terrestrial World. The ecosystems specifically are not specific but are all ecosystems. The mycorrhizal fungi reflect, and likely more than we know, this massive diversity of soils and plants as they interact across landscapes and are impacted by a climate that gives evidence of changing physically and chemically. Still, there are the hypotheses and here we attempt to address them directly and with as little ambiguity as we can muster. There is caution here also to be exercised. The authors of this document are humbled by the vast diversity that interplays on this planet, and of course especially by the diversity of the symbioses we review in this document. To be sure, we are aware that there is much we do not know. The danger lies in that readers will take what we have found here as absolute truth. This attitude could not be further from our intentions and violates the methodology of science [417]. In our field, there are no absolutes. We deal with probability, risk and complexity. Still, basically, what do we claim to have uncovered? Here we rely directly on examination of null hypotheses. Succinctly, these are as follows:

1. Null Hypothesis: Mycorrhizal diversity did not evolve in response to changes in environmental drivers. We find lack of evidence to support the null hypothesis (see especially Table 2 ).

2. Null Hypothesis: Mycorrhizal diversity will not be modified by present changes in environmental drivers. We find lack of evidence to support the null hypothesis (see Figure 3 and Table 5).

3. Null Hypothesis: Mycorrhizal changes in response to drivers will in turn not modify plant, community, and ecosystem responses to the same. We find lack of evidence to support the null hypothesis (see Figure 5).

4. Null Hypothesis: Mycorrhizas will not continue to evolve in response to present and future changes in environmental factors. We find this null hypothesis is still an open question and dependent on rate and intensity of climate change.

\subsection{Other Recent Reviews}

Although we state our hypotheses or predictions above, there are other well-known and some recent reviews that to some degree confirm these, to some degree refute and likewise do neither. We have worked the findings of these reviewers into the discussion throughout our above analyses and 
discussion. However, readers will find these more comprehensive summaries enlightening and perhaps justification for continued research: Dighton and Jansen [165], Molina et al. [161], Bledsoe [418], Miller and Jastrow [419], Thomas et al. [420], Blankinship and Hungate [421], and Rillig [422].

\section{Acknowledgements}

SE Bellgard would like to acknowledge: John Aronis and Priscilla Cameron for assistance with locating critical references; Christine Bezar for editorial excellence; Clémence Aliaga for assistance with formulation of tables; critique by Philip H. Glass; and discussions with the late Ross Beever, Andrea Vannini, Elaine Davison and Thomas Jung; SE Williams would like to thank Robin Long for assistance with the technical aspects of manuscript synthesis. The authors would like to thank Ipek Kurtböke for the invitation to contribute this review.

Once again 'tis spring and the sun slides further north.

On beach crustacean skittle, waves go back and forth.

A gull swoops, catching crab pecks out its eyes.

Smell of salt, taste of death, gull lifts its head and cries.

Human forms bake in sun, their skins crispy and gold.

Wetting lips with sacred brew, melanomas unfold.

Salmon swims in adjacent bay its spawning bed seeks.

Later floats belly up its rotting flesh reeks.

But this is the way of salmon returning to the historic egg bed.

Securing the next generation, but then belly up and dead.

Similar cycles are repeated in forests, grasslands and sea.

Be they eukaryote, prokaryote, archae.

A body, a shell, a capsule, is borne, matures and dies.

It matters not the creature be dumb, instinctive or wise.

Lipids, sugars and proteins: building blocks all the same.

Bacteria, blue whale, give them any name.

Shrubs in the foothills, gazelle on the plain.

Fungi in the forest floor, hedgehogs in the lane.

Ancient single celled mysteries that metabolize methane.

Secretive, antennaed arthropods that skittle down the drain.

All the myriad creatures nurse a similar flame.

All constrained by similar rules, playing a similar game.

From Paradigm Tossed, an unpublished poem by S. E. Williams

\section{References and Notes}

1. Dighton, J. Fungi in Ecosystem Processes; Marcel Dekker: New York, NY, USA, 2003.

2. Brundrett, M.C. Co-evolution of roots and mycorrhizas of land plants. New Phytol. 2002, 154, 275-304.

3. Jeffrey, C. The origin and differentiation of the archegoniate land plants. Bot. Not. 1962, 115, 446-454. 
4. Malloch, D.W.; Pirozynski, K.A.; Raven, P.H. Ecological and evolutionary significance of mycorrhizal symbioses in vascular plants (a review). Proc. Nat. Acad. Sci USA 1980, 77, 2113-2118.

5. Pirozynski, K.A.; Malloch, D.W. The origin of land plants: a matter of mycotrophism. BioSystems 1983, 6, 153-164.

6. Frey-Klett, P.; Garbaye, J.; Tarkka, M. Mycorrhiza helper bacteria revisited. New Phytol. 2007, $176,22-36$.

7. Bharadwaj, D.P.; Lundquist, P.-O.; Alström, S. Arbuscular mycorrhizal fungal spore-associated bacteria affect mycorrhizal colonization, plant growth and potato pathogens. Soil Biol. Biochem. 2008, 40, 2494-2501.

8. Kataoka, R.; Taniguchi, T.; Futai, K. Fungal selectivity of two mycorrhiza helper bacteria on five mycorrhizal fungi associated with Pinus thunbergii. World J. Microbiol. Biotechnol. 2009, 25, 1815-1819.

9. Miller, S.L. Functional diversity in fungi. Can. J. Bot. 1995, 73, S50-S57.

10. Leakey, R.; Lewin, R. The Sixth Extinction; Doubleday: New York, NY, USA, 1995.

11. Berch, S.M.; Warner, B.G. Fossil vesicular-arbuscular mycorrhizal fungi: two Glomus species (Endogonaceae, Zygomycetes) from late Quaternary deposits in Ontario, Canada. Rev. Palaeobot. Palynol. 1985, 45, 229-237.

12. Chase, M.W. The origin and biogeography of Orchidaceae. In Genera Orchidacearum, Vol. 2. Orchidoideae (Part 1); Pridgeon, A.M., Cribb, P.J., Chase, M.W., Rasmussen, F., Eds.; Oxford University Press: Oxford, UK, 2001; pp. 1-5.

13. Hibbett, D.S.; Matheny, P.B. The relative age of ectomycorrhizal mushrooms and their plant hosts estimated using Bayesian relaxed molecular clock analyses. BMC Biol. 2009, 7, 13.

14. Nixon, K.C.; Crepet, W.L. Late Cretaceous fossil flowers of ericalean affinity. Am. J. Bot. 1993, 80, 616-623.

15. Cullings, K.W. Single phylogenetic origin of ericoid mycorrhizae within the Ericaceae. Can. J. Bot. 1996, 74, 1896-1909.

16. Cairney, J.W.G. Evolution of mycorrhizal systems. Naturwissenschaften 2000, 87, 467-475.

17. Hibbett, D.S.; Grimaldi, D.; Donoghue, M.J. Fossil mushrooms from Cretaceous and Miocene ambers and the evolution of homobasidiomycetes. Am. J. Bot. 1997, 84, 981-991.

18. Stubblefield, S.P.; Taylor, T.N. Recent advances in paleomycology. New Phytol. 1988, 108, 3-25.

19. Berbee, M.L.; Taylor, J.W. Dating the evolutionary radiations of the true fungi. Can. J. Bot. 1993, 71, 1114-1127.

20. Phipps, C.J.; Taylor, T.N. Mixed arbuscular mycorrhizae from the Triassic of Antarctica. Mycologia 1996, 88, 707-714.

21. Dennis, R.L. A middle Pennsylvanian basidiomycete mycelium with clamp connections. Mycologia 1970, 6, 578-584.

22. Stubblefield, S.P.; Taylor, T.N.; Miller, C.E.; Cole, G.T. Studies of Carboniferous fungi. II. The structure and organization of Mycocarpon, Sprorocarpon, Dubiocarpon and Coleocarpon (Ascomycotina). Am. J. Bot. 1983, 70, 1482-1498. 
23. Taylor, T.N.; Remy, W.; Haas, H.; Kerp, H. Fossil arbuscular mycorrhizae from the Early Devonian. Mycologia 1995, 87, 560-573.

24. Taylor, T.N.; Krings, M. Fossil microorganisms and land plants: Associations and interactions. Symbiosis 2005, 40, 119-135.

25. Krings, M.; Kerp, H.; Hass, H.; Taylor, T.N.; Doztler, N. A filamentous cyanobacterium showing structured colonial growth from the Early Devonian Rhynie chert. Rev. Paleobot. Palynol. 2007, $146,265-276$.

26. Dotzler, N.; Krings, M.; Agerer, R.; Galtier, J.; Taylor, T.N. Combresomyces cornifer gen. sp. nov., an endophytic peronosporomycete in Lepidodendron from the Carboniferous of central France. Mycol. Res. 2008, 112, 1107-1114.

27. Sherwood-Pike, M.A.; Gray, J. Silurian fungal remains: probable records of the class Ascomycetes. Lethaia 1985, 18, 1-20.

28. Simon, L.; Bousquet, J.; Levesque, R.; Lalaonde, M. Origin and diversification of endomycorrhizal fungi and coincidence with vascular land plants. Nature 1993, 363, 67-69.

29. Pirozynski, K.A.; Dalpé, Y. Geological history of Glomaceae, with particular reference to mycorrhizal symbiosis. Symbiosis 1989, 7, 1-36.

30. Kenrick, P.; Crane, P.R. The origin and early evolution of plants on land. Nature 1997, 389, 33-39.

31. Reddecker, D.; Kodner, R.; Graham, L.E. Glomalean fungi from the Ordivician. Science 2000, 298, 1920-1921.

32. Wang, D.Y.-C.; Kumar, S.; Hedges, S.B. Divergence time estimates for the early history of animal phyla and the origins of animals, plants and fungi. Proc. R. Soc. Lond. B 1999, 266, 163-171.

33. Heckman, D.S.; Geiser, D.M.; Eidell, B.R.; Stauffer, R.L.; Kardos, N.; Hedges, S.B. Molecular evidence for the early colonisation of land by fungi and plants. Science 2001, 293, 1129-1133.

34. Johnson, N.C.; Graham, J.H.; Smith, F.A. Functioning of mycorrhizal associations along the mutualism-parasitism continuum. New Phytol. 1997, 135, 575-586.

35. Smith, S.E.; Read, D.J. Mycorrhizal Symbiosis, 3rd ed.; Academic Press: Amsterdam, The Netherlands and Boston, MA, USA, 2008.

36. McGee, P.A. Mycorrhizal associations of plant species in a semi-arid community. Aust. J. Bot. 1986, 34, 585-593.

37. Bellgard, S.E. Mycorrhizal associations of plant species in Hawkesbury Sandstone vegetation. Aust. J. Bot. 1991, 39, 357-364.

38. Imhof, S. Arbuscular, ecto-related, orchid myciorrhizas - three independent structural lineages towards mycoheterotrophy: implications for classifications. Mycorrhiza 2009, 19, 357-363.

39. Findlay, R.D. Mycorrhizal symbiosis: myths, misconceptions, new perspectives and future research priorities. Mycologist 2005, 19, 90-95.

40. Harley, J.L.; Smith, S.E. Mycorrhizal Symbiosis; Academic Press: London,UK, 1983.

41. Selosse, M.-A.; Setaro, S.; Glatard, F.; Richard, R.; Urcelay, C.; Weiß, M. Sebacinales are common mycorrhizal associates of Ericaceae. New Phytol. 2007, 174, 864-878.

42. Martin, J-F. Sur la mycorhization de Monotropa hypopitys par quelques espècies du genre Tricholoma. Bull de la Société Mycologique de France 1985, 101, 249-256. 
43. Arditti, J. Mycorrhiza. In Fundamentals of Orchid Biology; John Wiley: New York, NY, USA, 1992; Chapter 9, pp. 419-449.

44. Arditti, J. Chapter Two: Classification and naming of orchids. Fundamentals of Orchid Biology; John Wiley: New York, NY, USA, 1992; Chapter 2, pp. 55-101.

45. Dressler, R.L. The Orchids: Natural History and Classification, 2nd ed.; Harvard University Press: Cambridge, MA, USA, 1990.

46. Wolken, P.M.; Hull-Sieg, C.; Williams, S.E. Quantifying suitable habitat of the threatened western prairie fringed orchid. J. Range Manage. 2001, 54, 611-616.

47. Rosenthal, S. Communities, populations and individuals of arbuscular mycorrhizal fungi. New Phytol. 2008, 178, 253-266.

48. Tedersoo, L.; May, T.W.; Smith, M.E. Ectomycorrhizal lifestyle in fungi: global diversity, distribution, and evolution of phylogenetic lineages. Mycorrhiza 2010, 20, 217-263.

49. Fitter, A.H. Costs and benefits of mycorrhizas: implications for functioning under natural conditions. Experientia 1991, 47, 350-355.

50. Allen, M.F.; Smith, W.K.; Moore, T.S.; Christensen, M. Comparative water relations and photosynthesis of mycorrhizal and non-mycorrhizal Bouteloua gracilis H.B.K. Lag Ex Steud. New Phytol. 1981, 88, 683-693.

51. Stahl, P.D.; Schuman, G.E.; Frost, S.M.; Williams, S.E. Interaction of arbuscular mycorrhiza and seedling age on water stress tolerance of Artemisia tridentata ssp. wyomingensis. Soil Sci. Soc. Am. J. 1998, 62, 1309-1313.

52. Leake, J.R.; Read, D.J. Mycorrhizal fungi in terrestrial habitats. In The Mycota IV. Environmental and Microbial Relationships; Wicklow, D.T., Söderström, B., Eds.; Springer-Verlag: New York, NY, USA, 1997.

53. Rogers, R.D.; Williams, S.E. Effect of vesicular-arbuscular mycorrhizae on plant uptake of cesium and cobalt. Soil Biol. Biochem. 1986, 18, 371-376.

54. Repetto, O.; Bestell-Corre, G.; Dumas-Gaudot, E.; Berta, G.; Gianinazzi-Pearson, V.; Gianinazzi, S. Targeted proteomics to identify cadmium-induced protein modifications in Glomus mosseae-inoculated pea root. New Phytol. 2003, 157, 555-567.

55. Cromack, K., Jr.; Caldwell, B.A. The role of fungi in litter decomposition and nutrient cycling. In The Fungal Community: Its Organization and Role in the Ecosystem, 2nd ed.; Carroll, G.C., Wicklow, D.T., Eds.; Marcel Dekker: New York, NY, USA, 1992; pp. 653-668.

56. Marx, D.H. The influence of ectotrophic mycorrhizal fungi on the resistance of pine roots to pathogenic infections. I. Antagonsim of mycorrhizal fungi to root pathogenic fungi and soil bacteria. Phytopathology 1969, 59, 153-163.

57. Marx, D.H. The influence of ectotrophic mycorrhizal fungi on the resistance of pine roots to pathogenic infections. II. Resistance of mycorrhizae to infections by vegetative mycelium of Phtophthora cinnamon. Phytopathology 1970, 60, 1472-1473.

58. Allen, M.F. The Ecology of Mycorrhizae; Cambridge University Press: Cambridge, UK, 1991.

59. Read, D.J. Mycorrhizas in ecosystems. Experientia 1991, 47, 376-391.

60. Read, D.J. Mycorrhizas in ecosystems - Nature's responses to the Law of the Minimum. In Frontiers in Mycology; Hawkesworth, D.L., Ed.; Frontier Journal Series: Lausanne, Switzerland, 1991; pp. 1010-1130. 
61. Allison, V.J.; Miller. R.M.; Jastrow, J.D.; Matamala, R.; Zak, D.R. Changes in soil microbial community structure in a tallgrass prairie chronosequence. Soil Sci. Soc. Am. J. 2005, 69, 1412-1421.

62. Newsham, K.K.; Upson, R.; Read, D.J. Mycorrhizas and dark septate root endophytes in polar regions. Fungal Ecol. 2009, 2, 10-20.

63. Vogt, K.A.; Grier, C.C.; Meier, C.E.; Edmonds, R.L. Mycorrhizal role in net primary production an in nutrient cycling in Abes amabilis ecosystems in Western Washington. Ecology 1982, 63, 370-380.

64. Dighton, J. Acquisition of nutrients from organic resources by mycorrhizal autotrophic plants. Experientia 1991, 47, 362-369.

65. van Schöll, L.; Kuyper, T.W.; Smiths, M.M.; Landerweert, R.; Hoffland, E.; van Breeman, N. Rock-eating mycorrhizas: their role in plant nutrition and biogeochemical cycles. Plant Soil 2008, 303, 35-47.

66. Anderson, P.K.; Cunningham, A.A.; Patel, N.G.; Morales, F.J.; Epstein, P.R.; Daszak, P. Emerging infectious diseases of plants: pathogen pollution, climate change and agrotechnology drivers. Trends Ecol. Evol. 2004, 19, 535-544.

67. Loo, J.A. Ecological impacts of non-indigenous invasive fungi as forest pathogens. Biol. Invas. 2009, 11, 81-96.

68. Desprez-Loustau, R.C.; Buee, M.; Courtecuisee, R.; Garbaye, J.; Suffert, F.; Sache, I.; Rizzo, D.M. The fungal dimension of biological invasions. Trends Ecol. Evol. 2007, 22, 472-480

69. Cazares, E.; Luoma, D.L.; Amaranthus, M.P.; Chambers, C.L.; Lehmkuhl, J.F. Interaction of fungal sporocarp production with small mammal abundance and diet in Douglas-Fir stands in southern Cascades Ranges. NW Sci. 1999, 73, Special Issue, 64-76.

70. Claridge, A.W.; Trappe, J.M. Sporocarp mycophagy: nutritional, behavioral, evolutionary and physiological aspects. In The Fungal Community Its Organization and Role in the Ecosystem, 3rd ed.; Dighton, J.D., White, J.F., Oudemans, P., Eds.; CRC Press: Boca Raton, FL, USA, 2005; pp. 599-611.

71. Hanson, A.M.; Hodge, K.T.; Porter, L.M. Mycophagy among primates. Mycologist 2003, 17, 6-10.

72. Malajczuk, N.; Trappe, J.M.; Molina, R. Interrelationships among some ectomycorrhizal trees, hypogenous fungi and small mammals: Western Australian and northwestern American parallels. Aust. J. Ecol. 1987, 12, 53-55.

73. Frank, J.L.; Barry, S.; Southworth, D. Mammal mycophagy and dispersal of mycorrhizal inoculums in White Oaks Woodlands. NW Sci. 2006, 80, 264-273.

74. Nuñez, M.A.; Horton, T.R.; Simberloff, D. Lack of belowground mutualisms hinders Pinaceae invasions. Ecology 2009, 90, 2352-2359.

75. Gerdemann, J.W.; Trappe, J.M. The Endogonaceae in the Pacific Northwest. Mycologia Memoir 1974, 5, 1-76.

76. McIlven, W.D.; Cole, H. Spore dispersal by worms, ants, wasps and birds. Can. J. Bot. 1976, 54, 1486-1489. 
77. Ponder, F., Jr. Rabbits And Grasshoppers: Vectors Of Endomycorrhizal Fungi On New Coal Mine Spoil; Research note NC-250; North central forest experiment station: St. Paul, MN, USA, 1980.

78. Quammen, D. The Reluctant Mr. Darwin: An Intimate Portrait of Charles Darwin and the Making of His Theory of Evolution; Atlas Books and WW Norton: New York, NY, USA, 2006.

79. Tylianakis, J.M.; Didham, R.K.; Bascompte, J.; Wardle, D.A. Global change and species interactions in terrestrial ecosytems. Ecol. Lett. 2008, 11, 1351-1363.

80. Houghton, R.A. The global carbon cycle. (letter to the editor). Science 1988, 241, 1736.

81. Vu, J.C.V.; Allen, L.H., Jr. Crop plant responses to rising $\mathrm{CO}_{2}$ and climate change. In Handbook of Plant and Crop Physiology, 2nd ed.; Pessarakli, M., Ed.; Marcel Dekker: New York, NY, USA, 2002; pp. 35-55.

82. Betts, R.A.; Cox, P.M.; Lee, S.E.; Woodward, F.I. Contrasting physiological and structural vegetation feedbacks in climate change simulations. Nature 1997, 387, 796-799.

83. World Meteorological Organization. WMO Statement on the Status of the Global Climate in 2002; WMO Press release No. 684; WMO: Geneva, Switzerland, 2002.

84. Climate Change 2001: The Scientific Basis; Houghton, J.T., Ding, Y., Griggs, D.J., Noguer, M., van der Linden, P.J., Dai, X., Maskell, K., Johnson, C.A., Eds.; Cambridge University Press: Cambridge, UK, 2001.

85. Roots, E.F. Climate change: high-latitude regions. Clim. Change 1989, 15, 223-253.

86. Thuiller, W.; Lavorel, S.; Araújo, M.B.; Sykes, M.T.; Prentice, I.C. Climate change threats to plant diversity in Europe. Proc. Nat. Acad. Sci. USA 2004, 102, 8245-8250.

87. Climate Change 2007: the Physical Science Basis; Solomon, S., Qin, D., Manning, M., Marquis, M., Averyt, K., Tignor, M.M.B., Miller, H.L., Jr., Chen, Z., Eds.; IPCC: Geneva, Switzerland, 2007.

88. Walther, G.-R. Plants in a warmer world. Perspect. Plant Ecol. Evol. Syst. 2003, 6, 169-185.

89. Haeberli, W.; Beniston, M. Climate change and its impacts on glaciers and permafrost in the Alps. Ambio 1998, 27, 258-265.

90. Naftz, D.L.; Susong, D.D.; Schuster, P.F.; Cecil, L.D.; Dettinger, M.D.; Michel, R.L.; Kendall, C. Ice core evidence of rapid air temperature increases since 1960 in alpine areas of the Wind River Range, Wyoming, United States. J. Geophys. Res. 2002, 107, X-1-X-15.

91. Mikhalenko, V.N. Changes in Eurasian glaciation during the past century: glacier mass balance and ice core evidence. Ann. Glaciol. 1997, 24, 283-287.

92. Hileman, B. Case grows for climate change. Chem. Eng. News, 1999, 77, 16-23.

93. Sin'kevich, S.A. Climate warming in the twentieth century as reflected in Svalbard ice cores: glaciers-ocean-atmosphere: interactions. IAHS Publ. 1991, 208, 257-267.

94. Trenberth, K.E.; Dai, A.; Rasmussen, R.M.; Parsons, D.B. The changing character of precipitation. Am. Meteorol. Soc. 2003, September, 1205-1217.

95. Fitter, A.H.; Heinmeyer, A.; Staddon, P.L. The impact of elevated CO2 and global climate change on arbuscular mycorrhizas: a mycocentric approach. New Phytol. 2000, 147, 179-187.

96. Vitousek, P.M.; Aber, J.D.; Howarth, R.W.; Likens, G.E.; Matson, P.A.; Schindler, D.W.; Schlesinger, W.H.; Tilman, G.D. Human alteration to the global nitrogen cycle: causes and consequences. Ecol. Appl. 1997, 7, 737-750. 
97. Egerton-Warburton, L.M.; Johnson, N.C.; Allen, E.B. Mycorrhizal community dynamics following nitrogen fertilisation: A cross-site test in five grasslands. Ecol. Monogr. 2007, 77, 527-544.

98. Tétreault, J.P.; Bernier, B.; Fortin, J.A. Nitrogen fertilization and mycorrhizae of balsam fir seedlings in natural stands. Nat. Can. 1978, 105, 461-466.

99. Slankis, V. Soil factors influencing formation of mycorrhizae. Annu. Rev. Phytopathol. 1974, 12, 437-457.

100. Hetrick, B.A.D. Ecology of VA mycorrhizal fungi. In VA Mycorrhiza; Powell, C.L., Bagyaraj, D.J., Eds.; CRC Press: Boca Raton, FL, USA, 1984; pp. 35-56.

101. Schmidt, S.K.; Lipson, D.A.; Ley, R.E.; Fisk, M.C.; West, A.E. Impacts of chronic nitrogen additions vary seasonally and by microbial function group in tundra soils. Biogeochemistry 2004, 69, 1-17.

102. Einsenlord, S.D.; Zak, D.R. Simulated atmospheric nitrogen deposition alters actinobacterial community composition in forest soils. Soil Sci. Soc. Am. J. 2010, 74, 1157-1166.

103. Naftz, D.L.; Schuster, P.F.; Reddy, M.M. Assessment of spatial variability of major-ion concentrations and del oxygen-18 values in surface snow, Upper Fremont Glacier, Wyoming, U.S.A. Nordic Hydrol. 1994, 25, 371-388.

104. Burns, D.A. Atmospheric nitrogen deposition in the Rocky Mountains of Colorado and southern Wyoming - a review and new analysis of past study results. Atmos. Environ. 2003, 37, 921-932.

105. Baron, J.S.; Ojima, D.S.; Holland, E.A.; Parton, W.J. Analysis of nitrogen saturation potential in Rocky Mountain tundra and forest: Implications for aquatic systems. Biogeochemistry 1994, 27, 61-82.

106. Palmer, K.M.; Stanton, N.L.; Ben-David, M.; Mionczynski, J.; Williams, S.E. Are pika exposed to and affected by selenium deficiency? J. Wildl. Dis. 2007, 43, 475-484.

107. Taylor, T.N. The origin of land plants, a paleobotanical perspective. Taxon 1982, 31, 155-177.

108. Warcup, J.H.; McGee, P.A. The mycorrhizal associations of some Australian Asteraceae. New Phytol. 1983, 95, 667-672.

109. Khan, A.G. Occurrence and importance of mycorrhizae in aquatic trees of New South Wales, Australia. Mycorrhiza 1993, 3, 31-38.

110. Williams, S.E. Vesicular-arbuscular mycorrhizae associated with actinomycete nodulated shrubs Cercocarpus montanus Raf. and Purshia tridentata (Pursh.) D.C. Bot. Gaz. 1979, 140, S115-S119.

111. Kurtböke, D.I.; Neller, R.J.; Bellgard, S.E. Mesophyllic actinomyctes in the natural and reconstructed sand dune vegetation of Fraser Island, Australia. Microb. Ecol. 2008, 54, 332-240.

112. Herrmann, W.M. Tripartite Symbiotic Associations in Nitrogen-Fixing Plants of Mount Changbai Nature Reserve in Northeast China; Unpublished Doctorial Dissertation; Faculty of Biology (Botany), Ludwig Maximilian University: Munich, Germany, 1994.

113. Ames, R.N. Chitin decomposing actinomycetes associated with VAM fungus from a calcareous soil. New Phytol. 1989, 111, 67-71.

114. Sheehan, P.M. The late Ordivician mass extinction. Ann. Rev. Earth Pan. Sci. 2001, 29, 331-364.

115. Twitchett, R.J. The paleoclimatology, palaeoecology, and paleoenvironmental analysis of mass extinction events. Paleogeog. Paleoclimatol. Paleoecol. 2006, 232, 190-213. 
116. Benton, M.J.; Twitchett, R.J. How to (almost) kill all life: the end-Permian extinction event. Trends Ecol. Evol. 2003, 18, 358-365.

117. Mayhew, P.J.; Jenkins, G.B.; Jenkins, T.G. A long term association between global temperature and biodiversity, origination and extinction in the fossil record. Proc. $R$ Soc. B 2008, 275, 47-53.

118. Gorham, E.; Vitousek, P.M.; Reiners, W.A. The regulation of element budgets over the course of terrestrial ecosystem succession. Ann. Rev. Ecol. Syst. 1979, 10, 53-84.

119. Lewis, D.H. Mutualistic symbioses in the origin and evolution of land plants. In Symbiosis as a Source of Evolutionary Innovation; Margulis, L., Fester, R., Eds.; MIT Press: Cambridge, MA, USA, 1987; pp. 161-178.

120. Jackson, S.T.; Weng, C. Late Quaternary extinction of a tree species in eastern North America. Proc. Nat. Acad. Sci. USA 1999, 96, 13847-13852.

121. Brundrett, M.C. Diversity and classifications of mycorrhizal associations. Biol. Rev. 2004, 79, 473-495.

122. Kasting, J.F.; Ono, S. Palaeoclimates: the first two billion years. Phil. Trans. R. Soc. Brit. 2006, 361, 917-929.

123. Retallack, G.; Grandstaff, D.E.; Kimberley, M.M. The promise and problems of Precambrian paleosols. Episodes 1984, 7, 8-12.

124. Swarts, N.D.; Dixon, K.W. Terrestrial orchid conservation in the age of extinctions. Ann. Bot. 2009, 104, 543-556.

125. Mangan, S.A.; Adler, G.H. Consumption of arbuscular mycorrhizal fungi by terrestrial and arboreal small mammals in a Panamanian cloud forest. J. Mammol. 2000, 81, 563-570.

126. Lilleskov, E.A.; Bruns, T.B. Spore dispersal of a resupinate ectomycorrhizal fungus, Tomentella sublilacina, via soil food webs. Mycologia 2005, 97, 762-769.

127. Bell, D.T.; Hopkins, A.J.M.; Pate, J.S. Fire in the Kwongan. In Kwongan Plant Life of the Sandplain; Pate, J.S, Beard, J.S., Eds.; University of Western Australia Press: Nedlands, Australia, 1984; pp. 178-204.

128. Johnson, C.N. Interactions between fire, mycophagous mammals, and dispersal of ectomycorrhizal fungi in Eucalyptus forests. Oecologia 1995, 104, 1432-1439.

129. Goodwin, J. The role of mycorrhizal fungi in competitive interactions among native bunchgrasses and alien weeds: A review and synthesis. NW Sci. 1992, 66, 251-260.

130. Janos, D.P. Vesicular arbuslcuar mycorrhizae affect lowland tropical rainforest plant growth. Ecology 1980, 61, 151-162.

131. Pendelton, R.L.; Smith, B.N. Vesicular-arbuscular mycorrhizae of weedy and colonizer plant species at disturbed sites in Utah. Oecologia 1983, 59, 296-301.

132. Beckstead, J.; Meyer, S.E.; Allen, P.S. Bromus tectorum seed germination: between-population and between-year variation. Can. J. Bot. 1996, 74, 875-882.

133. Swaty, R.L.; Keckert, R.J.; Whitham, T.G.; Gehring, C.A. Ectomycorrhizal abundance and community composition shifts with drought: prediction from tree rings. Ecology 2004, 85, 1072-1084.

134. Vitousek, P.M.; D’Antonio, C.M.; Loope, L.L.; Westbrooks, R. Biological invasions as global environmental change. Am. Sci. 1996, 84, 468-478. 
135. Kriticos, D.J.; Suthers, R.W.; Adkins, S.W.; Maywald, G.F. Climate change and the potential distribution of Acacia nitolica ssp. indica in Australia. J. Appl. Ecol. 2003, 40, 111-124.

136. Johnson, N.C.; Rowland, D.L.; Corkidi, L.; Egerton-Warburton, L.M.; Allen, E.B. Nitrogen enrichment alters mycorrhizal allocation at five mesic to semiarid grasslands. Ecology 2003, 84, 1895-1908.

137. Johnson, N.C.; Wolf, J.; Koch, G.W. Interactions among mycorrhizae, atmospheric $\mathrm{CO}_{2}$ and soil $\mathrm{N}$ impact plant community composition. Ecol. Lett. 2003, 6, 532-540.

138. Cullings, K.W.; Vogler, D.R.; Parker, V.T.; Makhija, S. Defoliation effects on the ectomycorrhizal community of a mixed Pinus contorta/Picea engelmannii stand in Yellowstone Park. Oecologia 2001, 127, 533-539.

139. White, J.F., Jr, Taylor, T.N. Triassic fungi with suggested affinities to the Endogonales (Zygomycotina). Rev. Palaeobot. Palynol. 1989, 61, 53-61.

140. Sepkoski, D.M.; Raup, J.J., Jr. Periodic extinctions of families and genera. Science 1986, 231, 833-836.

141. Agerer, R. Anatomical charactersitcs of indentified ectomycorrhizas: an attempt towards a natural classification. In Mycorrhiza; Varma, A., Hock, B., Eds.; Springer-Verlag: Berlin, Germany, 1995; pp. 685-734.

142. Ashford, A.E.; Allaway, W.G. A sheathing mycorrhiza in Pisonia grandis R.Br. (Nyctaginanceae) with development of transfer cells rather than a hartig net. New Phytol. 1982, 90, 511-519.

143. Setaro, S.; Oberwinkler, F.; Kottke, I. Anatomy and ultrastructure of mycorrhizal associations of neotropical Ericaceae. Mycol. Progr. 2006, 5, 243-254.

144. Duddridge, J.A.; Read, D.J. An ultrastructural analysis of the development of mycorrhizas in Monotropa hypopitys. New Phytol. 1982, 92, 203-214.

145. Trappe, J.M. Phylogenetic and ecologic aspects of mycotrophy in the angiosperms from an evolutionary standpoint. In Ecophysiology in VA Mychorrizal Plants; Safir, G.R., Ed.; CRC Press: Boca Raton, FL, USA, 1987; pp. 2-25.

146. Hibbett, D.S.; Binder, M.; Bischoff, J.F.; Blackwell, M.; Cannon, P.F.; Eriksson, O.E.; Huhndorf, S.; James, T.; Kirk, P.M.; Lücking, R.; Lumbsch, T.; Lutzoni, F.; Matheny, P.B.; Mclaughlin, D.J.; Powell, M.J.; Redhead, S.; Schoch, C.L.; Spatafora, J.W.; Stalpers, J.A.; Vilgalys, R.; Aime, M.C.; Aptroot, A.; Bauer, R.; Begerow, D.; Benny, G.L.; Castlebury, L.A.; Crous, P.W.; Dai, Y.-C.; Gams, W.; Geiser, W.M.; Griffith, G.W.; Gueidan, C.; Hawksworth, D.L.; Hestmark, G.; Hosaka, K.; Humber, R.A.; Hyde, K.; Ironside, J.E.; Kõljalg, U.; Kurtzman, C.P.; Larsson, K.-H.; Lichtwardt, R.; Longcore, J.; Miądlikowska, J.; Miller, A.; Moncalvo, J.-M.; Mozley-Standridge, S.; Oberwinkler, F.; Parmasto, E.; Reeb, V.; Rogers, J.D.; Roux, C.; Ryvarden, L.; Sampaio, J.P.; Schüßler, A.; Sugiyama, J.; Thorn, R.G.; Tibell, L.; Untereiner, W.A.; Walker, C.; Wang, Z.; Weir, A.; Weiß, M.; White, M.M.; Winka, K.; Yao, Y.-J.; Zhang, N. A higher-level phylogenetic classification of the Fungi. Mycol. Res. 2007, 111, 509-547.

147. Schüßler, A.; Swarzott, D.; Walker, C. A new fungal phylum, the Glomeromycota: phylogeny and evolution. Mycol. Res. 2001, 105, 1413-1421.

148. Morton, J.B. Evolutionary relationships among arbuscular mycorrhizal fungi in the Endogonaceae. Mycologia 1990, 82, 192-207. 
149. McLean, C.B.; Cunnington, J.H.; Lawrie, A.C. Molecular diversity within and between ericoid endophytes from the Ericaceae and Epacridaceae. New Phytol. 1999, 144, 351-358.

150. Sharples, J.M.; Chambers, S.M.; Meharg, A.A.; Cairney, J.W.G. Genetic diversity of root-associated endophytes from Calluna vulgaris at contrasting field site. New Phytol. 2000, 148, 153-162.

151. Taylor, T.N.; Osborn, J.M. The importance of fungi in shaping the palaeoecosystem. Rev. Paleobot. Palynol. 1996, 90, 249-262.

152. Kenrick, P.; Crane, P.R. The origin and early evolution of plants on land. Nature 1989, 389, 33-39.

153. Ramirez, S.R.; Gravendeel, B.; Singer, R.B.; Marshall, C.R.; Pierce, N.E. Dating the origin of the Orchidaceae from a fossil orchid and its pollinator. Nature 2007, 448, 1042-1045.

154. Currah, R.S.; Zelmer, C.D.; Hambleton, S.; Richardson, K.A. Fungi from orchid mycorrhizas. In Orchid Biology: Reviews and Perspectives VII; Arditti, J., Pridgeon, A.M. Eds.; Kluwer: Dordrecht, The Netherlands, 1997; pp. 117-170.

155. Warcup, J.H.; Talbot, P.H. Perfect states of Rhizoctonias. New Phytol. 1980, 86, 267-272.

156. Arditti, J.; Ernst, R. Reciprocal movement of substances between orchids and mycorrhizae. In Proceedings of the Seventh World Orchid Conference 1972; Medellin, Colombia, 1974; pp. 299-307.

157. Hadley, G. Orchid mycorrhiza: In Orchid Biology: Reviews and Perspectives; Arditti, J., Ed.; Cornell University Press: Ithaca, NY, USA, 1982; pp. 83-118.

158. Clements, M.A. The germination of Australian orchid seed. In Proceedings of the Orchid Symposium, 13th International Botanical Congress, Sydney, Australia, 21-28 August 1981; Lawler, L., Kerr, R.D., Eds.; Orchid Society of New South Wales: Sydney, Australia, 1981.

159.Batty, A.L.; Dixon, K.W.; Brundrett, M.C.; Sivasithamparam, K. Orchid conservation and mycorrhizal associations. In Microorganisms in Plant Conservation and Biodiversity; Sivisithamparam, K., Dixon, K.W., Barrett, R.L., Eds.; Kluwer: Dordrecht, The Netherlands, 2002; pp. 195-226.

160. Dixon, K.W.; Sivasithamparam, K.; Read, D.J. Ericoid mycorrhizas in plant communities. In Microorganisms in Plant Conservation and Biodiversity; Sivasithamparam, K., Dixon, K.W., Barret, R.L., Eds.; Kluwer, Dordrecht, The Netherlands, 2002; pp. 227-240.

161. Molina, R.; Massicotte, H.; Trappe, J.M. Specificity phenomena in mycorrhizal symbioses: Community-ecological consequences and practical implications. In Mycorrhizal Functioning: An Integrative Plant-Fungal Process; Allen, M.F., Ed.; Chapman and Hall: London, UK, 1992; pp. 357-423.

162. Friese, C.F.; Morris, S.J.; Allen, M.F. Disturbance in natural ecosystems: Scaling from fungal diversity to ecosystem functioning. In The Mycota IV: Environmental and Microbial Relationships; Wicklow, D.T., Soderstrom, B., Eds.; Springer Verlag: Berlin, Germany, 1997; pp. 47-63

163. Van der Putten, W.H.; Macel, M.; Visser, M.E. Predicting species distributions and abundance responses to climate change: why it is essential to include biotic interactions across trophic levels. Phil. Trans. Brit. R. Soc. B. 2010, 365, 2025-2034. 
164. Emanuel, W.R.; Shugart, H.H.; Stevenson, M.P. Climate change and the broad-scale distribution of terrestrial ecosystem complexes. Clim. Change 1985, 7, 29-43.

165. Dighton, J.; Jansen, A. Atmospheric pollutants and ectomycorrhizas, more questions than answers. Environ. Pollut. 1991, 73, 179-204.

166. Staddon, P.L.; Heinemeyer, A.; Fitter, A.H. Mycorrhizas and global environmental climate change: research at different scales. Plant Soil 2002, 244, 253-261.

167. Smith, S.D.; Strain, B.R.; Sharkey, T.D. Effect of CO2 enrichment on four grass species from the Great Basin grasses. Funct. Ecol. 1987, 1, 139-143.

168. Reekie, E.G.; Bazzaz, F.A. Competition and patterns of resource use among seedlings of five tropical trees grown at ambient and elevated $\mathrm{CO}_{2}$. Oecologia 1989, 79, 212-222.

169. Bazzaz, F.A. The response of natural ecosystems to rising global $\mathrm{CO}_{2}$ levels. Annu. Rev. Ecol. Syst. 1990, 21, 176-196.

170. Bazzaz, F.A.; Williams, W.E. Atmospheric $\mathrm{CO}_{2}$ concentrations within the canopy of as mixed forest: Implications for seedling growth. Ecology 1990, 72, 12-16.

171. Parton, W.G.; Scurlock, J.M.C.; Ojima, D.S.; Schimel, D.S.; Hall, D.O.; Coughenour, M.B.; Garcia Moya, E.; Gilmanov, T.G.; Kamnalrut, A.; Kinyamario, J.I.; Kirchner, T.; Kittel, T.G.; Menaut, J.-C.; Sala, O.E.; Scholes, R.J.; van Veen, J.A. Impact of climate change on grasslands production and soil carbon worldwide. Global Change Biol. 1995, 1, 13-22.

172. Luo, Y.; Wan, S.; Hui, F.; Wallace, L.L. Acclimatization of soil respiration to warming in tall grass prairie. Nature 2001, 413, 622-625.

173. Tolley, L.C.; Strain, B.R. Effects of $\mathrm{CO}_{2}$ enrichment and water stress on Liquidambar styrciflua and Pinus taeda seedlings. Oecologia 1985, 65, 166-172.

174. Poorter, H. Interspecific variation in growth response of plants to elevated $\mathrm{CO}_{2}$ concentration. Vegetatio 1993, 104-105, 77-97.

175. Rogers, H.H.; Prior, S.A.; Runion, G.B.; Mitchell, R.J. Root to shoot ratio of crops as influenced by $\mathrm{CO}_{2}$. Plant Soil 1996, 187, 229-248.

176. Reich, P.B.; Knops, J.; Tilman, D.; Craine, J.; Ellsworth, D.; Tjoleker, M.; Lee, T.; Wedin, D.; Naeem, S.; Bahauddin, D.; Hendrey, G.; Jose., S.; Wrage, K.; Goth, J.; Bengston., W. Plant diversity enhances ecosystem responses to elevated $\mathrm{CO}_{2}$ and nitrogen deposition. Nature 2001, 410, 809-810.

177. Williams, W.E.; Garbutt, K.; Bazzaz, F.A.; Vitousek, P.M. The response of plants to elevated $\mathrm{CO}_{2}$. IV Two deciduous-forest tree communities. Oecologia 1986, 69, 454-459.

178. Sellers, P.J.; Bounoua, L.; Collatz, G.J.; Randall, D.A.; Dazlich, D.A.; Los, S.O.; Berry, J.A.; Fung, I.; Tucker, C.J.; Field, C.B.; Jensen, T.G. Comparison of radiative and physiological effects of doubled atmospheric $\mathrm{CO}_{2}$ on climate. Science 1996, 271, 1402-1406.

179. Bunce, J.A. Responses of stomatal conductance to light humidity and temperature in winter wheat and barley grown at three concentrations of carbon dioxide in the field. Global Change Biol. 2000, 6, 371-382.

180. Augé, R.M. Water relations, drought and vesicular-arbuscular mycorrhizal symbiosis. Mycorrhiza 2001, 11, 3-42.

181. Nicklaus, P.A.; Leadley, P.W.; Schmidt, B.; Körner, C.H. A long-term field study on biodiversity $\mathrm{X}$ elevated $\mathrm{CO}_{2}$ interactions. Ecol. Monogr. 2001, 71, 341-356. 
182. Schortemeyer, M.; Dijkstra, P.; Johnson, D.W.; Drake, B.G. Effects of elevated atmospheric $\mathrm{CO}_{2}$ concentration on $\mathrm{C}$ and $\mathrm{N}$ pools and rhizosphere processes in a Florida scrub oak community. Global Change Biol. 2000, 6, 383-391.

183. Pendall, E.; Bridgham, S.; Hanson, P.J.; Huntgate, B.; Kicklighter, D.W.; Johnson, D.W.; Law, B.E.; Luo, Y.; Megonigal, J.P.; Olsrud, M.; Ryan, M.G.; Wan, S. Below ground process reponses to elevated $\mathrm{CO}_{2}$ and temperature: a discussion of observation, measurement methods and models. New Phytol. 2004, 162, 311-322.

184. Norby, R.J.; O’Neill, E.G.; Luxmoore, R.G. Effects of atmospheric $\mathrm{CO}_{2}$ enrichment on the growth and mineral nutrition of Quercus alba seedlings in nutrient-poor soil. Plant Physiol. 1986, 82, 83-89.

185. King, J.S.; Thomas, R.B.; Strain, B.R. Growth and carbon allocation in root systems of Pinus taeda and Pinus ponderosa seedlings as affected by varying $\mathrm{CO}_{2}$, temperature and nitrogen. Tree Physiol. 1996, 16, 635-642.

186. Curtis, P.S.; Wang, X. A meta-analysis of elevated $\mathrm{CO}_{2}$ effects on woody plants, form and physiology. Oecologia 1998, 113, 299-313.

187. Kandeler, E.; Kampichler, C.; Horak, O. Influence of heavy metals on the functional diversity of soil communities, Biol. Fertil. Soils 1996, 23, 299-306.

188. Callaghan, T.V.; Bjorn, L.O.; Chernov, Y.; Chapin, T.; Christensen, T.R.; Huntly, B.; Ims, R.A.; Johansson, M.; Jolly, D.; Jonasson, S.; Matveyeva, N.; Panikov, N.; Oechel, W.; Shaver, G. Effects on the function of Arctic ecosystems in the short- and long-term perspectives. Ambio 2004, 33, 448-458.

189. Langen, P.L.; Alexeev, V.A. Polar amplification as a preferred response in an idealized aquaplanted GCM. Clim. Dynam. 2007, 29, 305-317.

190. Peat, H.J.; Clarke, A.; Convey, P. Diversity and biogeography of the Antarctic flora. J. Biogeogr. 2007, 34, 132-146.

191. Charles-Edwards, D.A.; Charles-Edwards, J.; Cooper, J.P. The influence of temperature on photosynthesis and transpiration in ten temperate grass varieties grown in four different environments. J. Exp. Bot. 1971, 22, 650-662.

192. Acock, B.; Allen, L.H.J. Crop responses to elevated carbon dioxide concentrations. In Direct Effects of Increasing Carbon Dioxide on Vegetation; Strain, B.R., Cure, J.D., Eds.; US Department of Energy: Washington, DC, USA, 1985; pp. 53-98.

193. Ehlinger, J.R.; Monson, R.K. Evolutionary and ecological aspects of photosynthetic pathway variation. Annu. Rev. Ecol. Syst. 1993, 24, 411-439.

194. Niu, S.; Li, Z.; Xia, J.; Han, Y.; Wu, M.; Wan, S. Climatic warming changes plant photosynthesis and its temperature dependence in a temperate steppe of northern China. Environ. Exp. Bot. 2007, 63, 91-101.

195. Neilson, R.P.; Pitkelta, L.F.; Solomon, A.M.; Nathan, R.; Midgley, G.F.; Fragoso, J.M.V.; Lischke, H.; Thompson, K. Forecasting regional to global plant migration in response to climate change. BioScience 2005, 5, 749-759.

196. Innes, J.L. High-altitude and high-latitude tree growth in relation to past, present and future global climate change. The Holocene 1991, 1, 168-173. 
197. Borgaonkar, H.P.; Ram, S.; Sikder, A.B. Assessment of tree ring analysis of high-elevation Cedrus deodara D.Don from Western Himalaya (India) in relation to climate and glacier fluctuations. Dendrochronolgia 2009, 27, 59-69.

198. Inouye, D.W.; Barr, B.; Armitiage, K.T.; Inouye, B.D. Climate change is affecting altitudinal migrants and hibernating species. Proc. Nat. Acad. Sci. USA 2000, 97, 1630-1633.

199. Menzel, A.; Estrella, N.; Fabian, P. Spatial and temporal variability of the phenological seasons in Germany from 1951 to 1996. Global Change Biol. 2001, 7, 657-666.

200. Visser, M.E.; Both, C. Shifts in phenology due to global climate change: the need for a yardstick. Proc. R. Soc. B. 2005, 272, 2561-2569.

201. Bokhorst, S.; Bjerke, J.W.; Bowles, F.W.; Melilo, J.; Callaghan, T.V.; Phoenix, G.K. Impacts of extreme winter warming in the sub-Arctic: growing season responses of dwarf shrub heathlands. Global Change Biol. 2008, 14, 2603-2612.

202. Huntley, B. How plants respond to climate change: migration rates, individualism and the consequences for plant communities. Ann. Bot. 1991, 67, 15-22.

203. Badeck, F.-W.; Bonderau, A.; Böttcher, K.; Doktor, D.; Lucht, W.; Schaber, J.; Sitch, S. Responses of spring phenology to climate change. New Phytol. 2004, 162, 295-309.

204. Parmesan, C. Ecological and evolutionary responses to recent climate change. Ann. Rev. Ecol. Evol. Syst. 2006, 37, 637-669.

205. Davis, M.B.; Zabinski, C. Changes in geographical range resulting from greenhouse warming: effects on biodiversity in forests. In Global Warming and Biological Diversity; Peters, R.L., Lovejoy, T.E., Eds.; Yale University Press: New Haven, CT, USA, 1992; pp. 297-308.

206. Lanner, R.M.; Van Devender, T.R. The recent history of pines in the American southwest. The ecology and biogeography of Pinus. In Ecology and Biogeography of Pinus; Richardson, D.M., Ed.; Cambridge University Press: Cambridge, UK, 1998; pp. 171-182.

207. Wardle, P.; Coleman, M.C. Evidence for rising upper limits of four native New Zealand forest trees. N.Z. J. Bot. 1992, 30, 303-314.

208. Grabherr, G.; Gotfried, M.; Pauli, H. Climate effects on mountain plants. Nature 1994, 369, 448.

209. Kennedy, A.D. Antarctic terrestrial ecosystem response to global environmental change. Annu. Rev. Ecol. Syst. 1995, 683-704.

210. Kullman, L. 20th century climate warming and tree-limit rise in southern Scandes of Sweden. Ambio 2001, 30, 72-80.

211. Sturm, M.; Racine, C.R.; Tape, K. Increasing shrub abundance in the Arctic. Nature 2001, 411, 546-547.

212. Walther, G-R.; Post, E.; Convey, P.; Menzel, A.; Parmesan C.; Beebee, T.J.C.; Fromentin, J.-M.; Hoegh-Guldberg, O.; Barlein, F. Ecological responses to recent climate change. Nature 2002, 416, 389-395.

213. Harsch, M.A.; Hulme, P.E.; McGlone, M.S.; Duncan, R.P. Are treelines advancing? A global meta-analysis of treelines response to climate warming. Ecol. Lett. 2009, 12, 1040-1049.

214. Pate, J.S.; Dixon, K.W.; Orshan, G. Growth and life form characteristics of Kwongan species. In Kwongan: Plant Life of the Sandplain; Pate, J.S., Beard, J.S., Eds.; UWA Press: Nedlands, Western Australia, 1984; pp. 84-100. 
215. Dale, V.H.; Joyce, L.A.; McNulty, S.; Neison, R.P.; Ayres, M.P.; Flannigan, M.D.; Hanson, P.J.; Irland, L.C.; Lugo, A.E.; Peterson, C.J.; Simberloff, D.; Swanson, F.J.; Stocks, B.J.; Wotton, M. Climate change and forest disturbances. BioScience 2001, 51, 723-734.

216. Ottersen, G.; Planque, B.; Belgrano, A.; Post, E.; Reid, P.C.; Stenseth, N.C. Ecological effects of the North Atlantic Oscillation. Oecologia 2001, 128, 1-14.

217. Hampe, A. Bioclimate envelope models: what they detect and what they hide. Global Ecol. Biogeogr. 2004, 13, 469-476.

218. Fire Note. Southern Seasonal Bushfire Assessment 2009-2010: Summary; Issue 39; Bushfire Cooperative Research Centre/Australian Fire and Emergency Services Authority: East Melbourne, Australia, 2009.

219. Kaspar, T.C.; Bland, W.L. Soil temperature and root growth. Soil Sci. 1992, 154, 290-299.

220. Fitter, A.H.; Self, G.K.; Brown, T.K.; Bogie, D.S.; Graves, J.D.; Benham, D.; Ineson, P. Root production and turnover in an upland grassland subjected to artificial warming respond to radiation flux and nutrients, not temperature. Oecologia 1999, 120, 575-581.

221. Parton, W.J.; Schimel, D.S.; Cole, C.V.; Ojima, D.S. Analysis of factors controlling soil organic matter levels in Great Plains Grasslands. Soil Sci Soc. Am. J. 1987, 51, 1173-1179.

222. Hungate, B.A.; Holland, E.A.; Jackson, R.B.; Cappin, F.S., III; Mooney, H.A.; Field, C.B. The fate of carbon in grasslands under carbon dioxide enrichment. Nature 1997, 388, 576-579.

223. Edwards, N.T.; Norby, R.J. Below-ground respiratory responses of sugar maple and red maple saplings to $\mathrm{CO}_{2}$ enrichment and elevated air temperature. Plant Soil 1999, 206, 85-97.

224. Melillo, J.M.; Steudler, P.A.; Aber, J.D.; Newkirk, K.; Lux, H.; Bowles, F.P.; Catricala, C.; Magill, A.; Ahrens, T.; Morriseau, S. Soil warming and carbon-cycle feedbacks to the climatic system. Science 2002, 298, 2173-2176.

225. Burton, A.J.; Melilo, J.M.; Frey, S.D. Adjustment of forest ecosystem root respiration as temperature warms. J. Integr. Plant Biol. 2008, 50, 1467-1483.

226. Loiseau, P.; Sousana, J.F. Elevated $\mathrm{CO}_{2}$, temperature increase, and $\mathrm{N}$ supply effects on the turnover of below-ground carbon in a temperate ecosystem. Plant Soil 1999, 210, 233-247.

227. Dodd, J.; Heddle, E.M.; Pate, J.S.; Dixon, K.W. Rooting patterns of sandplain plants and their functional significance. In Kwongan: Plant life of the Sandplain; Pate, J.S., Beard, J.S., Eds.; UWA Press: Nedlands, Western Australia, 1984; pp. 146-177.

228. Manion, P.D. Tree Disease Concepts, 2nd ed.; Prentice Hall Career \& Technology: New Jersey, NJ, USA, 1991.

229. Negrón, J.F. Probability of infestation and extent of mortality associated with Douglas-fir beetle in the Colorado Front Range. Forest Ecol. Manage. 1998, 107, 71-85.

230. Hanson, P.J.; Weltzon, J.F. Drought disturbances from climate change: response of United Sates Forests. Sci. Total Environ. 2000, 262, 215-220.

231. Beier, C. Climate change and ecosystem function-full-scale manipulations of $\mathrm{CO}_{2}$ and temperature. New Phytol. 2004, 162, 243-251.

232. Touchette, B.W.; Steudler, S.E. Climate change, drought, and wetland vegetation. In Proceedings of the 2007 National Conference on Environmental Science and Technology; Uzochukwa, G.A., Schimmel, K., Chang S.-Y.,Kabadi, V., Luster-Teasley, S., Reddy, G., Nzewi, E., Eds.; Springer Science+Business Media: Berlin, Germany, 2000; p. 239. 
233. McKee, W.H., Jr.; McKevlin, M.R. Geochemical processes and nutrient uptake by plants in hydric soils. Environ. Toxicol. Chem. 1993, 12, 2197-2207.

234. Hansen, E.M.; Goheen, G.J.; Jules, E.S.; Ullian, B. Managing Port-Orford-cedar and the introduced pathogen Phytophthora lateralis. Plant Dis. 2000, 84, 4-14.

235. Jung, T.; Hansen, E.M.; Winton, L.; Osswald, W.; Delatour, C. Three new species of Phytophthora from European oak forests. Mycol. Res. 2002, 106, 397-411.

236. Jung, T.; Nechwatal, J.; Cooke, D.E.L.; Hartmann, G.; Blanshke, M.; Osswald, W.F.; Duncan, J.M.; Delatour, C. Phytophthora pseudosyringae sp. Nov., a new species causing root and collar rot of deciduous tree species in Europe. Mycol. Res. 2003, 107, 772-789.

237. Tillman, D. Plant Strategies and the Dynamics and Structure of Plant Communities; Princeton University Press: Princeton, NJ, USA, 1988.

238. Marschner, H.; Kirkby, E.; Cakmak, I. Effect of mineral nutritional status of shoot-root partitioning of photoassimilates and cycling of mineral nutrients. J. Exp. Bot. 1996, 47, 1255-1263.

239. Binkley, D.; Högberg, P. Does atmospheric deposition of nitrogen threaten Swedish forests? For. Ecol. Manage. 1997, 92, 119-152.

240. Aber, J.D.; McDowell, W.; Nadelhoffer, K.; Magil, A.; Berntson, G.; Kamakea, M.; McNulty, S.; Currie, W.; Rustad, L.; Fernandez, I. Nitrogen saturation in temperate forest ecosystems, hypotheses revisited. BioScience 1998, 48, 921-934.

241. Martinelli, L.A.; Piccolo, M.C.; Townsend, A.R.; Vitousek, P.M.; Cuevas, E.; McDowell, W.; Robertson, G.P.; Santos, O.C.; Treseder, K. Nitrogen stable isotopic composition of leaves and soil: tropical versus temperate forests. Biogeochemistry 1999, 46, 45-65.

242. Gough, L.; Osenberg, C.W.; Gross, K.L.; Collins, S.L. Fertilization effects on species density and primary productivity in herbaceous plant communities. Oikos 2000, 89, 428-439.

243. Matson, P.; Lohse, K.A.; Hall, S.J. The globalization of nitrogen deposition: consequences for terrestrial ecosystems. Ambio 2002, 31, 113-119.

244. Below, F.E. Nitrogen metabolism and crop productivity. In Handbook of Plant Crop Physiology, 2nd ed.; Marcel Dekker: New York, NY, USA, 2002.

245. Fenn, M.E.; Haeuber, R.; Tonnesen, G.S.; Baron, J.S.; Grossman-Clarke, S.; Hope, D.; Jaffe, D.A.; Copeland, S.; Geiser, L.; Rueth, H.M.; Sickman, J.O. Nitrogen emissions, deposition and monitoring in the Western United States. BioScience 2003, 53, 391-403.

246. Fenn, M.E.; Barron, J.S.; Allen, E.B.; Rueth, H.M.; Nydick, K.R.; Giser, L.; Bowman, W.B.; Sickman, J.O.; Meixner, T.; Johnson, D.W.; Neitlich, P. Ecological effects of nitrogen deposition in the Western United States. BioScience 2003, 53, 404-420.

247. Treseder, K.K.; Allen, M.F. Mycorrhizal fungi have a potential role in soil carbon storage under elevated $\mathrm{CO}_{2}$ and nitrogen deposition. New Phytol. 2000, 147, 189-200.

248. Doran, J.W. Soil microbial and biochemical changes associated with reduced tillage. Soil Sci. Soc. Am. J. 1980, 44, 765-771.

249. Parmesan, C.; Yohe, G. A globally coherent fingerprint of climate change and impacts across natural systems. Nature 2003, 421, 37-42.

250. Jasper, D.J.; Abbott, L.K.; Robson, A.D. The loss of VA mycorrhizal infectivity during bauxite mining may limit the growth of Acacia pulchella R.Br. Aust. J. Bot. 1989, 37, 33-42. 
251. McGonigle, T.P.; Evans, D.G.; Miller, M.H. Effect of degree of soil disturbance on mycorrhizal colonisation and phosphorus absorption by maize in growth chamber and field experiments. New Phytol. 1990, 116, 629-636.

252. Bellgard, S.E. Soil disturbance and infection of Trifolium repens roots by vesicular-arbuscular mycorrhizal fungi. Mycorrhiza 1993, 3, 25-29.

253. Strain, B.R.; Bazzaz, F.A. Terrestrial communities. In $\mathrm{CO}_{2}$ and Plants: the Resposnse of Plants to Rising Atmospheric Carbon Dioxide; Lemon, E., Ed.; Westview Press: Boulder, CO, USA, 1983; pp. 840-849.

254. Cribb, P.J.; Kell, S.P.; Dixon, K.W.; Barrett, R.L. Orchid conservation: a global perspective. In Orchid Conservation; Dixon, K.W., Kell, S.P., Cribbs, P.J., Eds.; Natural History Publications: Kota Kinabalu, Malaysia, 2003; pp. 1-24.

255. Woldendorp, G.; Keenan, R.J. Coarse woody debris in Australian forest ecosystems: A review. Austral Ecol. 2005, 30, 834-843.

256. Esler, A.E. Naturalisation of plants in urban Auckland, New Zealand 5. Success of the alien species. N.Z. J. Bot. 1988, 26, 565-584.

257.Staddon, P.L.; Jakobsen, I.; Blum, H. Nitrogen inputs mediates the effects of free-air $\mathrm{CO}_{2}$ enrichment on mycorrhizal fungal abundance. Global Change Biol. 2004, 10, 1678-1688.

258. Markkola, A.M.; Ohtonen, R.; Tarvainen, O.; Ahonen-Jonnarth, U. Estimates of fungal biomass in Scots pine stands on an urban pollution gradient. New Phytol. 1995, 131, 139-147.

259. Stankevičienè, D.; Pečiulyte, D. Functioning of the ectomycorrhizae and soil micro fungi in deciduous forests situated along a pollution gradient next to a fertilizer factory. Pol. J. Environ. Stud. 2004, 13, 715-721.

260. Arnebrant, K. Nitrogen amendments reduce the growth of extrametrical ectomycrrhizal mycelium. Mycorrhiza 1994, 5, 7-15.

261. Heinmeyer, A.; Ridgeway, K.P.; Edwards, E.J.; Young, J.P.W.; Fitter, A.H. Impact of soil warming and shading on colonization and community structure of arbuscular mycorrhizal fungi in roots of a native grassland community. Global Change Biol. 2003, 10, 52-64.

262. Heinmeyer, A.; Fitter, A.H. Impact of temperature on arbuscular mycorrhizal (AM) symbiosis: growth responses of the host plant and its AM fungal partner. J. Exp. Bot. 2004, 55, 525-534.

263. Clark, N.M.; Rilling, M.C.; Nowak, R.S. Arbuscular mycorrhizal abundance in the Mojave Desert: seasonal dynamics and impacts of elevated $\mathrm{CO}_{2}$. J. Arid. Environ. 2009, 73, 834-843.

264. McAfee, B.J.; Fortin, J.A. The influence of $\mathrm{pH}$ on the competitive interactions of ectomycorrhizal mycobionts under field conditions. Can. J. For. Res. 1987, 17, 959-965.

265. Giovanetti, M. Seasonal variations of vesicular-arbuscular mycorrhizas and endogenaceous spores in a maritime sand dune. Trans. Brit. Mycol. Soc. 1985, 84, 679-684.

266. Gemma, J.N.; Koske, R.E.; Carreiro, M. Seasonal dynamics of selected species of V-A mycorrhizal fungi in a sand dune. Mycol. Res. 1989, 92, 317-321.

267. Brundrett, M.C.; Abbott, L.K. Mycorrhizal fungus propagules in the jarrah forest I. Seasonal study of inoculum levels. New Phytol. 1994, 127, 539-546.

268. Diaz, S. Effect of elevated $\left[\mathrm{CO}_{2}\right]$ at the community level mediated by root symbionts. Plant Soil 1996, 187, 309-320. 
269. Hodge, S. The relationship between Drosophila occurrence and mould abundance on rotting fruit. Brit. J. Entomol. Nat. Hist. 1996, 9, 87-89.

270. Villeneuve, N.; Le Tacon, F.; Bouchard, D. Survival of inoculated Laccaria bicolor in competition with native ectomycorrhizal fungi and effects on the growth of outplanted Douglas-fir seedlings. Plant Soil 1991, 135, 95-107.

271. Bagley, S.J.; Orlovich, D.A. Genet size and distribution of Amanita muscaria in a suburban park, Dunedin, New Zealand. New Zeal. J. Bot. 2004, 42, 939-947.

272. Gardner, J.H.; Malajczuk, N.J. Recolonisation of rehabilitated bauxite mine sites in Western Australia by mycorrhizal fungi. For. Ecol. Man. 1988, 24, 27-42.

273. Moorman, T.; Reeves, F.B. The role of endomycorrhizae in revegetation practices in the semi-arid west. II. A bioassay to determine the effects of land disturbance on endomycorrhizal populations. Am. J. Bot. 1979, 66, 14-18.

274. Gould, A.B.; Libertia, A.E. Effects of topsoil storage during surface mining on the viability of vesicular-arbuscular mycorrhiza. Mycologia 1981, 73, 914-922.

275. Ruiz-Lozano, J.M.; Azcon, R. Viability and infectivity of mycorrhizal spores after long term storage in soils with different water potentials. Appl. Soil Ecol. 1996, 3, 183-186.

276. Thiet, R.K.; Boerner, R.E.J. Spatial patterns of ectomycorrhizal fungal inoculum in arbuscular mycorrhizal barrens communities: implications for controlling invasion by Pinus virginiana. Mycorrhiza 2007, 17, 507-517.

277. O’Neill, E.G. Responses of soil biota to elevated atmospheric carbon dioxide. Plant Soil 1994, $165,55-65$.

278. Staddon, P.L.; Fitter, A.H. Does elevated atmospheric carbon dioxide affect arbuscular mycorrhizas? Trends Ecol. Evol. 1998, 13, 455-458.

279. Treseder, K. Meta-analysis of mycorrhizal responses to nitrogen, phosphorus, and atmospheric $\mathrm{CO}_{2}$ in field studies. New Phyt. 2004, 164, 347-355.

280. Alberton, O.; Kuyper, T.W.; Gorissen, A. Taking mycocentrism seriously: mycorrhizal fungal and plant responses to elevated $\mathrm{CO}_{2}$. New Phytol. 2005, 167, 859-868.

281. Lukac, M.; Calfapietra, C.; Godbold, D.L. Production, turnover and mycorrhizal colonization of root systems of three Populus species grown under elevated $\mathrm{CO}_{2}$ (POPFACE). Global Change Biol. 2003, 9, 838-848.

282. Olsrud, M.; Melillo, J.M.; Christensen, T.R.; Michelsen, A.; Wallander, H.; Olsson, P.A. Response of ericoid mycorrhizal colonisation and functioning to global change factors. New Phytol. 2004, 162, 459-469.

283. Bakkens, M.; Alkemade, J.R.M.; Ihle, F.; Leemans, R.; Latour, J.B. Assessing affects of forecasted climate change on the diversity and distribution of European higher plants. Global Change Biol. 2002, 8, 390-407.

284. Stendell, E.R.; Horton, E.R.; Bruns, T.D. Early effects of prescribed fire on the structure of the ectomycorrhizal community in Sierra Nevada ponderosa pine forest. Mycol. Res. 1999, 103, 1353-1359.

285. Hansen, E.M. Alien forest pathogens: Phytophthora species are changing world forests. Boreal Environ. Res. 2008, 13, 33-41. 
286. Heinemeyer, A.; Ineson, P.; Ostle, N.; Fitter, A.H. Respiration of the external mycelium in the arbuscular mycorrhizal symbiosis shows strong dependence on recent photosynthates and acclimation to temperature. New Phytol. 2006, 171, 159-170.

287. Troeh, F.R.; Thompson, R.M. Nitrogen (Ch. 10) and Calcium, Magnesium and Sulfur (Ch. 13). In Soils and Soil Fertility, 5th ed.; Oxford University Press: New York, NY, USA, 1993; pp. 193-213, 259-263.

288. Peterson, G.A.; Williams, S.E.; Moser, L.E. Inorganic fertilizer use and its effects on semiarid and arid region soils. In Semiarid Lands and Deserts: Soil Resource and Reclamation; Skujiňš, J., Ed.; Marcel Dekker: New York, NY, USA, 1991; pp. 543-580.

289. Carney, J.L.; Garrett, H.E.; Hedrick, H.G. Influence of air pollutant gasses on oxygen uptake of pine roots with selected ectomycorrhizae. Phytopath. 1978, 68, 116-11-63.

290. Churetta, J.A.; Williams, S.E. Pisolithus tinctorius and Pinus contorta interactions in acidic soils of Yellowstone National Park; Abstracts, 782; In American Society of Agronomy/Soil Science Society of America Annual Meetings, Las Vegas, NV, USA, October 1989.

291. Kytöviita, M.-M.; Ruotsalainen, A.L. Mycorrhizal benefit in two low arctic herbs increases with increasing temperature. Am. J. Bot. 2007, 94, 1309-1315.

292. Loree, M.A.J.; Williams, S.E. Colonization of western wheatgrass (Agropyron smithii Rhbd.) by vesicular arbuscular mycorrhizal fungi during revegetation of a strip mine. New Phytol. 1987, 106, 735-744.

293. White, J.A.; DePuit, E.J.; Smith, J.L.; Williams, S.E. Establishment of vesicular-arbuscular mycorrhizal fungi on irrigated reclamation in southwestern Wyoming. Soil Sci. Soc. Am J. 1992, 56, 1464-1469.

294. Miller, S.L.; McClean, T.M.; Stanton, N.L.; Williams, S.E. Mycorrhization, physiognomy, and first year survivability of conifer seedlings following natural fire in Grand Teton National Park. Can. J. For. Res. 1998, 28, 115-122.

295. Bellgard, S.E.; Whelan, R.J.; Muston, R.M. The impact of wildfire on vesicular-arbuscular mycorrhizal fungi and their potential to influence the re-establishment of post-fire plant communities. Mycorrhiza 1995, 4, 139-146.

296. Bowman, D.M.J.S.; Fensham, R.J. Response of a monsoon forest-savanna boundary to fire protection, Weipa, northern Australia. Austral Ecol. 1991, 16, 111-118.

297. Newsham, K.K; Fitter, A.H.; Watkinson, A.R. Arbuscular mycorrhiza protect an annual grass from root pathogenic fungi in the field. J. Ecol. 1995, 83, 991-1000.

298. Johnson, N.C.; Wolf, J.; Reyes, M.A.; Panter, A.; Koch, G.W.; Redman. A. Species of plants and associated arbsucular mycorrhizal fungi mediate mycorrhizal responses to $\mathrm{CO}_{2}$ enrichment. Global Change Biol. 2005, 11, 1156-1166.

299. Wolf, J.; Johnson, N.C.; Rowlant, D.L.; Reich, P.B. Elevated $\mathrm{CO}_{2}$ and plant species richness impact arbuscular mycorrhizal fungal spore communities. New Phytol. 2003, 157, 579-588.

300. Stahl, P.D.; Williams, S.E. Oil shale process water affects activity of vesicular-arbuscular fungi and rhizobium 4 years after application to soil. Soil Biol. Biochem. 1986, 18, 451-455.

301. Bellgard, S.E. The propagules of vesicular-arbuscular mycorrhizal (VAM) fungi capable of initiating VAM infection after topsoil disturbance. Mycorrhiza 1992, 1, 147-152. 
302. Al-Qarawi, A.A. Relationships Amoung Nitrogen Availability, Vesicular-Arbuscular Mycorrhizae, And Bromus Tectorum in Disturbed Sites in Colorado; Dissertation; Colorado State University: Fort Collins, CO, USA, 2002.

303. Hawkes, C.V.; Belnap, J.; D’Antonio, C.; Firestone, M.K.Arbuscular mycorrhizal assemblages in native plant roots change in the presence of invasive exotic grasses. Plant Soil 2006, 281, 369-380.

304. Rowe, H.I; Brown, C.S.; Claassen, V.P. Comparisons of mycorrhizal responsiveness with field soil and commercial inoculums for six native montane species and Bromus tectorum. Rest. Ecol. 2007, 15, 44-52.

305. Rowe, H.I.; Brown, C.S. Native plant growth and seedling establishment in soils influenced by Bromus tectorum. Range. Ecol. Man. 2008, 61, 630-639.

306. Jenny, H. Factors of Soil Formation; McGraw Hill: New York, NY, USA, 1941.

307. Ditzler, C.A.; Engel, R.J.; Ahrens, R.J. Soil taxonomy and soil survey. In Soil Classification: A Global Desk Reference; Eswaran, H., Rice, T., Ahrens, R., Stewart, B.A., Eds.; CRC Press: Boca Raton, FL, USA, 2003; pp. 221-230.

308. Hewitt, A.E. New Zealand Soil Classification_purposes and principles. In Soil Classification: A Global Desk Reference; Eswaran, H., Rice, T., Ahrens, R., Stewart, B.A., Eds.; CRC Press: Boca Raton, FL, USA, 2003; pp. 179-186.

309. Nachtergaele, F.O.F. The future of the FAO legend and the FAO/UNESCO soil map of the world. In Soil Classification: A Global Desk Reference; Eswaran, H., Rice, T., Ahrens, R., Stewart, B.A., Eds.; CRC Press: Boca Raton, FL, USA, 2003; pp. 147-156.

310. Deckers, J.; Driessen, P.; Nachtergaele, F.O.F.; Spaargaren, O.; Berding, F. Anticipated developments of the world reference base for soil resources. In Soil Classification: A Global Desk Reference; Eswaran, H., Rice, T., Ahrens, R., Stewart, B.A., Eds.; CRC Press: Boca Raton, FL, USA, 2003; pp. 245-256.

311. Jamagne, M.; King, D. The current French approach to a soilscapes typology. In Soil Classification: A Global Desk Reference; Eswaran, H., Rice, T., Ahrens, R., Stewart, B.A., Eds.; CRC Press: Boca Raton, FL, USA, 2003; pp 157-178.

312. Goryachkin, S.V.; Tonkonogov, V.D.; Gerasimova, M.I.; Lebedeva, I.I.; Shihov, L.L.; Targulian, V.O. Changing concepts of soil and soil classification in Russia. In Soil Classification: A Global Desk Reference; Eswaran, H., Rice, T., Ahrens, R., Stewart, B.A., Eds.; CRC Press: Boca Raton, FL, USA, 2003; pp. 187-200.

313. United States Department of Agriculture (USDA). Soil Taxonomy: A Basic System of Soil Classification for Making and Interpreting Soil Survey, 1999. Available online: http://soils.usda.gov/technical/classification/taxonomy/ (accessed on 12 May 2010).

314. Staffeldt, E.E.; Vogt, K.B. Mycorrhizae of desert plants. In Reports of 1974 Progress Volume 3: Process Studies (Microbiological Section); Ecology Center, Utah State University: Logan, UT, USA, 1975; pp. 63-69.

315. Singleton, P.C.; Williams, S.E. Effects of Long Term Storage on the Fertility and Biological Activity of Topsoil. Final Report; The Institute of Energy and Environment, The University of Wyoming: Laramie, WY, USA, 1979. 
316. White, J.A.; Munn, L.C.; Williams, S.E. Edaphic and reclamation aspects of vesicular-arbuscular mycorrhizae in Wyoming Red Desert Soils. Soil Sci. Soc. Am. J. 1989, 53, 86-90.

317. Klopatek, C.C.; DeBano, L.F.; Klopatek, J.M. Impact of fire on the microbial processes in pinyon-juniper woodlands: Management implications. In Effects of Fire Management on Southwestern Natural Resources, Proceedings of the Symposium, Tuscon, AZ, USA; General Technical Report RM-191; USDA Forest Service: Fort Collins, CO, USA, 1988; pp. 197-205.

318. Lesica, P.; Antibus, R.K. Mycorrhizae of alpine fell-field communities on soils derived from crystalline and calcareous parent materials. Can. J. Bot. 1986, 64, 1691-1697.

319. Haselwandter, K. Mycorrhizal infection and its possible ecological significance in climatically and nutritionally stressed alpine plant communities. Angew. Botanik 1987, 61, 107-114.

320. Williams, S.E.; Belden, R.P.; Stahl, P.D. Soil characteristics which influence alpine revegetation during road construction in southeastern Wyoming. In 6th High Altitude Revegetation Conference Proceedings, Colorado State University, Fort Collins, CO, USA, 1985; pp. 242-254.

321. Gemma, J.N.; Koske, R.E. Seasonal variation in spore abundance and dormancy of Gigaspora gigantea and in mycorrhizal inoculums potential of a dune soil. Mycologia 1988, 80, 211-216.

322. Sylvia, D.M. Spatial and temporal distribution of vesicular-arbuscular mycorrhizal fungi associated with Uniola paniculata in Florida foredunes. Mycologia 1986, 78, 728-734.

323. Nicolson, T.H.; Johnston, C. Mycorrhiza in the Gramineae III. Glomus fasciculatus as the endophyte of pioneer grasses in a maritime sand dune. Trans. Br. Mycol. Soc. 1979, 72, 261-268.

324. Koske, R.E.; Sutton, J.C.; Sheppard, B.R. Ecology of Endogone in Lake Huron sand dunes. Can. J. Bot. 1975, 53, 87-93.

325. Jehne, W.; Thompson, C.H. Endomycorrhizae in plant colonization on coastal sand-dunes at Cooloola, Queensland. Aust. J. Ecol. 1981, 6, 221-230.

326. Bowen, G.D. Coping with low nutrients. In Biology of Australian Plants; Pate, J.S.; McComb, A.J., Ed.; Unversity of Western Australia Press: Nedlands, Australia, 1981; pp. 33-64.

327. Jackson, N.E.; Franklin, R.E.; Miller, R.H. Effects of vesicular-arbuscular mycorrhizae on growth and phosphorous content of three agronomic crops. Soil Sci. Soc. Amer. Proc. 1972, 36, 64-67.

328. Dighton, J.; Mason, P.A.; Poskitt, J.M. Field use of ${ }^{32} \mathrm{P}$ to measure phosphate uptake by birch mycorrhizas. New Phytol. 1990, 116, 655-661.

329. Harvey, A.E.; Jurgensen, M.F.; Larsen, M.J. Clearcut harvesting and ectomycorrhizae: survival of activity on residual roots and influence on a bordering forest stand in western Montana. Can. J. For. Res. 1980, 10, 300-303.

330. Harvey, A.E.; Larsen, M.J.; Jurgensen, M.F. Partial cut harvesting and ectomycorrhizae: early effects in Douglas-fir-larch forests of western Montana. Can. J. For. Res. 1980, 10, 436-440.

331. Harvey, A.E.; Larsen, M.J.; Jurgensen, M.F. Distribution of ectomycorrhizae in a mature Douglas-fir-larch forest soil in western Montana. For. Sci. 1976, 22, 393-398.

332. Klages, M.G.; McConnell, R.C.; Nielson, G.A. Soils of the Coram Experimental Forest. Mont. Agric. Exp. Stn. Res. Rep. 1976, 91, 43.

333. Wilson, G.W.T.; Hetrick, B.A.D.; Kitt, D.G. Suppression of mycorrhizal growth response of big bluestem by non-sterile soil. Mycologia 1988, 80, 338-343. 
334. Wallace, L.L.; Svejcar, T. Mycorrhizal and clipping effects on Andropogon gerardii photosynthesis. Am. J. Bot. 1987, 74, 1138-1142.

335. Anderson, R.C.; Ebbers, B.C.; Liberta, A.E. Soil moisture influences colonization of prairie cordgrass (Spartina pectinata Lind.) by vesicular-arbuscular mycorrhizal fungi. New Phytol. 1986, 102, 523-527.

336. Zajicek, J.M.; Hetrick, B.A.D.; Owensby, C.E. The influence of soil depth on mycorrhizal colonization of forbs in the tallgrass prairie. Mycologia 1986, 78, 316-320.

337. Hicks, P.M.; Loynachan, T.E. Phosphorus fertilization reduces vesicular-arbuscular mycorrhizal infection and changes nodule occupancy of field-growth soybean. Agron. J. 1987, 79, 841-844.

338. Gross, R.W. Mycorrhizae of ponderosa pine in Nebraska grassland soils. University of Nebraska Res. Bull. 1960, 192, 1-47.

339. Menge, J.A.; Grand, L.F. Effect of fertilization on production of epigeous basidiocarps by mycorrhizal fungi in loblolly pine plantations. Can. J. Bot. 1978, 56, 2357-2362.

340. Heckman, J.R.; Angle, J.S. Variation between soybean cultivars in vesicular-arbuscular mycorrhizal fungi colonization. Agron. J. 1987, 79, 428-430.

341. Day, L.D.; Sylvia, D.M.; Collins, M.E. Interactions among vesicular-arbuscular mycorrhizae, soil, and landscape position. Soil Sci. Soc. Am. J. 1987, 51, 635-639.

342. Lamb, R.J.; Richards, B.N. Some mycorrhizal fungi of Pinus radiata and P. elliptic var. elliptic in Australia. Trans. Br. Mycol. Soc. 1970, 54, 371-378.

343. Skinner, M.F.; Bowen, G.D. The penetration of soil by mycelia strands of ectomycorrhizal fungi. Soil Biol. Biochem. 1974, 6, 57-61.

344. Hayman, D.S.; Mosse, B. Improved growth of white clover in hill grasslands by mycorrhizal inoculation. Ann. Appl. Biol. 1979, 93, 141-148.

345. Haselwandter, K. Mycorrhizal status of ericaceous plants in alpine and subalpine areas. New Phytol. 1979, 83, 427-431.

346. Thomazina, L.I. Mycorrhiza in plants of the 'Cerrado'. Plant Soil 1974, 41, 429-711.

347. Salinas, J.G.; Sanz, J.I.; Sieverding, E. Importance of VA mycorrhizae for phosphorus supply to pasture plants in tropical Oxisols. Plant Soil 1985, 84, 347-360.

348. Huang, R.S.; Smith, W.K.; Yost, R.S. Influence of vesicular-arbuscular mycorrhiza on growth, water relations, and leaf orientation in Leucaena leucocephala (Lam.) de Wit. New Phytol. 1985, 99, 229-243.

349. Vander Zaag, P.; Fox, R.L.; De La Pena, R.S.; Yost, R.S. P nutrition of cassava, including mycorrhizal effects on P, K, S, Zn, and Ca uptake. Field Crop Res. 1979, 2, 253-263.

350. Waters, J.R.; McKelvey, K.S.; Luoma, D.L.; Zabel, C.J. Truffle production in old-growth and mature fir stands in northeastern California. For. Ecol. Manage. 1997, 96, 155-166.

351. James, H.; Court, M.N.; Macleod, D.A.; Parsons, J.W. Relationships between growth of sitka spruce (Picea sitchensis), soil factors and mycorrhizal activity on basaltic soils in western Scotland. Forestry 1978, 51, 105-119.

352. Theodorou, C. Soil moisture and the mycorrhizal association of Pinus radiata D. Don. Soil Biol. Biochem. 1978, 10, 33-37. 
353. Linkins, A.E.; Antibus, R.K. Ectomycorrhizal fungi of Salix rotundifolia Trautv. II. Impact of surface applied Prudhoe Bay Crude Oil on mycorrhizal root respiration and cold acclimation. Arctic 1978, 31, 381-391.

354. Christie, P.; Nicolson, T.H. Are mycorrhizas absent from the Antarctic? Trans. Br. Mycol. Soc. 1983, 80, 557-560.

355. Sylvia, D.M.; Williams, S.E. Vesicular-arbuscular mycorrhizae and environmental stress. In Mycorrhizae in Sustainable Agriculture; Special Publication No. 54; Bethlenfalvay, G.J., Linderman, R.G., Eds.; American Society of Agronomy: Madison, WI, USA, 1992; pp. 101-124.

356. Lodge, D.J. The influence of soil moisture and flooding on formation of VA-endo- and ectomycorrhizae in Populus and Salix. Plant Soil 1989, 117, 243-253.

357. Dighton, J.; Skefington, R.A. Effects of artificial acid precipitation on the mycorrhizas of Scots pine seedlings. New Phytol. 1987, 107, 191-202.

358. Moyerson, B.; Beever, R.E. Abundance and characteristics of Pisolithus ectomycorrhizas in NZ geothermal areas. Mycologia 2004, 96, 1225-1232.

359. Porter, W.M.; Robson, A.D.; Abbott, L.K. Field survey of the distribution of vesicular-arbuscular mycorrhizal fungi in relation to soil pH. J. Appl. Ecol. 1987, 24, 659-662.

360. Green, N.E.; Graham, S.O. The influence of $\mathrm{pH}$ on the germination of vesicular-arbuscular mycorrhizal spores. Mycologia 1976, 68, 929-935.

361. Sanon, A.; Martin, S.A.; Thioulouse, J.; Plenchette, C.; Spichiger, R.; Lepage, M.; Duponnois, R. Displacement of an herbaceous plant species community by mycorrhizal and non-mycorrhizal Gmelina arborea, an exotic tree, grown in a microcosm experiment. Mycorrhiza 2006, 16, 125-132.

362. Greipsson, S.; Di Tommaso, A. Invasive non-native plants alter the occurrence of arbuscular fungi and benefit from this association. Ecol. Restor. 2006, 24, 236-241.

363. Pringle, A.; Bever, J.D.; Gardes, M.; Parrent, J.L.; Rillig, M.C.; Klironomos, J.N. Mycorrhizal symbioses and plant invasions. Ann. Rev. Ecol. Evol. Syst. 2009, 40, 699-715.

364. Singh, B.K.; Nunuan, N.; Ridgway, K.P.; McNicol, J.; Young, J.P.W.; Daniell, T.J.; Prosser, J.I.; Millard, P. Relationship between assemblages of mycorrhizal fungi and bacteria on grass roots. Environ. Microbiol. 2007, 10, 534-541.

365. Klironomos, J.N.; Moutoglis, P. Colonization of nonmycorrhizal plants by mycorrhizal neighbours as influenced by the collembolan, Folsomia candida. Biol. Fert. Soils 1999, 29, 277-281.

366. Perez-Moreno, J.; Read, D.J. Nutrient transfer from soil nematodes to plants: a direct pathway provided by the mycorrhizal mycelial network. Plant Cell Environ. 2002, 24, 1219-1226.

367. Pyare, S.; Longland, W.S. Patterns of ectomycorrhizal-fungi consumption by small mammals in remnant old-growth forests of the Sierra Nevada. J. Mammol. 2001, 82, 681-689.

368. Diez, J. Invasion biology of Australian ectomycorrhizal fungi introduced with eucalyptus plantations into the Iberian Peninsula. Biol. Invas. 2005, 7, 3-15.

369. Plant Invasions: Human Perceptions, Ecological; Impacts and Management; Tokarska-Guzik, B., Brock, J.H., Brundu, G., Child, L., Daehler, C.C., Pyšek, P., Eds.; Backhuys: Leiden, The Netherlands, 2008. 
370. Dickie, I.A.; Bolstridge, N.; Cooper, J.A.; Peltzer, D.A. Co-invasion by Pinus and its mycorrhizal fungi. New Phytol. 2010, 187, 1-10.

371. Throop, H.L.; Lerdau, M.T. Effects of nitrogen deposition on insect herbivory: implications for community and ecosystem processes. Ecosystems 2004, 7, 109-133.

372. Jones, M.E.; Paine, T.D.; Fenn, M.E.; Poth, M.A. Influence of ozone and nitrogen on bark beetle activity under drought conditions. Forest Ecol. Manage. 2004, 200, 67-76.

373. Johnson, N.C. Can fertilization of soil select less mutualistic mycorrhizae? Ecol. Appl. 1993, 3, 749-757.

374. Gryndler, M.; Hršelova, H.; Vosatka, M.; Votruba, J.; Klir, J. Organic fertilization changes the response of mycelium of arbuscular mycorrhizal fungi and their sporulation to mineral NPK supply. Folia Microbiol. 2001, 46, 540-542.

375. Roth, D.R.; Fahey, T.J. The effects of acid precipitation and ozone on the ectomycorrhizae of red spruce saplings. Water, Air Soil Pollut. 1998, 103, 263-276.

376. Van Dijk, H.F.G.; de Louw, M.H.J.; Roelofs, J.G.M.; Verburgh, J.J. Impacts of artificial ammonium-enriched rainwater on soils and young coniferous trees in a greenhouse. Part II. Effects on the trees. Environ. Pollut. 1990, 63, 41-59.

377. Van der Eerden, L.J.; Lekkerkerk, L.J.A.; Smeulder, S.M.; Jansen, A.J. Effects of ammonium and ammonium sulphate on Douglas fir (Pseuotsuga menziesii). Environ. Pollut. 1992, 76, 1-9.

378. Sårstad, S.M.; Jenssen, H.B. Interpretation of regional differences in the fungal biota as effects of atmospheric pollution. Mycol. Res. 1993, 97, 1451-1458.

379. Wallender, T.; Kottke, I. Nitrogen deposition and ectomycorrhizas. New Phytol. 1998, 139, 169-187.

380. Frey, S.D.; Knorr, M.; Parrent, J.L.; Simpson, R.T. Chronic nitrogen enrichment affects the structure and function of the soil microbial community in temperate hardwood and pine forests. Forest Ecol. Manage. 2004, 196, 159-171.

381. Markkola, A.M.; Ohtonen, R. The effects of acid deposition in the forest humus. In Ectomycorrhiza and Acid Rain; CEC Air Pollution Research Report 12; Jansen, A.E., Dighton, J., Bresser, A.H.M., Eds.; Biological Station Wijster Botany: Bilthoven, The Netherlands, 1988.

382. Bespolova, A.Y.U.; Marfenina, O.E.; Motuzova, O.B. The effects of two common soil microfungi, Mucor hiemalis and Trichoderma viride, on heavy metals availability in polluted soil. In Proceedings of the 15th International Symposium on Environmental Biogeochemistry Biogeochemical Processes and Cycling in the Environment, Wroclaw, Poland, September 11-15, 2001; p. 101.

383. Hildebrandt, U.; Regvar, M.; Bothe, H. Arbuscular mycorrhiza and heavy metal tolerance. Phytochemistry 2007, 68, 139-146.

384. Negrón, J.F.; McMillin, J.D.; Anhold, J.A.; Coulson D. Bark beetle-caused mortality in a drought-affected ponderosa pine landscape in Arizona, USA. For. Ecol. Man. 2009, 257, 1353-1362.

385. Adams, H,D.; Guardiola-Claramonte, M.; Barron-Gafford, G.A; Camilo Villegas, J.; Breshears, D.D.; Zou, C.B., Troch, P.A.; Huxman, T.E. Temperature sensitivity of drought-induced tree mortality portends increased regional die-off under global-change-type drought. P.N.A.S. 2009, 106, 7063-7066. 
386. Chung, C.; Zak, D.R.; Reich, P.B; Ellsworth, D.S Plant species richness, elevated $\mathrm{CO}_{2}$ and atmospheric nitrogen deposition alter soil microbial community composition and function, Global Change Biol. 2007, 13, 980-989.

387. Nottingham, A.T.; Turner, B.L.; Winter, K.; van der Heijden, M.G.A.; Tanner, E.V.J. Arbuscular mycorrhizal mycelia respiration in a moist tropical forest. New Phytol. 2010, 186, 957-967.

388. Franklin, J.F.; Shugart, H.H.; Harmon, M.E. Tree death as an ecological process. Bioscience 1987, 37, 550-556.

389. Scholthof, K.-B.G. The disease triangle: pathogens, the environment and society. Nat. Rev. Microbiol. 2007, 5, 152-156.

390. Valdés, M.; Asbjornsen, H.; Gómez-Cárdenas, M.; Juárez, M.; Voght, K.A. Drought effects on fine-root and ectomycorrhizal-root biomass in managed Pinus oaxacana Mirov stands in Oaxaca, Mexico. Mycorrhiza 2006, 16, 117-124.

391. Jung, T.; Blanshke, M. Phytophthora root and collar rots of alder in Bavaria: distribution, modes of spread and possible management strategies. Plant Pathol. 2004, 53, 197-208.

392. Jung, T.; Blanshke, M. Phytophthora root rot in declining forest trees. Phyton (Austria) 1996, 36, 95-102.

393. Davison, E.M. Are jarrah (Eucalyptus marginata) trees killed by Phytophthora cinnamomi or water-logging? Aust. For. 1997, 60, 116-124.

394. Davison, E.M.; Tay, F.C.S. Predictions of where minimal damage to jarrah roots could result in tree death. New Phytol. 1995, 131, 393-401.

395. Johnson, P.R Causes and consequences of changes to New Zealand's fungal biota. New Zeal. J. Ecol. 2009, 34, 175-184.

396. Crimmins, T.M.; Crimmins, M.A.; Bertelsen, C.D. Flowering range changes across an elevation gradient to warming summer temperatures. Global Change Biol. 2009, 15, 1141-1152.

397. Dullinger, S.; Dirnböck, T.; Grabherr, G. Patterns of shrub invasions into high mountain grasslands of the Northern Calcareous Alps, Austria. Arct. Antarct. Alp. Res. 2003, 35, 434-441.

398. Richardson, D.M.; Bond, W.J. Determination of plant distributions: evidence from pine invasions. Am. Nat. 1991, 137, 639-668.

399. Dulamusuren, C.; Hauck, M.; Mühlenberg, M. Insect and small mammal herbivores limit tree establishment in northern Mongolian steppe. Plant Ecol. 2008, 195, 143-156.

400. Hauck, M.; Dulamusuren, C.; Heimes, C. Effects of insect herbivory on the performance of Larix sibirica in a forest-steppe ecotone. Environ. Exp. Bot. 2008, 62, 351-356.

401. Olsrud, M.; Carlsson, B.Á.; Svensson, B.M.; Michelsen, A.; Melilo, J.M. Responses of fungal root colonisation, plant cover and leaf nutrients to long-term exposure to elevated atmospheric $\mathrm{CO}_{2}$ and warming in subarctic birch understory. Global Change Biol. 2010, 16, 1820-1829.

402. Trappe, J.M. What is a mycorrhiza? Mycorrhiza in integrated systems-from genes to plant development. In Proceedings of the Fourth European Symposium on Mycorrhiza; Azcon-Aguilar, C., Barea, J.-M., Eds.; Commission of the European Union: Luxembourg, 1996; pp. 3-6.

403. Jumponnen, A.; Trappe, J.M. Dark septate endophytes: a review of facultative biotrophic root-colonizing fungi. New Phytol. 1998, 140, 295-310.

404. Jumpponen, A. Dark septate endophytes - are they mycorrhizal? Mycorrhiza 2001, 11, 207-211. 
405. Mandyam, K.; Jumpponen, A. Seeking the elusive function of the root-colonising dark spetate endophytic fungi. Stud. Mycol. 2005, 53, 173-189.

406. Vandenkoornhuyse, P.; Baldauf, S.L.; Leyval, C.; Straczek, J.; Young, J.P.W. Extensive fungal diversity in plant roots. Science 2002, 295, 2051

407. Zhu, Y.-G.; Miller, R.M. Carbon cycling by arbuscular mycorrhizal fungi soil-plant systems. Trends Plant Sci. 2003, 8, 407-409.

408. Godbold, D.L.; Bernston, G.M. Elevated $\mathrm{CO}_{2}$ concentrations changes ectomycorrhizal morphotype assemblages in Betula papyrifera. Tree Physiol. 1997, 17, 347-350.

409. Godbold, D.L.; Berntson, G.M.; Bazzaz, F.A. Growth and mycorrhizal colonization of three North American tree species under elevated atmospheric $\mathrm{CO}_{2}$. New Phytol. 1997, 137, 433-440.

410. Fitter, A.H. Water relations of red clover Trifolium pratense L. as affected by VA mycorrhizal infection and phosphorus supply before and during drought. J. Exp. Bot. 1988, 39, 595-603.

411. Field, C.B.; Jackson, R.B.; Mooney, H.A. Stomates response to increased $\mathrm{CO}_{2}$ : implications from the plant to the global scale. Plant, Cell Environ. 1995, 18, 1214-1225.

412. Augé, R.M; Moore, J.L; Sylvia D.M.; Cho, K. Mycorrhizal promotion of host stomatal conductance in relation to irradiance and temperature. Mycorrhiza 2004, 85-92.

413. Pankhow, W.; Boller, T.; Wiemken, A. The significance of mycorrhizas for protective ecosystems. Experientia 1991, 47, 391-394.

414. Daniell, T.J.; Hodge, A.; Young, J.P.W.; Fitter, A.H. How many fungi does it take to change a plant community? Trends Plant Sci. 1999, 4, 81-82.

415. Kohut, R. The long-term effects of carbon dioxide on natural systems: issues and research needs. Environ. Int. 2003, 29, 171-180.

416. Liu, H.; Feng, C.L.; Luo, Y.B.; Chen, B.S.; Wang, Z.S.; Gu, H.Y. Potential challenges of climate change to orchid conservation in a wild orchid hotspot in southwestern China. Bot. Rev. 2010, 76, 174-192.

417. Williams, S.E. Organized doubt. In A Brand of Excellence: Teaching and Learning; Wangberg, J.K., Ed.; University of Wyoming: Laramie, WY, USA, 2008; pp. 55-74.

418. Bledsoe, C.S. Physiological ecology of ectomycorrhizae: Implications for field application. In Mycorrhizal Functioning, an Integrative Plant-Fungal Process; Allen, M.F., Ed.; Routledge, Chapman \& Hall: New York, NY, USA, 1992; pp. 424-437.

419. Miller, R.M.; Jastrow, J.D. The application of VA mycorrhizae to ecosystem restoration and reclamation. In Mycorrhizal Functioning, An Integrative Plant-Fungal Process; Allen, M.F., Ed.; Routledge, Chapman \& Hall: New York, NY, USA, 2002; pp. 438-467.

420. Thomas, R.B.; Van Bloem, S.J.; Schlesinger, W.H. Climate change and symbiotic nitrogen fixation in Agroecosystems. In Agroecosystems in a Changing Climate; Newton, P.C.D., Carran, R.A., Edwards, G.R., Niklaus, P.A. Eds.; CRC Taylor and Francis Group: Boca Raton, LA, USA 2007; pp. 85-116.

421. Blankinship, J.C.; Hungate, B.A. Belowground food webs in a changing climate. In: Agroecosystems in a Changing Climate; Newton, P.C.D., Carran, R.A., Edwards, G.R., Niklaus, P.A. Eds.; CRC Taylor and Francis Group: Boca Raton, LA, USA, 2007; pp. 117-150. 
422. Rillig, M.C. Climate change effects on fungi in agroecosystems. In Agroecosystems in a Changing Climate; Newton, P.C.D., Carran, R.A., Edwards, G.R., Niklaus, P.A. Eds.; CRC Taylor and Francis Group: Boca Raton, LA, USA, 2007; pp. 211-230.

(C) 2011 by the authors; licensee MDPI, Basel, Switzerland. This article is an open access article distributed under the terms and conditions of the Creative Commons Attribution license (http://creativecommons.org/licenses/by/3.0/). 